Securing Protected Areas

The Decision-making of Poachers and Rangers

Nick van Doormaal 



\section{Securing Protected Areas}

The Decision-making of Poachers and Rangers

Nick van Doormaal 


\section{Manuscript committee}

Prof. dr. C.C.J.H. Bijleveld Netherlands Institute for the Study of Crime and Law Enforcement (NSCR) / Vrije Universiteit Amsterdam

Prof. dr. R.V. Clarke

Rutgers University

Prof. dr. M.L. Gore

University of Maryland

Prof. dr. ir. F. van Langevelde Wageningen University

Prof. dr. F.A. van Tubergen Utrecht University

ISBN: 978-94-6416-154-0

Cover design and layout: Birgit Vredenburg | www. persoonlijkproefschrift.nl Printing: Ridderprint BV | www.ridderprint.nl

\section{@ 2020 Nick van Doormaal}

All rights reserved. No part of this publication may be reproduced or transmitted in any form or by any means, electronic or mechanical, including photocopy, recording, or any information storage or retrieval system, without permission in writing from the author. The copyright of the articles that have been accepted for publication or that already have been published, has been transferred to the respective journals. 


\section{Securing Protected Areas}

\section{The Decision-making of Poachers and Rangers}

\section{Het beschermen van beschermde gebieden \\ Het keuzegedrag van stropers en rangers}

(met een samenvatting in het Nederlands)

\section{Proefschrift}

ter verkrijging van de graad van doctor aan de

Universiteit Utrecht op gezag van de rector magnificus, prof.dr. H.R.B.M. Kummeling, ingevolge het besluit van het college voor promoties in het openbaar te verdedigen op vrijdag 18 december 2020 des middags te 2.30 uur door

Nick Bernardus Johannes Petrus van Doormaal

geboren op 26 september 1989

te Diessen 


\section{PROMOTOR}

Prof. dr. S. Ruiter

\section{COPROMOTOR}

Dr. A.M. Lemieux 


\section{TABLE OF CONTENTS}

$\begin{array}{lll}\text { Chapter } 1 & \text { Synthesis } & 13\end{array}$

Introduction $\quad 15$

Research aim and focus 18

Theoretical framework 19

Deterring wildlife poaching $\quad 21$

Data and methodology 23

$\begin{array}{ll}\text { Overview of chapters } & 27\end{array}$

Discussion 33

$\begin{array}{ll}\text { Limitations } & 37\end{array}$

Future research and practical implications 38

Conclusion 41

Chapter 2 Understanding site selection of illegal border crossings $\quad 43$ into a fenced protected area: a rational choice approach

Introduction 44

Theoretical framework and hypotheses $\quad 46$

Methods $\quad 49$

Data collection and preparation $\quad 49$

Analytic strategy $\quad 55$

Results $\quad 57$

Discussion $\quad 60$

Conclusion 65

Chapter 3 Exploring anti-poaching strategies for wildlife crime with $\quad 67$ a simple and general agent-based model

Introduction $\quad 69$

$\begin{array}{ll}\text { Objective } & 70\end{array}$

The general model: animals, poachers, and rangers $\quad 70$

Example: Rhino poaching in South Africa $\quad 72$

Scenarios with different anti-poaching strategies $\quad 76$

Discussion and model improvements $\quad 79$

Conclusion 82 
Chapter 4 Understanding detection probabilities of wildlife poaching:

a rigorous method for comparing patrol strategies using an experimental design

Introduction

Improving detection strategies for wildlife crimes $\quad 87$

Methods $\quad 91$

Analysis 93

Results 96

$\begin{array}{ll}\text { Discussion } & 97\end{array}$

$\begin{array}{lll}\text { Chapter } 5 \text { Corruption and the shadow of the future: a generalization } \quad 107 & 107\end{array}$ of an ABM with repeated interactions

$\begin{array}{ll}\text { Introduction } & 109\end{array}$

Objective 112

$\begin{array}{ll}\text { Model framework } & 113\end{array}$

Agent characteristics and behaviour $\quad 114$

$\begin{array}{ll}\text { Scenario simulations } & 119\end{array}$

$\begin{array}{ll}\text { Results } & 121\end{array}$

Discussion 126

$\begin{array}{lr}\text { Conclusion } & 129\end{array}$

$\begin{array}{ll}\text { Nederlandse samenvatting } & 133\end{array}$

References $\quad 143$

$\begin{array}{lr}\text { Acknowledgements } & 159\end{array}$

$\begin{array}{ll}\text { About the author } & 163\end{array}$ 



\section{LIST OF FIGURES}

Figure 1.1. Abstract representation of the different stages within the chain of wildlife 16 crime and the focus of this dissertation

Figure 2.1. The rhino poaching crime script and its seven stages in sequential order 45

Figure 2.2. Abstract representation of the study area with a $3 \times 3$ reference grid plotted on top (dotted lines)

Figure 3.1. Scenario simulation results presented in boxplots. The upper row (a, b) 77 shows the results for rangers using a standard patrol strategy. The lower row (c, d) shows the results of fence patrol teams. The left column (a, c) shows the effect of adding more ranger teams. The right column (b, d) shows the effect of increasing patrol duration. The bars bearing the same letters are not significantly different at the $5 \%$ level.

Figure 3.2. Results of the patrol strategy comparison presented in boxplots. The 79 left plot shows the result of a virtual park with one poacher and the right plot shows the result of a park with four poachers. The bars bearing the same letters are not significantly different at the $5 \%$ level.

Figure 4.1. Hypothetical true spatial distribution of all crimes (A) and illustration of how patrol might bias the recorded distribution (B)

Figure 4.2. Flowchart of the necessary steps before a wildlife crime ends up recorded in a law enforcement database.

Figure 4.3. Kaplan-Meier survival curve of fake snares over time. The dashed lines show when snare sweeps were conducted.

Figure 4.4. Density plot of detection probabilities by patrol strategies from 10.000 bootstrap resamples.

Figure 5.1. Diagram visualising the three potential outcomes of two agents interacting

Figure 5.2. Simulation results for the effect of repeated interactions on the number of corrupt agents at the end of each simulation run. No weights to the agents' memory were assigned. For statistical comparisons, a KruskalWallis test was conducted followed by a Dunn's post-hoc test. The plots bearing the same letters are not statistically significantly different at the $5 \%$ level 
Figure 5.3. Simulation results for the effect of repeated interactions together with assigning weights to agent's memory on the number of corrupt agents at the end of each simulation run. For statistical comparisons, a KruskalWallis test was conducted followed by a Dunn's post-hoc test. The plots bearing the same letters are not statistically different at the 5\% level

Figure 5.4. Survival curves for duration until transition from high levels to low 125 levels of corruption for simulation runs with one and multiple repeated interactions. Each coloured line represents a different number of interactions. No weights were assigned to agent's memory. The dashed lines show the median survival time for that scenario Model sensitivity to parameter settings

Figure 5.5. Survival curves for duration until transition from high levels to low levels of corruption for simulation runs with one and multiple repeated interactions. Each coloured line represents a different number of interactions. The left graph (A) shows scenarios with the weight parameter set to $50 \%$, the right graph (B) has weight set to $100 \%$. The dashed lines show the median survival time for that scenario 


\section{LIST OF TABLES}

Table 1.1. Overview of the research questions, topic, and type of study per chapter 27

Table 2.1. Overview of the explanatory variables used in Chapter 2

Table 2.2. Frequency table for the number of illegal border crossings between $2011 \quad 53$ and 2016

Table 2.3. Comparison of the descriptive statistics of the continuous variables for 54 all border cells

Table 2.4. Frequency table for the binary variables used in this chapter 55

Table 2.5. Logistic regression model using penalised MLE using both entry and 59 exit crossings

Table 2.6. Logistic regression model using penalised MLE using all illegal entry 59 crossings

Table 2.7. Logistic regression model using penalised MLE using all illegal exit 59 crossings.

Table 2.8. Quasi-Poisson model using entry and exit crossings without the outlier 60 of 55 illegal crossings.

Table 4.1. Patrol effort for different strategies 98

Table 4.2. Number of detected fake snares and detection rates for the different 99 snare sweep strategies

Table 5.1. The $2 \times 2$ corruption game payoff structure

Table 5.2. Overview of the corruption model's defaults setting based on Hammond 119 (2000)

Table 5.3. Overview of the corruption model's defaults setting based on Hammond 120 (2000)

Table 5.4. Summary of the median time until transition for the different scenarios 124

Table 5.5. Summary of the scenario runs with varying values of corruption payoff, 126 honest payoff, and suspension term 




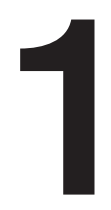

Synthesis

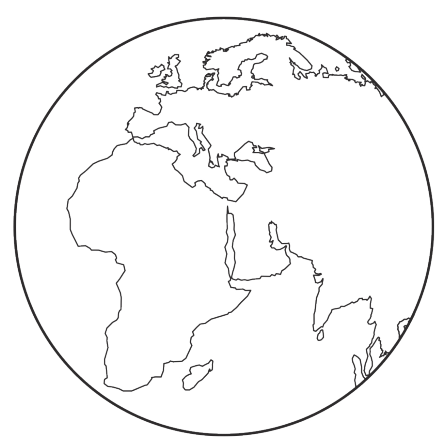




\section{INTRODUCTION}

Andy wakes up early today. He moves around the house to grab a few things, including a dozen metal wires. Andy plans on setting these as traps for catching wildlife in the nearby 'Nonwane Nature Reserve'. For a number of years, Andy has been hunting inside Nonwane, and he knows exactly where to go. A water hole just across the reserve's fence is the favourite drinking spot for all sorts of animal species, a perfect place to set traps. Setting traps is easy enough, but Andy will first have to cross the reserve's fence to get to the water hole. Above all, he has to keep a very low profile because rangers patrol the reserve. He does not want to draw any attention to himself and avoids walking directly on the sandy roads. Those tracks would be easy to see and might be traced back to Andy.

After a good hour of walking, Andy reaches the fence line of the reserve. He climbs a nearby tree and uses a large overhanging branch to get over the fence. Andy moves quietly through the bush, still avoiding sandy roads. He reaches the water hole and searches for fresh animal trails to set his traps. So far so good. All that is left now is to look at his other, older traps to check the catch of the day. Soon enough, Andy spotted a small antelope caught in one of his older traps. The unfortunate creature managed to get snared around its neck and was strangled to death. Andy quickly butchers the antelope, and makes his way back towards the fence. In a few days, he'll be back again to set more traps and see what else got caught.

Later that week, the ranger teams of Nonwane Nature Reserve start their day. One of the patrol teams, Romeo One, just finished their morning routine: check for entry-points along the reserve's border, search for footprints, and report any suspicious vehicles in the vicinity. This time, however, Romeo One had to fill in for another team that is currently suspended. Romeo One does not know this part of the reserve well, but received orders to check on a nearby water hole. Camera traps were set up at the water hole and data show that animals visit it often. Romeo One continued their patrol, walking towards the water hole. This led them to the first snare. A closer look revealed that it was set very recently. 
The rangers' experience tells them "there is never just one snare". Poachers often set many snares at the same time to increase their chances of success. Romeo One decided to change their strategy and comb the area for more snares. By the end of their search Romeo One had found ten more snares, both fresh and old. The rangers were surprised to find so many old snares. Why were these not picked up by the other team? Romeo One starts to speculate: "Maybe this explains why the other team got suspended? Was one of our own bribed to turn a blind eye?"

\section{Wildlife crime chain}

Romeo One is a hypothetical example of one of the many patrol teams responsible for protecting national parks, nature reserves, and other important natural areas. Such protected areas are often affected by poaching activities because of the abundance of natural resources within those areas. Stories of poached elephants, rhinos, and tigers often come to mind, but wildlife crime threatens many other species too. For example, parrots and lemurs are taken from the wild and sold as pets (Pires and Guerette 2014; Reuter, Lafleur, and Clarke 2017), pangolins are heavily poached to supply the traditional medicine trade (Zhou et al. 2014), megafauna are hunted for their meat (Ripple et al. 2019), and endangered species of trees and flowers are illegally harvested and used as firewood, ornaments, and medicine (Phelps and Webb 2015; Wangchuk and Olsen 2010).

Despite considerable conservation efforts in recent years, wildlife crime remains a growing issue worldwide. The first 'World Wildlife Crime Report' has identified that most countries in the world play a role in wildlife crime (UNODC 2016). Wildlife crime has major economic and social impacts. It not only drives many species into extinction (UNODC 2016), but uncontrolled poaching also represents a serious threat to the economic stability of any nation that relies on natural resources as sources of income for development, for example with tourism (Warchol 2004). High levels of wildlife crimes are generally related to weak governance and corruption (Fajardo del Castillo 2016). The United Nations recognises the need to take urgent action and included the protection of terrestrial ecosystems as one of the Sustainable Development Goals (United Nations 2019). 
Wildlife crime is not a single event, but rather a chain of crime events, as depicted in Figure 1.1 and adapted from Moreto and Lemieux (2015) and 't Sas-Rolfes et al. (2019). Poaching, the illegal taking of wild flora and fauna, is the first event in a series of crimes that supply the demand for illicit wildlife products. After a poaching event, wildlife will typically be processed, transported to markets, traded, and consumed by the end user. Depending on the context, a number of different people or groups of people can be involved at various stages of the wildlife crime chain. The first stage of the wildlife crime chain will almost always start with a motivated poacher trying to illegally obtain a wildlife product inside a protected area. To prevent this product from entering the market, robust security of protected areas is essential. The studies in this dissertation focus on the poaching stage (Figure 1.1).

\section{Focus of}

dissertation

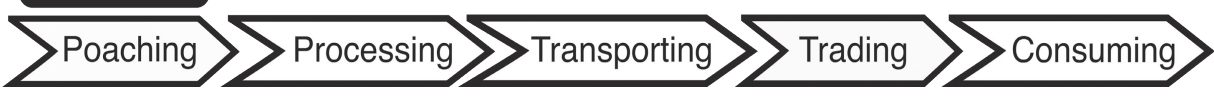

Figure 1.1. Abstract representation of the different stages within the chain of wildlife crime and the focus of this dissertation

\section{Securing protected areas}

Law enforcement plays a key role in ensuring adequate security of protected areas. They do this by, among others, providing support to local communities, responding to human-wildlife conflicts, and carrying out patrols inside the protected area (Moreto, Brunson, and Braga 2017; Nolte 2016; Struhsaker, Struhsaker, and Siex 2005). Site security is then defined as the aggregate outcome of those combined efforts by law enforcement. Deterring poaching activities through detection and apprehension is a core responsibility for law enforcement rangers (Hilborn et al. 2006; Jachmann 2008). Unfortunately, these men and women often lack resources to patrol the entire protected area on a regular basis, and basic training has been found to be insufficient in many areas worldwide (Belecky, Singh, and Moreto 2019). Furthermore, corruption among rangers has been identified as a facilitator of wildlife poaching (UNODC 2017). Despite these challenges, rangers are essential for understanding where poaching occurs. In fact, the 
vast majority of information on where poaching activities occur is collected by patrolling rangers.

Given the large size of many protected areas and limited resources for patrols, rangers need to know where high-risk poaching areas are located (Gavin, Solomon, and Blank 2010). In the opening story, Romeo One was sent to a water hole because it was identified as a high-risk area that needed extra protection. This is similar to hot spot policing to address crime problems in cities. Police resources are deployed to crime clusters or 'hot spots' with the aim of reducing crime in those locations (Braga et al. 2019; Braga, Papachristos, and Hureau 2014). However, urban police agencies typically have more data available to identify crime hot spots. The police can often use reported crimes to identify hot spots, but this is not possible for wildlife poaching. The non-human victims of wildlife poaching cannot 'call the cops', also referred to as the 'silent victim' problem (Lemieux 2014). Most information on wildlife poaching comes from proactive and reactive patrols. This may lead to a misleading or inaccurate picture of the poaching patterns and trends, especially with incomplete or infrequent patrol coverage.

Hot spot policing is built upon theories from the field of environmental criminology. Unlike traditional criminological theories that focus on explaining why an offender commits a crime, environmental criminology aims to understand and explain crime patterns as a function of opportunity structures that vary across time and space. Understanding the role of environments and being aware of the way that crime is patterned can ultimately help to design crime prevention strategies (Clarke 1983). Poaching problems can also be viewed through this lens to better understand the role opportunity plays in explaining crime patterns (Kurland and Pires 2017).

Our current understanding of where poaching occurs comes mostly from the biological and wildlife conservation sciences. These studies have predominantly analysed the spatial distributions of poached animal carcasses and often show clustering around particular landscape features like roads, water holes, and park boundaries (Haines et al. 2012; Kimanzi et al. 2015; Rifaie, Sugardjito, and Fitriana 2015; Sibanda et al. 2016). Much less attention has been given to the other stages related to the crime commission 
process, for example where poachers decide to enter or exit a protected area and why those specific locations were chosen. In the last decade, criminologists have also started to study wildlife poaching, mainly with qualitative, descriptive, conceptual, or exploratory research designs (Lynch et al. 2017). Recent reviews show that quantitative studies on the decisionmaking of poachers and rangers are missing from the literature (Kurland et al. 2017; Lynch et al. 2017; McFann and Pires 2020). Hence, here lies an opportunity to apply a criminological perspective outside of its traditional urban setting and advance current wildlife poaching research.

\section{RESEARCH AIM AND FOCUS}

Current research on wildlife poaching is mostly small-scale and qualitative, or only focused on where poached animal carcasses were found. Quantitative studies on the decision-making of poachers and rangers are missing from the literature. Such studies are necessary to better understand the entire crime commission process from beginning to end, to capture what happens before and after wildlife is poached. The objective of this dissertation is to answer pieces of the broad research question,'how does the decisionmaking of poachers and rangers influence security of protected areas?'

The specific aim of this dissertation are twofold. The first aim is to look at the research question through a criminological lens. While criminological theories were originally developed for understanding offender decisionmaking in urban environments, this dissertation assumes that poaching problems can also be studied in a similar way as traditional crimes. The second aim is to develop methodologies to better understand, design and compare patrol strategies. Law enforcement practitioners would benefit because a better understanding of where poaching occurs can help with patrol deployment and be used for designing prevention strategies. For both aims, we apply a multi-disciplinary approach to three specific poaching problems: rhino poaching, the detection of poacher snares, and collusive corruption among patrolling rangers. 


\section{THEORETICAL FRAMEWORK}

\section{Rational choice perspective}

This dissertation starts from the rational choice perspective (RCP) to explain the decision-making process of poachers (Clarke and Cornish 1985). RCP can be used to understand how environmental characteristics contribute to where crime is committed, without explaining motivations of offenders. It assumes offenders are goal-oriented and make decisions structured by the social environment and situational circumstances. The characteristics that affect offender decision-making vary greatly at both the different moments of the crime commission process and among different types of crimes. The offender, however, is not omnipotent nor omniscient, and therefore his decision-making and choices are constrained by time, cognitive ability and information for engaging in a criminal behaviour (Clarke and Felson 1993). This results in a 'limited' or 'bounded' rationality for the offender.

This line of thinking is not unique to criminology and similar approaches can be seen in other disciplines. For example, Bernasco (2009) described the similarities of RCP and 'optimal foraging theory' within the field of behavioural ecology (Pyke, Pulliam, and Charnov 1977; Schoener 1971). While optimal foraging theory is aimed at explaining and predicting foraging behaviour of animals, it is not a far stretch to see its similarities to the offenders and explaining their decisions about where to commit crime (Bernasco 2009). More particularly, RCP could help in developing testable predictions about such offender decisions.

RCP has been applied to explain spatial crime patterns in urban area (Bernasco and Nieuwbeerta 2005; Gottschalk 2016; Vandeviver et al. 2015), but can also be used to explain wildlife poaching in protected areas (Hill 2015). Just as offenders and police in urban environments, poachers and rangers can also be seen as goal-oriented people who make decisions to achieve their objectives. In the introductory story, Andy's objective was to set snares and remain undetected, while Romeo One aimed to detect any suspicious activity, but ultimately to prevent poaching altogether. Recent studies within environmental criminology have applied RCP to understand the decision-making of poachers (Marteache and Pires 2019; Pires and 
Clarke 2012). This dissertation adds to the growing body of literature using $\mathrm{RCP}$ to explain poaching problems.

\section{Interlinked decisions}

We assume that poachers are motivated and rational individuals aiming to maximise their chances to obtain their desired wildlife product, while taking efforts to minimise risk. Similarly, we assume that rangers behave rational too, only their goal is to increase the costs of poaching by patrolling target areas where most poaching is expected. The spatial behaviour of poachers and rangers are interlinked and captured by the triple foraging concept: "animals search for food, poachers search for animals, and rangers search for poachers" (Lemieux 2014). At the same time, poachers also seek to avoid rangers, and have to consider where patrols will likely be conducted. This results in a complex and dynamic cat-and-mouse game, in which both poachers and rangers are responsive to the decisions of the other group. Rangers will have to combine their knowledge and experience on past poaching events to anticipate where poachers will 'forage' and plan their deployments accordingly. If they do so effectively, it would contribute to better security of protected areas.

\section{Deterrence theory}

By assuming rational decision-making of poachers, patrol strategies can be designed to increase the costs or reduce the rewards of offending. More specifically, ranger patrols operate on the basis of a deterrence model through detection and apprehension (Moreto and Gau 2017). This is similar to how law enforcement in urban environments operates as well. The model of deterrence can be framed theoretically as the "economic model of rational deterrence" (Becker 1968). It divides the costs of committing a crime into three components related to punishment: severity, certainty, and celerity (swiftness). The severity of punishment needs to be strong enough to sufficiently counterbalance the benefits of a particular crime. Certainty applies to the likelihood of receiving punishment, whereas celerity applies to the timing of imposing punishment. Studies have shown that these three components do not have an equal influence on deterrence (Chalfin and McCrary 2017; Nagin 2013; Paternoster 2010). While the role of severity and celerity remains unclear, certainty of punishment is commonly 
found to be important for crime deterrence (Nagin 2013). Although crime deterrence outside of Western urban environments is understudied, our analytic strategies and models assume that the mechanisms are generally applicable, also to poaching problems in protected area.

\section{DETERRING WILDLIFE POACHING}

For deterrence strategies reliant on detection and arrest to be more effective, rangers would benefit from having detailed information on where poaching activities are most likely to occur. Although crime patterns are generally hard to identify, this is particularly challenging for wildlife poaching for two main reason.

The first challenge is related to the 'silent victim' problem: wildlife cannot report crimes (Lemieux 2014). As a result, most information on poaching activity comes from proactive and reactive patrols. Given the large landscapes and the limited resources available, often only a fraction of the entire protected area ends up being patrolled by rangers. Hypothetically speaking, a poaching problem can cease to exist from a law enforcement perspective when they stop patrolling. If no patrols are conducted to detect and record crime, then no data will be available on the problem. This will make it seem that the poaching problem has disappeared. The incomplete knowledge of poaching levels and distributions is also known as the 'dark figure' of crime (Biderman and Reiss 1967). In short, our understanding of where poaching occurs depends on where law enforcement resources are deployed; the levels of poaching in unpatrolled areas remain unknown (Gavin et al. 2010).

A potential way to mitigate this challenge is by focussing on the borders of the protected areas. Every poacher who wants to hunt inside a protected area has to find a way to enter it, and, after a certain amount of time, find a way to exit it. Understanding why a particular entry or exit location was chosen can provide new insights into the decision-making of poachers that would remain unknown when only animal carcass locations are analysed. This information allows rangers to identify possible risk locations for illegal border crossings and can be used to refine patrol strategies. For example, 
regular border patrols can increase a potential poacher's awareness of patrol presence in these areas. The idea behind it is that if the risk of detection is perceived high enough, then poachers might give up on their goal; the expected reward would then not outweigh the involved risk. Team Romeo One was instructed to patrol along the boundaries of the protected area for precisely this reason, because such visible patrolling could deter potential poachers. It might influence Andy's decision-making on where and when to poach, or ultimately even deter him from crossing the border altogether.

The second challenge for rangers is related to the detection and reporting of poaching. Ideally, rangers detect all poaching activities on their patrol. In reality, however, the presence of a ranger team does not guarantee that all illegal activities will actually be detected. Previous studies have shown that detectability of poaching signs can vary substantially among different levels of experience, available information, landscapes, and seasons (Becker et al. 2013; Ibbett et al. 2020; O'Kelly et al. 2018; Rija 2017; Wato, Wahungu, and Okello 2006). Additionally, the detection of illegal activities alone is not enough, because rangers also need to accurately report their observations. Potential factors influencing adequate reporting of observations include equipment failure, inability to use the recording equipment correctly, forgetting to record observations, but also collusion with poachers. Most studies on poaching acknowledge the challenges of detecting and recording poaching activity, but few have estimated baseline detection probabilities or explored different strategies that may lead to increased performance. Strategies that address the detection problem have the potential to secure better information used for making deployment decisions, which could ultimately lead to better security of protected areas.

\section{When deterrence models fail}

Patrol efforts are most successful if they are based on accurate predictions of where and when poaching activity is likely to occur, and when poachers are not able to predict where rangers are likely to patrol (Xu et al. 2017). In all the research aimed at improving law enforcement strategies, corruption is the 'elephant in the room' (UNODC 2017; Williams and Parry-Jones 2016). Even if we assume patrol strategies are designed in the most optimal way, they mean nothing when the rangers carrying out those strategies behave 
corruptly. We refer to this as collusive corruption, because ranger teams will have to collectively agree to a behave corruptly.

From a deterrence perspective, collusive corruption can reduce the certainty of punishment, but also the severity of punishment in certain scenarios. For example, paying a bribe is often a less severe punishment than receiving the actual punishment set by law. The costs poachers face when they would be caught for their illegal activity can be reduced by colluding with corrupt rangers. For example, corrupt rangers can ensure that no patrol team is present at the time of the poaching event (UNODC 2017). The corrupt ranger will often receive financial benefits through demanding bribes or a share of the poacher's profit. Hence, there's an incentive for people to act corruptly. Collusive corruption is not without risk though, because rangers team members must be able to trust one another. The threat of being betrayed by a fellow team member can potentially have even bigger consequences, making corruption a potential costly, yet often a very profitable strategy. To prevent that collusive corruption undermines the developed strategies, a better understanding of how these corrupt interactions influence site security is needed. The deterrence theory can also be used to design anticorruption measurement and explore conditions that lead to changes in levels of corruption.

To summarise, studying poaching is challenging because of the silent victim problem, the detection and reporting of poaching, and possible corruption amongst law enforcement rangers. The next section will go in more detail on the data and methodologies used in this dissertation to address these challenges.

\section{DATA AND METHODOLOGY}

The aims of this dissertation are realised through a multi-disciplinary approach by combining methods from criminology, artificial intelligence, and wildlife conservation. Here we provide a brief description of those data and methods: patrol data, agent-based modelling and experimental designs within criminology. 


\section{Patrol data}

In many protected areas today, rangers are often required to record their own patrol routes and observations using GPS devices. This is necessary because most signs of wildlife poaching are only detected and reported by patrolling rangers. Given the limited resources available to enforcement teams and the large sizes of protected areas, law enforcement managers therefore need to know which areas have been covered by patrols and what the teams detected and reported. In recent years, various data management systems have been developed for law enforcement in protected areas (Hötte et al. 2016; Stokes 2010). These systems help to record up-to-date, standardised and cost-effective information, but can also be used to track, evaluate and guide performance of patrolling rangers.

Tracking technologies have the potential to learn more precisely about where the rangers are doing what during their patrol and for how long. However, police officers in urban areas are typically not required to record their own patrol routes. As a result, little is known about how police patrols are tracked and most empirical research on urban crimes do not have access to information on the whereabouts of law enforcement (Sherman 2013; Wain and Ariel 2014). For this dissertation, ranger patrol data were available and used to understand the decision-making of poachers and rangers.

The data collected by patrolling rangers may not be an accurate representation of the true distribution of wildlife poaching (Gavin et al. 2010). The collected data could be potentially biased because of the silent victim problem and incomplete or infrequent patrol coverage (Lemieux 2014). Overcoming these difficulties to study the poacher decision-making is no easy task. However, fenced protected areas offer a unique opportunity to study specific stages of a poaching event. If poachers want to poach inside a fenced area, they have to find a way to enter it, and, after a certain amount of time, find a way to exit it. The directionality of their movements allowed us to separate the poachers' journey to crime and journey from crime. Knowing what environmental factors influence the decision-making of poachers during these specific stages can then be strategically used to make such a crime less rewarding or more risky. Ultimately, patrol data have 
the potential to identify hot spots of illegal activities, design interventions, and assess patrol performance (Moreto et al. 2014; Stokes 2010).

\section{Agent-based modelling}

Site security can be seen as the aggregate outcome of how poachers and law enforcement rangers behave and influence each other. RCP and deterrence theory help us understand the decision-making processes of poachers and rangers, but exactly how they influence site security is more complex. Agent-based modelling (ABM) is a tool that can help us understand how macro-level phenomena such as security of protected areas arise out of the complex interplay between individual-level decision-makers (Epstein and Axtell 1996). A core assumption in ABM is that macro-level phenomena are the aggregate outcome of all individual behaviours of agents. Each individual agent makes autonomous decisions, reacting to its environment and the behaviour of other agents.

In the context of this dissertation, ABM allows us to tailor models to specific settings, for example one that is focused on the behaviour of a particular species, patrol strategy, or protected area. In these models we can explore how security is influenced by the micro-level behaviour of the interacting agents (animals, poachers, and rangers) and their spatial-temporal movements (Hill 2015). At the same time, ABM also contributes to theory, because it forces the researcher to be explicit about all the assumptions and behavioural rules inside the model. This could ultimately lead to theory formalisation, which is uncommon in the social sciences in general and in criminology in particular (Bruch and Atwell 2015; Gerritsen 2015).

Computer simulations do require programming skills, but many different scenarios can be simulated when the programming is completed. While $\mathrm{ABM}$ is not meant to replace real-world experimentation, it can be an easier, cheaper, and more ethical alternative if done correctly. ABM allows us to explore model outcomes under a range of conditions to find out what is promising and what is unlikely to work. The models can generate new hypotheses that can then be empirically tested in the real-word. This dissertation expands the application of ABM into new areas of wildlife poaching. The developed models can also be relevant for practitioners when 
developing crime prevention strategies because counterfactual scenarios are generally hard to study.

\section{Experimental designs}

Experimental research designs are widely used in the sciences and are considered the gold standard for evaluating causal hypotheses. The social sciences, and criminology in particular, have generally been regarded as non-experimental and are often characterised as observational (Dezember et al. 2020; Jackson and Cox 2013). The principle of all experimental designs is to randomly assign conditions or treatments. If a difference in a particular outcome measurement exists between the treatment group and control group, then we reasonably conclude that the treatment caused the difference. These designs provide a strong foundation for advancing scientific quality, evidence-based policy, and causal inference. Understandably, an experimental approach for studying criminal behaviour is not always feasible or desirable. Common explanations for the lack of experimental research in criminology are ethical concerns, hurdles to practical implementation, and a lack of training and mentoring in experimental methods (Braga et al. 2014; Farrington 2013). The existing studies with experimental designs have mostly focused on policing behaviour and on evaluating the effectiveness of patrol strategies (Ratcliffe et al. 2011; Sherman and Weisburd 1995). For example, police raids on crack houses were randomised to test the hypothesis that public displays of police power deter other forms of crime (Sherman et al. 1995).

Many new law enforcement strategies are developed to increase patrol performance. While these new strategies are often developed with the best intentions, they are rarely tested rigorously (Sherman 2013). This means that it is often unknown whether a particular strategy works or not, or may even be counterproductive. The same holds true for ranger patrol strategies. For example, even if a particular strategy detects more poaching events, this does not necessarily mean it is indeed performing better. Other factors like rangers patrolling in an area with more poaching, increase in patrol effort, or more resources available for patrol operations could also be responsible for the increase in recorded poaching events. The ideal scenario is to study strategies and technologies in an environment with a known (spatial) 
distribution of poaching (llbbett et al. 2020; O'Kelly et al. 2018). Such studies are challenging to conduct because they require substantial investment and a collaborative relationship between academics and practitioners (Hulme 2014). It also creates ethical challenges when ongoing law enforcement operations are disrupted. Overcoming these challenges is no easy task, but this dissertation shows that it can be done. Experiments like the one presented in this dissertation are rarely conducted, but can provide evidence for what patrol strategies might work for a particular wildlife poaching problem.

\section{OVERVIEW OF CHAPTERS}

This section provides an overview of the empirical chapters of this dissertation (Table 1.1), followed by a summary of their findings, discussion and conclusion. ${ }^{1}$

Table 1.1. Overview of the research questions, topic, and type of study per chapter

\begin{tabular}{|c|c|c|c|}
\hline Ch & Research question & Research topic & Type of study \\
\hline 2 & $\begin{array}{l}\text { What environmental attributes make a } \\
\text { location attractive for rhino poachers to } \\
\text { cross the fence of a protected area? }\end{array}$ & $\begin{array}{l}\text { Decision-making } \\
\text { of poachers }\end{array}$ & $\begin{array}{l}\text { Observational } \\
\text { study }\end{array}$ \\
\hline 3 & $\begin{array}{l}\text { How does the dynamic decision-making } \\
\text { between poachers, and rangers change } \\
\text { the aggregate poaching levels? }\end{array}$ & $\begin{array}{l}\text { Decision-making } \\
\text { of poachers and } \\
\text { rangers }\end{array}$ & $\begin{array}{l}\text { Computer } \\
\text { simulation study }\end{array}$ \\
\hline 4 & $\begin{array}{l}\text { What is the detection probability of } \\
\text { wildlife snaring and how can different } \\
\text { patrol strategies potentially increase that } \\
\text { probability? }\end{array}$ & $\begin{array}{l}\text { Decision-making } \\
\text { of rangers and } \\
\text { patrol strategies }\end{array}$ & $\begin{array}{l}\text { Experimental } \\
\text { field study }\end{array}$ \\
\hline 5 & $\begin{array}{l}\text { How do repeated interactions between } \\
\text { the same pair of agents change the } \\
\text { aggregate corruption levels? }\end{array}$ & $\begin{array}{l}\text { Collusive } \\
\text { corruption } \\
\text { among rangers }\end{array}$ & $\begin{array}{l}\text { Computer } \\
\text { simulation study }\end{array}$ \\
\hline
\end{tabular}

1 The chapters of this dissertation have been written as individual manuscripts, which have either been published or submitted to scientific journals. This might result in some overlap (e.g., introducing 'silent victims', and patrolling rangers) and stylistic inconsistencies of tables and figures that could not be avoided. 


\section{Chapter 2 - Understanding site selection of illegal border crossings into a fenced protected area: a rational choice approach}

Studies on the spatial-temporal distributions of poached animals have provided insight into poachers' target selection. However, this is only one activity of the crime commission process. Poachers also need to decide on where to cross the border of a protected area before and after their hunt. Understanding why a particular entry or exit location was chosen can provide new insights into the spatial decision-making of poachers that otherwise would be unknown from only analysing animal carcass locations. This information allows rangers to identify possible risk locations for illegal border crossings, which can be used to refine patrol strategies.

Chapter 2 aims to explain the spatial decision-making of rhino poachers. It analyses what environmental attributes make a location attractive for rhino poachers to cross a fenced protected area. Guided by the rational choice approach, the hypotheses presented assume poachers select sites from which they expect to obtain the highest rewards, with minimal effort and risk. Unique to this chapter was an ability to separate the journey to crime and journey from crime; the directionality of movement enabled rangers to classify illegal border crossings as entries or exits. This made it possible to determine the similarities and differences between the two which is rather rare in environmental criminology.

This chapter found that half of all illegal crossings occurred at a specific location along the border. This location was particularly attractive to poachers because of an unfenced bridge over a large river. It provided poachers easy access to and from the protected area, because at all other locations they would need to cross a border fence. Next, we analysed the poacher's target selection in general. Poachers go for the nearest way out of the reserve, by choosing exit sites near high rhino densities. The entry sites are also near high rhino densities, suggesting that poachers try to minimise time spent inside the reserve, but also that they already have knowledge about rhino locations before entering the restricted-access reserve. Furthermore, poachers select sites with high road density outside the reserve. Roads outside the reserve facilitate the journey-to-crime by providing easier access to the reserve. 
The reward and risk aspects of the rational choice framework were found to be most strongly related to the rhino poacher's spatial preference for illegal border crossings. Effort was also found to be a significant predictor but not as strong as the reward and risk aspects, and only for entries. The chapter lays a foundation for understanding the spatial decision-making of poachers and developed a methodology that can be replicated in other protected areas.

Chapter 3 - Exploring anti-poaching strategies for wildlife crime with a simple and general agent-based model

Understanding and preventing wildlife poaching is challenging because of the complex and reciprocal relation between the behaviour of poachers and rangers. Their behaviour results in a cat-and-mouse game, in which both poachers and rangers respond to the actions of the other. To tackle this complexity, Chapter 3 introduces a simple, general agent-based model of wildlife poaching. This ABM can be used to explore how security is influenced by the micro-level behaviour of poachers and rangers.

We assume that poachers and rangers are motivated and rational individuals aiming to maximise their benefits with minimal efforts. We illustrated our model by applying it to the context of rhino poaching in South Africa. We simulated a protected area with a population of rhino agents. Poacher agents go in and out to hunt for them. Ranger agents try to disrupt and catch the poachers using a particular patrol strategy. We implemented two different patrol strategies in the model; standard patrols and fence patrols. The two strategies were compared with a 'worst-case scenario': an area without any ranger teams to protect it. For each patrol strategy, the number of ranger teams and the duration of their patrols were varied, in combination with different numbers of poachers.

The results show that in general the more rangers are being deployed, the less rhinos were poached. More 'boots on the ground' is one way of strengthening formal surveillance, thereby increasing the risk of detection and arrest. The increase in formal surveillance leads to a higher chance of getting detected and reduces the chances of success. When the number of ranger teams is limited, a different strategy is to go on longer patrols to 
increase patrol area coverage. However, the results of this chapter showed that longer patrols were not more effective in protecting rhinos than shorter patrols. The results also showed that fence patrols were more effective in protecting rhinos than the standard patrols. More specifically, one fence patrol team was equally effective as two or four standard patrol teams. Fence patrols have a higher likelihood of picking up poacher signs, because poachers always start and end at the borders. In addition to that, while patrolling, the ranger agents also leave signs that influence the poacher's decision-making and likely deters them.

Our conclusions lead to the hypothesis that patrol strategies are at least equally as important as increasing the number of resources available. Future research could empirically test this hypothesis in the real-word. Such information expands the application of ABM into new areas of wildlife poaching, but is also relevant for practitioners when developing prevention strategies for poaching.

Chapter 4 - Understanding detection probabilities of wildlife poaching: a rigorous method for comparing patrol strategies using an experimental design

Rangers need to know where crime occurs to effectively design crime reduction strategies. Although crime is generally hard to measure, obtaining a representative sample is particularly challenging for wildlife poaching. Many studies on poaching acknowledge the challenges of detection, but few address the issue. Data on poaching activities may be an inaccurate reflection of the true spatial distribution of events because of low detection rates. As a result, the information rangers have on where poaching occurs will often be biased, especially if certain areas are more frequently patrolled than others. If the underlying biases behind recorded poaching data are not properly understood, then the risk of misleading patrol deployments remains high. The evaluation of detection probabilities can only be done in scenarios with known spatial distributions of wildlife poaching. This requires experimental designs and field experiments to properly evaluate the context, mechanism, and outcomes of detection strategies. However, such experiments are largely absent from conservation literature focussing on wildlife poaching. 
Chapter 4 outlines a methodology for estimating the detection probabilities of wildlife poaching and presents a case study that uses the approach to compare different patrol strategies. The strategies were tested in a field experiment in which the number and spatial distribution of 'fake' crimes were known. The experiment was conducted with rangers and volunteers in a private nature reserve in South Africa. To showcase the proposed methodology, one specific type of poaching was chosen: snaring. Using an experimental design with a known spatial distribution of fake snares, it was possible to estimate the baseline detection probability for ranger teams and compare this to three different patrol strategies: directed patrols, patrols with independent observers, and systematic search patterns.

Despite the fact that the experiment was conducted in a relatively small area, most of the fake snares were never detected even after six months. From a conservation perspective, this highlights the threat of actual snares; even those that were set several months ago can still be harmful to local wildlife. Although detection probabilities were generally low, most snares were detected when systematic search strategies were used. By systematically combing an area, patrol effort is more concentrated, whereas the effort of the other patrol strategies was more diffused. The trade-off is that it takes more time to eventually cover the area of interest.

Detection experiments like the one presented here are rarely conducted, but can provide evidence for what strategies might work for a particular problem. This chapter lays a foundation for understanding the detection probability of poacher snares, and developed a methodology that can be adjusted for other regions and other types of poaching problems. Future studies can build upon these findings to explore other factors such as seasonality and vegetation.

Chapter 5 - Corruption and the shadow of the future: a generalization of an $A B M$ with repeated interactions

Law enforcement rangers are responsible for ensuring adequate security in today's protected areas. However, even if we assume patrol strategies are designed in the most optimal way, they mean nothing when the rangers carrying out those strategies behave corruptly. Generally speaking, rangers 
in protected areas have low salaries, while high-value wildlife products on the black market can fetch a year's worth of income. Choosing to behave corruptly will yield the highest rewards that a ranger otherwise would not be able to get. Collusive corruption is not without risk though, because all rangers on the same team must trust each other. The threat of being betrayed by a fellow team member can potentially have even bigger consequences, making collusive corruption a potential costly, yet often a very profitable strategy. Previous studies on corruption have used agent-based models to explore how the aggregate outcome of individual decisions influence levels of corruption under varying conditions. The interactions between agents, however, were often modelled as one-shot, random encounters. Assuming this kind of interactions for ranger teams would not be realistic, because teams are often stationed together over extended periods of time.

To better understand collusive corruption among ranger teams, assuming repeated interactions between the same individuals would better reflect reality than one-shot interactions. Chapter 5 improves upon an existing agent-based corruption model (Hammond 2000) by allowing for repeated interactions between the same pairs of agents. We aim to examine if and how repeated interactions between agents change the aggregate corruption levels.

The results showed that transitions from high to low levels of corruption only occurred for scenarios with one or few repeated interactions. The number of corrupt agents remained high with repeated interactions and often a transition to a low aggregate-level corruption did not happen. We interpret this result as the certainty of punishment diminishing with increasing numbers of repeated interactions. When an agent has "learned" that its partner is willing to act corruptly, the most optimal decision is to act corruptly as well. In short, learning that your partner is corrupt, removed the certainty of punishment. From that moment onwards, agents have no incentive to report their partner and no one will get suspended for acting corruptly.

To increase the perceptions of certainty of punishment, one should aim to create a setting that reduces the number of repeated interactions. For ranger teams, such scenarios would represent situations in which individual 
rangers would not learn about the probability their fellow team members would act corruptly. This might be implemented by introducing rotation schemes. Future research could empirically test how staff rotation schemes impact levels of ranger misconduct. The ABM presented here should be regarded as a theoretical exploration to better understand the complexity of corruption and deterrence. While the results come from an abstract computer simulation model, they can help us understand what interventions may lead to lower levels of corruption in the real-world.

\section{DISCUSSION}

In the opening story, we read about a poacher named Andy and a patrol team, Romeo One. We saw that Andy made specific decisions to obtain bushmeat, while keeping a low profile. Similarly, Romeo One used different patrol strategies and tactics to search for illegal activities inside the protected area. While the story is fictitious, we constructed the decision-making of Andy and Romeo One from known behaviour of poachers and rangers. Guided by the rational choice perspective, this dissertation set out to inform parts of the question, 'how does the decision-making of poachers and rangers influence security of protected areas?' To do this, we developed several methodologies to better understand, design and compare patrol strategies.

\section{Decision-making of poachers}

While the rational choice perspective was originally developed for understanding offender decision-making in urban areas, this dissertation shows its applicability for understanding poaching problems in protected areas. Chapter 2 shows that the distance to high rhino densities played an important role for rhino poachers on where to enter and exit a protected area. By choosing these locations, poachers increase their chances of encountering a rhino, and hence increase their chances of obtaining high rewards. Furthermore, by minimising the time spent inside the protected area, poachers reduce their chances of encountering a ranger team on patrol. 
Unique to this dissertation was the ability to study the similarities and differences between the journey to crime and from crime. Typically, poachers face greater risk in their journey from crime compared to their journey to crime. For example, if a rhino poacher is arrested with a rhino horn, he could serve a prison sentence for up to 10 years, whereas getting caught with just a firearm is punishable by a few weeks of imprisonment (De Wet 2014). This is similar to crime journeys in urban areas. In fact, it is unlikely that urban offenders will ever be arrested on their journey to crime, because they will likely not have done anything criminal at this stage. For example, a burglar will only have committed a crime when he breaks into someone's home. All the actions leading up to that event, are likely non-criminal. However, once the offender leaves the burgled house with stolen goods, his travel back home involves greater risk compared to the journey to crime.

The finding that poachers enter the protected area close to where rhinos were located also raised another question: "How do poachers know the locations of high rhino densities in a fenced reserve?" In the study's context, poachers have no legitimate way of knowing this because the access to the protected area is restricted. We have speculated that somebody familiar with the protected area potentially colluded with rhino poachers. While we did not study corruption specifically in Chapter 2, it is likely that corruption plays a role in rhino poaching too (Milliken and Shaw 2012; UNODC 2017). In fact, we could not disclose the study area and location of the border crossings for this reason, because this may undermine ongoing operations and prevention efforts.

Effort also played a role in the decision-making of poachers, but to a lesser extent. We found that effort only played a role for the journey to crime. During the journey from crime, a poacher wants to exit quickly. Whether or not the exit site has good accessibility may be less important. While our results could be context specific, it does highlight the usefulness of breaking down a larger problem into smaller ones. By doing so, we found that the reward and risk aspects of the rational choice framework were found to be most strongly related to the rhino poacher's spatial preference for illegal border crossings. Effort was also found to be a significant predictor but not as strong as the reward and risk aspects, and only for the journey to 
crime. Knowing what environmental factors influence the decision-making of poachers can then be strategically used to make such a crime less rewarding or more risky.

\section{Decision-making of patrolling rangers}

Given the large size of many protected areas, a seemingly logical response is to call for more 'boots on the ground' as a way to increase risk of detection (Challender and MacMillan 2014). Strengthening formal surveillance has the potential to increase the risks of poaching, but it does not guarantee increased performance if law enforcement resources are managed inefficiently (Bennett 2011; Wellsmith 2011). This was the underlying theme in Chapter 3 and Chapter 4; it not only matters where patrols are conducted, but also how those patrols are being done.

We modelled the decision-making of poachers and their responses to several patrol strategies with an agent-based model (ABM) in Chapter 3. Our abstract model leads to the hypothesis that patrol strategies are at least as important as increasing the number of resources available. More specifically, deploying the available ranger agents more strategically was just as effective as doubling the number of ranger agents. Our ABM findings are not proof in itself and will need to be empirically tested, ideally with an experimental design. That said, in Chapter 4 we conducted such a field experiment to explore how different patrol strategies could potentially increase the detection probability of snares. We found that the detection probabilities of systematic searches were approximately twice as high compared to normal law enforcement operations. While this strategy is focused more on reducing the expected rewards of poaching, it does highlight the importance of how patrols are conducted when limited resources are available.

\section{Influence of collusive corruption}

We recognise that any patrol strategy will likely fail unless corruption is tackled. Before any intervention or strategy is to be implemented, law enforcement should carefully examine if and how their organisation is affected by corruption. We explored the role of corruption with an abstract model in Chapter 5 to see what conditions could lead to lower levels of corruption. Despite the artificial environment in which corruption was studied, the results 
can still be relevant for the context of colluding rangers. Rangers are often stationed together and work together in teams over extended periods of time. Because these teams operate in remote environments with little to no supervision, opportunities for colluding with fellow rangers can occur. This was also highlighted in a recent survey on the working conditions of rangers: "Rangers take bribes not because their salaries are inadequate, they take them because they believe no one notices" (Belecky et al. 2019). When a ranger finds out that his fellow team member is willing to act corruptly, the most optimal decision is to act corruptly as well.

\section{Scientific progress}

Our current understanding of where poaching occurs comes mostly from the biological sciences. These studies have predominantly focused on what landscape features correlate with the spatial distribution of poached wildlife. All the actions and decisions of a poacher leading up to a poaching event are often not considered. Therefore, in this dissertation, we focused on the context in which poachers and rangers make decisions by assuming that poaching problems can be understood from a rational choice perspective. This shifts the focus to the whole crime commission process instead of locations of poached wildlife.

The break-down of the poachers' crime journey allowed us to better understand why certain decisions were made leading up to a poaching event, but also when trying to escape the protected area. Few criminological studies were able to do so, because it is difficult to collect accurate data on both the journey to and from crime. Additionally, few studies so far have focused on the interactions between poachers and rangers. The decisionmaking of poachers need to be well understood so that patrol strategies can be designed in the most optimal way. Patrol strategies should be evaluated using field experiments to provide rigorous evidence for with might work for a particular problem. However, experimental evidence is still uncommon in the field of criminology because of its ethical, legal, and practical challenges (Dezember et al. 2020). This dissertation lays a foundation for understanding several patrol strategies, and developed methodologies that can be adjusted for other regions and other types of wildlife crimes. 


\section{LIMITATIONS}

The studies presented here have several limitations that should be addressed in future research on the subject. In this dissertation we assumed that the rational choice perspective $(\mathrm{RCP})$ can also be used to understand poaching problems. However, we did not conduct a true assessment of whether RCP is a suitable approach for understanding the decisionmaking of poachers and rangers compared to possible other opportunity frameworks, for example routine activity theory (Cohen and Felson 1979; Warchol and Harrington 2016), and crime pattern theory (Brantingham and Brantingham 2008; Kurland, Pires, and Marteache 2018). Other studies within environmental criminology have applied RCP to understand the decision-making of poachers (Marteache and Pires 2019; Pires and Clarke 2012). These studies have not systematically assessed the applicability of RCP either, but they did conclude that RCP can be used to discover what makes poaching generally attractive and why. Additionally, we neglected the drivers and motivation of poaching. These are equally important for understanding poaching problems, but such research requires different type of data, which we did not have access to. Research on wildlife poaching is growing, but much is still unknown about how poachers plan and carry out their hunt. Until we gain more knowledge on the poacher's decision-making, $\mathrm{RCP}$ can help to fill in some of these gaps on how people poach.

The empirical chapters of this dissertation focused predominately on two poaching problems; rhino poaching and bushmeat snaring, both in South African contexts. Exactly how generalisable our findings will be to other types of wildlife poaching or other environments depends on the context. Other protected areas that are targeted by rhino poachers may observe different patterns, but here too poachers make decisions on where to offend. RCP and the developed methodologies in this dissertation can then serve as a starting point for understanding the decision-making of poachers. Hence, the environmental features that influence a poacher's decision on where to commit crime could well be context-dependent, but RCP provides a generic explanation. RCP emphasises the need to consider how offenders are trying to obtain the highest rewards with minimal risk and effort. 
Another main limitation is related to patrol-based data. Most poaching events can only be identified through ranger patrols and the reported data might not be a representative sample of all poaching activities. Using these data for crime analysis can therefore be misleading or inaccurate, especially if patrol effort can not be taken into account. This was a main limitation of Chapter 2 where we could not account for patrol effort in our analysis. Our results may therefore be a mixed product of both patrol effort and poacher behaviour. Based on visits to the protected area, we believe that this was less of a problem for our analysis in Chapter 2, because rangers were able to cover most of the reserve's border on a regular basis.

In this dissertation, we intentionally aimed for abstract and simple agentbased models to reduce complexity. To do this, we had to make several assumptions that also resulted in a less realistic model. For example, in Chapter 3 we assume that all ranger teams are equal: there are no differences in detection rate and in performance among the ranger agents. Similarly, in Chapter 5, we assume that an honest agent will always report a corrupt agent. Furthermore, the conclusions based on computer simulations are not proof in itself of a particular relationship between the model variables and the emergent phenomena; alternative specifications may lead to the same dynamics or results (Epstein 2006). As long as the abstraction is limited, however, reduced complexity simulations still provide useful outputs. The abstract models can lead us to new hypotheses that can then be empirically tested in future research, and this is a critical step for model validation.

\section{FUTURE RESEARCH AND PRACTICAL IMPLICATIONS}

There are several recommendations that can be derived from the findings of this dissertation. Knowing what environmental factors influence the decisionmaking of poachers can be strategically used to make such a crime less rewarding or more risky (Clarke 1983; Lemieux 2014). However, the decisionmaking of poachers is still poorly understood. While some have reviewed the current literature on poaching (Kurland et al. 2017; van Velden, Wilson, and Biggs 2018), the fields of criminology and wildlife conservation will likely benefit from a systematic review on the decision-making of poachers. 
Similarly, many evaluations of law enforcement interventions are not designed in such a way that allow for proper evaluations (Baylis et al. 2016; Kurland et al. 2017). Aside from the testing the effectiveness of an intervention, the evaluation should also consider the involved mechanisms, moderators, implementation, and economics (Johnson, Tilley, and Bowers 2015). This is challenging to do, but several frameworks like 'EMMIE' (Johnson et al. 2015) and the guidelines by the 'Centre of Evidence-Based Conservation' (CEE 2013) have been published to guide such work. Future crime research could push the field of criminology forward with more well-designed experiments and evaluations. This should generate a better understanding of crime problems and prevention strategies (Farrington 2013).

The role of data in understanding poaching problems should not be undervalued. Several tools for law enforcement are now readily available to standardise data collection and management. These tools are relatively easy to use, but data collection should not become a goal in itself. A clear problem needs to be defined to reveal what information is available and what data need to be collected. Similarly, specialised technologies should only be used when a clearly defined problem requires it. For example, snare detection technologies are available and potentially effective (Borrion et al. 2019), but may not be financially or logistically sustainable.

Future research and evaluations should also focus more on the role of corruption. In Chapter 5 we suggested to introduce rotation schemes as a way to increase the perceptions of certainty of punishment. Staff rotation schemes, but also introducing independent observers have the potential to reduce levels of collusive corruption in organisational or institutional settings (Abbink 2004; Bühren 2020), but this has not been examined in the context of patrolling rangers. Rotation schemes or independent observers could potentially negatively impact team performance because rangers have to find out every time what the other is capable of. Hence, more research on rotation schemes in a law enforcement setting is needed to fully understand its effect on corruption and ranger performance. 


\section{The role of patrols}

Deterring poaching activities through detection and apprehension is a core responsibility for law enforcement rangers. However, some of the findings of this dissertation questions the utility of patrols. This became particularly apparent when studying patrol strategies to increase the detection probability of snares; most snares were never detected even when the best strategy was used. In this section, we briefly reflect on the utility of patrols in protected areas.

Ranger patrols in protected areas are in way similar to police patrols in urban areas. Both aim to reduce and deter illegal activities though detection and apprehension. In many scenarios, official crime data are used to identify crime hot spots and for deployment strategies. Research on urban policing shows that hot spot policing is more effective than random policing (Braga et al. 2019). It is therefore not surprising that law enforcement in protected areas use similar strategies to reduce poaching. However, there are also important differences related to the expectations of police. The responsibilities of urban police are not only to reduce and deter crime; they also serve as a community service and provide safety and reassurance to people (Skogan and Frydl 2004). Hence, even if we assume that police have limited effect on reducing levels of crime, people still expect police to be around as a community services and maintain social order (Rowland and Coupe 2014).

Reverting back to ranger patrols in protected areas, we can see that the expectations are different from police officers in urban areas. Rangers aim to protect non-human victims, wildlife, who do not expect anything nor ask for accountability. Hence, the main purpose of ranger patrols is to detect and deter poaching. Rigorous evaluations on the effectiveness of current patrol strategies are therefore necessary to learn if patrols indeed have the desired effect. This dissertation developed several methodologies that can guide such evaluations of patrol strategies.

To be clear, we do not advocate to stop patrolling altogether. Ranger patrols still have a role to play. In fact, most information on poaching activities are recorded by patrolling rangers. However, it is unlikely that patrols will be 
effective for deterring or reducing all poaching problems. This is especially true if law enforcement's main focus is to increase the number of resources available. If we learn that patrols have a negligible effect on a particular poaching problem, then law enforcement would need to shift its focus towards other approaches. For example, law enforcement in protected areas could focus more on providing support to local communities or responding to human-wildlife conflicts (Moreto et al. 2017; Struhsaker et al. 2005). Future research should also focus on such strategies to better understand how they influence poaching. Well-designed evaluations would then also reveal any unintended consequences.

\section{CONCLUSION}

This dissertation revolved around the research question, "how does the decision-making of poachers and rangers influence security of protected areas?' Studying poaching is challenging, but we could address these challenges with a multi-disciplinary approach that built on insights from criminology, wildlife conservation, and artificial intelligence. In this dissertation, we focused on the context in which poachers and rangers make decisions by assuming that poaching problems can be understood from a rational choice perspective. While this perspective was originally developed for understanding the decision-making of urban offenders, this dissertation showed that it can also be used for understanding poaching problems in protected areas. The break-down of the poachers' crime journey allowed us to better understand why certain decisions were made leading up to a poaching event, but also when trying to escape the protected area. The decision-making of poachers need to be well understood so that patrol strategies can be designed in the most optimal way. This dissertation highlights that managing and deploying law enforcement resources more strategically is just as important as increasing the number of resources. This is especially true if operations are affected by corruption. This dissertation developed several methodologies to better understand, design, and evaluate patrol strategies, which can also be adjusted for other regions and other types of wildlife crimes. 



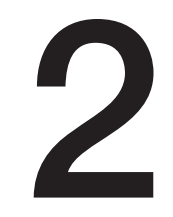

Understanding site selection of illegal border crossings into a fenced protected area: a rational choice approach

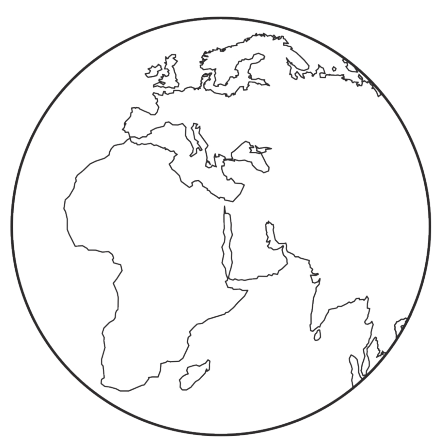




\section{ABSTRACT}

This chapter investigates illegal border crossings by rhino poachers into a fenced reserve in South Africa, comparing journeys to and from crime using a rational choice approach. Using various regression models, our analysis indicates poachers prefer to enter and exit the reserve near high rhino densities, while high road densities outside the reserve increase the odds of an illegal entry. The results also show that half of the incursions occurred at a single location, leading us to describe the special circumstances of this outlier. The chapter lays a foundation for understanding the location choices poachers make and presents a methodology that can be replicated in other reserves. $^{2}$

2 This chapter was co-authored by A.M. Lemieux and S. Ruiter. A version of this chapter is published as: van Doormaal, N., A. M. Lemieux, and S. Ruiter. 2018. 'Understanding Site Selection of Illegal Border Crossings into a Fenced Protected Area: A Rational Choice Approach'. Crime Science 7(1). https://doi.org/10.1186/s40163-018-0081-9. 


\section{INTRODUCTION}

\section{Rhino poaching in South Africa}

Wildlife conservationists and criminologists have conducted a substantial amount of research on the rhino-poaching crisis in South Africa and on the illegal wildlife trade (Ayling 2013; Haas and Ferreira 2015; Hill 2015; MuleroPázmány et al. 2014; Warchol and Kapla 2012). Rhino poaching has surged in response to increases in black market prices for horn (Milliken, Emslie, and Talukdar 2009). South Africa plays an important role in rhino conservation because it holds about $82 \%$ of the total rhino population in Africa (Emslie 2012). Most of these rhinos live within protected, often fenced reserves.

Studies on the spatial-temporal distributions of poached animals provided insight into poachers' target selection (Haines et al. 2012). However, this is only one stage of the rhino poaching crime script (Figure 2.1). Crime scripts are a useful method to obtain a structured understanding of all stages within the crime commission process (Cornish 1994). The illegal border crossing into a fenced protected area is first offence in the rhino poaching crime script that rangers can detect and report. Poachers need to decide on where to cross the border before they can start hunting. After a certain amount of time inside a reserve, they make a decision on where to exit the area. Understanding the sequence of actions that are involved in rhino poaching is important for law enforcement to identify possible risk locations inside the reserve.

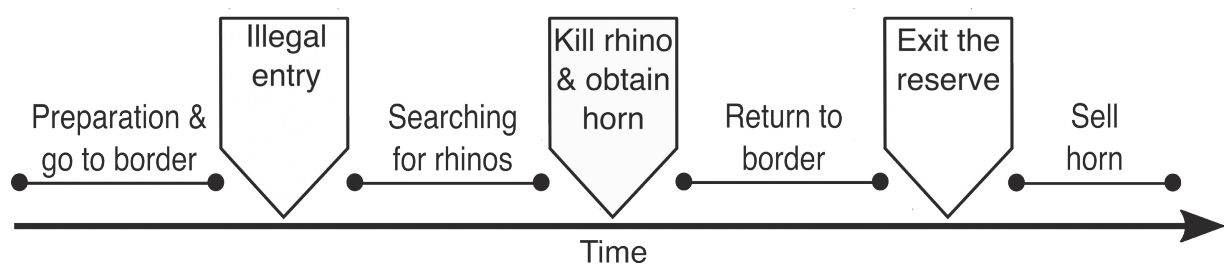

Figure 2.1. The rhino poaching crime script and its seven stages in sequential order

\section{Explaining illegal border crossings: a rational choice perspective}

The spatial-temporal behaviour of offenders is often explained from a variety of approaches like the rational choice perspective (RCP) (Cornish and Clarke 1987), routine activity theory (Cohen and Felson 1979), and 
crime pattern theory (Brantingham and Brantingham 2008). In the case of target selection, offenders first select an area within which to offend and then select a specific target (Bernasco and Nieuwbeerta 2005; Cornish and Clarke 1987). RCP has been applied to explain crime events in urban areas (Bernasco and Nieuwbeerta 2005; Gottschalk 2016; Vandeviver et al. 2015), but can also be used to explain crime in nature reserves, including wildlife poaching (Hill, Johnson, and Borrion 2014).

This chapter aims to understand the rhino poachers' spatial preferences for illegal border crossings in a partially fenced nature reserve in South Africa. It addresses the question what environmental attributes make a location attractive for rhino poachers to cross? This research provides a framework for studying illegal crossings. The chapter expands the application of crime theory into new areas of wildlife poaching and provides information relevant to wildlife practitioners.

\section{THEORETICAL FRAMEWORK AND HYPOTHESES}

RCP assumes offenders are goal-oriented and make rational decisions structured by the social environment and situational circumstances (Cornish and Clarke 1987). This means that environmental characteristics make it more or less rewarding, costly, and risky for poachers to commit crime. We assume that poachers want to avoid detection while simultaneously maximising their chances to obtain rhino horn (Eloff and Lemieux 2014).

\section{Poacher crime journeys}

Before presenting hypotheses, it is important to discuss how border site attractiveness differ between entry and exit sites. This distinction is related to what is called the 'journey to crime' and the 'journey from crime' (Brantingham and Brantingham 1981). For this chapter, the journey to crime involves the travel to where poachers enter the reserve and their hunt inside the reserve to a rhino kill site or abandonment point. The journey from crime is travel from a rhino kill site or abandonment point back to the border where poachers select an exit site. Previous research on crime journeys indicates that the offender's travel is local in nature and described by a distance decay function (Lu 2003; Rossmo 1999; Tonkin et al. 2010). Studies on the journey 
from crime are rare because it is difficult to collect accurate data on where and how offenders may have travelled during or after they commit a crime (Synnott et al. 2016).

Reverting back to RCP, offenders face greater risk in the journey from crime, compared to the journey to crime. To illustrate, the punishment of getting caught with a rhino horn is much higher, a fine up to 10 million ZAR (approximately US\$660,000 in June 2016) or imprisonment of up to 10 years, whereas getting caught with a firearm only is punishable by a few weeks of imprisonment (De Wet 2014). Hence, poachers may select different border sites based on whether they are trying to break in or escape from the reserve.

\section{Increase rewards}

Theory suggests offenders select targets that yield the highest rewards. Hübschle (2016) found that $1 \mathrm{~kg}$ of rhino horn sells for approximately US $\$ 25,000$ to $\$ 65,000$ on Vietnamese black markets, although poachers likely sell the horn below optimum prices to secure immediate income (Milliken and Shaw 2012). Poachers are paid approximately US $\$ 1750$ to US $\$ 6500$ for $1 \mathrm{~kg}$ of rhino horn (Haas and Ferreira 2016; Smith 2015). Rhinos are the most valuable species to poach in South Africa which is why individuals target these animals over other species. Rhinos are not evenly distributed over the landscape, with higher densities found in habitats more suitable to the species (Emslie 2012). This should impact the spatial decisions poachers make.

Hypothesis 1: The closer the border site is to areas with high rhino densities, the more likely it is selected by a poacher to enter the fenced reserve.

\section{Minimise risk}

Offenders select sites that minimise their risk of detection. Rangers are responsible for protecting wildlife from poachers. Poachers can reduce the risk of apprehension by rangers by spending little time inside the reserve. This may be especially true for successful poachers as they want to escape the reserve quickly after obtaining rhino horn. Thus, rhino densities form an important part of a poacher's risk consideration. 
Hypothesis 2a: The closer the border site is to high rhino densities, the more likely it is selected by a poacher to exit the fenced reserve.

Rangers are not the only capable guardians; informal guardians can also prevent a criminal act from happening (Brown and Altman 1982; HollisPeel et al. 2011). In this chapter's context this includes private landowners and tourist operators, who are capable of reporting suspicious activity. Tourist operators make a living off the wildlife inside the reserve and have an incentive to report anything suspicious. A poacher would therefore avoid areas around tourist lodges. Private homes and tourist facilities inside the reserve house these guardians, which leads to Hypothesis $2 b$.

Hypothesis 2b: A border site without buildings present inside the fenced reserve is more likely to be selected by a poacher to enter or exit.

\section{Minimise effort}

Theory suggests offenders select sites that require minimal effort. Here, we look at the communication between offender and co-offenders. Wildlife poachers in South Africa often work in groups of two to three individuals (Kruger National Park 2016; Ramsay 2014). Evidence suggests that one poacher drops off the others and stays behind to pick them up later (MuleroPázmány et al. 2014; Snitch 2014; Spicer 2014). Communication via mobile phones facilitates the ability to organise a rendezvous efficiently but network coverage is a limiting factor. Therefore, offenders may select exit sites with usable mobile phone signal to make contact with co-offenders.

Hypothesis 3a: A border site with usable phone signal is more likely to be selected by a poacher to exit the fenced nature reserve.

Site accessibility also reduces effort (Clare, Fernandez, and Morgan 2009). For example, property crimes are most likely to occur on accessible streets within a road network and have higher levels of traffic (Frith, Johnson, and Fry 2017). A high density of roads outside the reserve may lead to more illegal crossings because these areas provide easier access. Ease of access facilitates easier drop-off by their co-offenders, but also allows them to escape faster after exiting the reserve. 
Hypothesis 3b: The higher the road density outside the reserve, the more likely a border site is selected by a poacher to enter or exit the fenced reserve.

\section{Navigation}

Based on experiences in the field, we formulated a fourth criterion: navigation. Navigating through a reserve is challenging because no road markers exist for orientation. Poachers may overcome this by using large landmarks as a navigational guide. Landmarks can serve either as beacons at a target location or mark paths along the way (Foo et al. 2005). Examples of landmarks that poachers may use are power lines, radio towers, or tall factory chimneys.

Hypothesis 4: The closer the border site is to large landmarks, the more likely it is selected by a poacher to enter or exit the fenced reserve.

\section{METHODS}

\section{Study area}

We conducted this research in a partially fenced private nature reserve in the North-Eastern part of South Africa. The border connected to another reserve is unfenced. Given the sensitive nature of rhino security information (Chapman and Grafton 2008), we present no information that identifies the study area or the border crossing sites. The reserve consists of nine smaller management sections, each with a warden coordinating anti-poaching measures. Seven sections are responsible for patrolling the reserve's border and monitor 9-24\% of the total outer borders. While no information was available on the spatial distribution of patrols during the study period, the teams cover most of their borders on a daily basis.

\section{DATA COLLECTION AND PREPARATION}

\section{Illegal border crossings data}

The reserve's ranger teams documented 110 illegal border crossings between 2011 and 2016. Rangers report illegal crossings while on patrol along the border. They classified each crossing as an entry or exit based 
on the detected signs around the site, for example direction of footprints or cuts in the fence. When possible, the team tries to follow the tracks to see where they lead and if they can find any more evidence, for example snares or an animal carcass. If any evidence near the crossing location suggests that the poacher was not a rhino poacher, for example camp fires or snares, then these data entries were removed from our dataset. It is important to note that not all poachers were successful in killing a rhino. Our dataset included crossings from successful and unsuccessful poachers. The reserve is divided into a grid where each grid cell is $1.02 \mathrm{~km}$ by 1.1 $\mathrm{km}\left(0.01^{\circ} \times 0.01^{\circ}\right)$. Each cell has a unique reference number. The rangers recorded all border crossings using this grid reference system (see Figure 2.2) and therefore, we carried out the analyses on this level as well. The fenced border goes through 90 grid cells and hence this was the population size of the research.

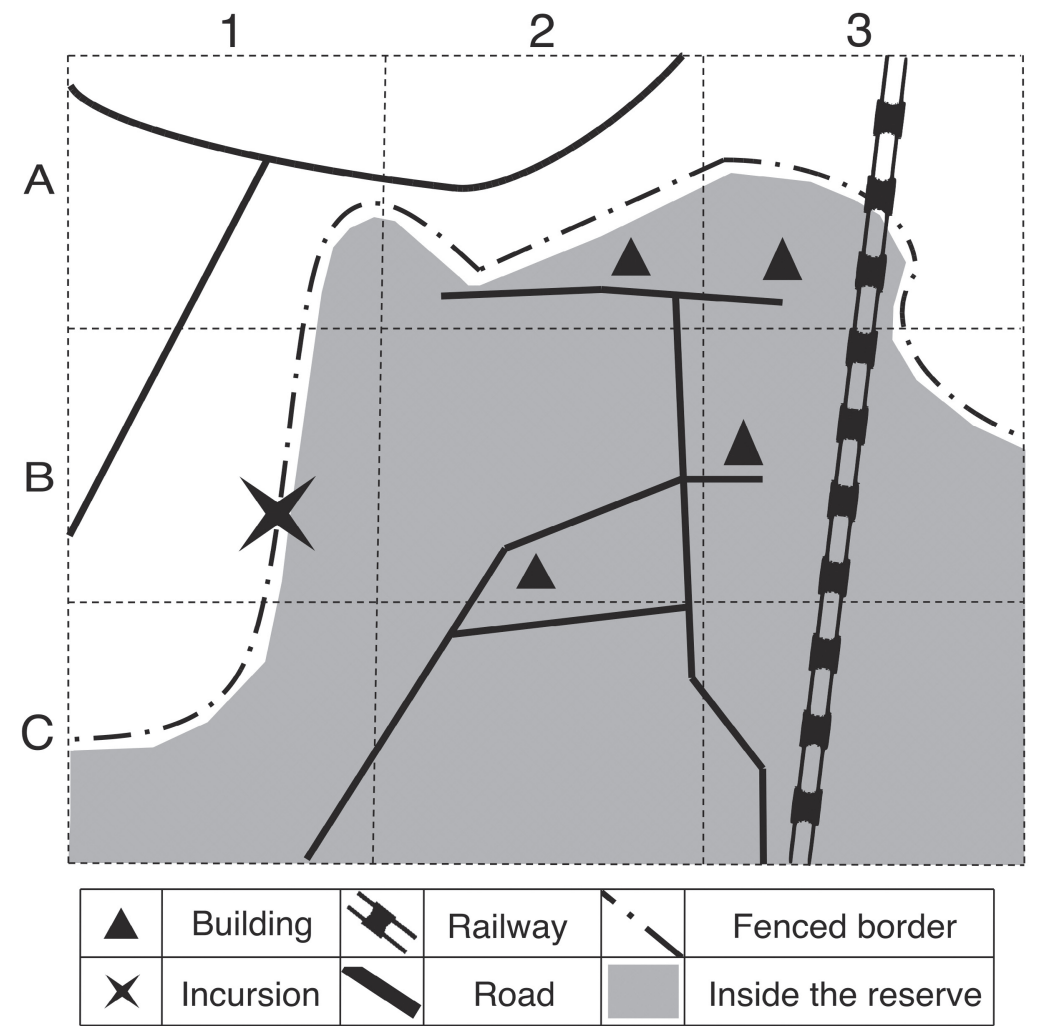

Figure 2.2. Abstract representation of the study area with a $3 \times 3$ reference grid plotted on top (dotted lines) 


\section{Environmental variables}

The reserve provided data on rhino distributions, tourist lodges, private homes, roads, and landmarks. We measured mobile phone signal during a field survey in June- July 2016. Table 2.1 describes the environmental variables. We used the yearly animal count surveys conducted in the reserve for the rhino density distribution. The count surveys are conducted every September and in a systematic way that covers the whole reserve; aggregated rhino counts from 2011 to 2016 were used. Rhino densities showed some minor fluctuations between the years, but overall they were quite stable. A common way to estimate a species' spatial distribution is by using a kernel density estimate (KDE). This produces a 'hot spot' map showing the spatial variation in rhino density across the study area. A KDEvalue of at least twice the standard deviation above the mean was classified as a rhino density hot spot (Hart and Zandbergen 2014). Next, we divided the reserve's border into points with a 10-m interval and calculated the distance from each of these points to the nearest rhino density hot spot. Finally, we averaged all the points along the border within the same 1.02 $\mathrm{km}$ by $1.1 \mathrm{~km}$ grid cell to calculate the average distance to the nearest rhino hot spot. We used these measurements for the descriptive statistics. For the analysis, we took the natural logarithm and multiplied this by -1 so that high values indicate areas near high rhino densities. We refer to this variable as 'proximity to rhino' in the analysis.

\section{Table 2.1. Overview of the explanatory variables used in Chapter 2}

\begin{tabular}{|c|c|c|c|c|}
\hline & Variable & Measure & Rationale & Hypothesis \\
\hline 1 & $\begin{array}{l}\text { Distance to } \\
\text { rhino }\end{array}$ & $\begin{array}{l}\text { Average distance }(\mathrm{km}) \\
\text { to nearest rhino hot } \\
\text { spot }\end{array}$ & Reward & $\begin{array}{l}\text { More illegal border } \\
\text { entries in areas near } \\
\text { high rhino densities }\end{array}$ \\
\hline $2 a$ & $\begin{array}{l}\text { Distance to } \\
\text { rhino }\end{array}$ & $\begin{array}{l}\text { Average distance }(\mathrm{km}) \\
\text { to nearest rhino hot } \\
\text { spot }\end{array}$ & Minimal risk & $\begin{array}{l}\text { More illegal border exits } \\
\text { in areas near high rhino } \\
\text { densities }\end{array}$ \\
\hline $2 b$ & Buildings & $\begin{array}{l}1=\text { Buildings present } \\
0=\text { No buildings }\end{array}$ & Minimal risk & $\begin{array}{l}\text { Fewer illegal border } \\
\text { crossings where } \\
\text { buildings are present }\end{array}$ \\
\hline $3 a$ & Phone signal & $\begin{aligned} 1= & \text { Usable signal } \\
0= & \text { No or unusable } \\
& \text { signal }\end{aligned}$ & $\begin{array}{l}\text { Minimal } \\
\text { effort }\end{array}$ & $\begin{array}{l}\text { More border exits in } \\
\text { areas with a usable } \\
\text { phone signal }\end{array}$ \\
\hline
\end{tabular}


Table 2.1. Continued.

\begin{tabular}{lllll}
\hline \multicolumn{1}{c}{ Variable } & Measure & Rationale & Hypothesis \\
\hline 3b & Roads outside & $\mathrm{Km}$ road $/ \mathrm{km}^{2}$ & $\begin{array}{l}\text { Minimal } \\
\text { effort }\end{array}$ & $\begin{array}{l}\text { More illegal border } \\
\text { crossings in areas with } \\
\text { high road densities } \\
\text { outside the reserve }\end{array}$ \\
& $\begin{array}{llll}\text { Distance to } \\
\text { power lines }\end{array}$ & $\begin{array}{l}\text { Average distance }(\mathrm{km}) \\
\text { to nearest power line }\end{array}$ & Navigation & $\begin{array}{l}\text { More illegal border } \\
\text { crossings in areas near } \\
\text { power lines }\end{array}$ \\
\hline
\end{tabular}

The 10-m interval points were used to calculated the distance to the nearest large landmark. We choose power lines to act as navigational landmarks. The power lines crossing the border are visible at large distances from inside and outside the reserve. This would help poachers navigating through the reserve. We averaged distances for each border cell to estimate the average distance to the nearest power line.

We scored the variable 'buildings' as 1 if they were present within a border grid cell and 0 if they were not. We measured the variable 'roads outside' as the total road length outside the reserve divided by the area outside the reserve within the grid cell (see Figure 2.2).

We measured mobile phone signal for two major network providers in South Africa. The mobile application 'GSM Field Test' continuously recorded the Received Signal Strength Indication (RSSI) (Kozyukov 2014). The values range between - 50 and $-150 \mathrm{dBm}$ with higher values indicating a stronger signal. We took a reading every $10 \mathrm{~m}$ along the border and averaged the measurements per grid cell for each network provider. Next, we used the highest value to determine if there was any usable signal in that cell. As a general rule, values between - 110 and - $50 \mathrm{dBm}$ have a usable signal, while values lower than - $110 \mathrm{dBm}$ were considered to be unusable (Mammen 2015). Finally, we scored the variable as 1 if the average signal along the border was above $-110 \mathrm{dBm}$, and 0 if it was lower, i.e. no signal.

\section{Descriptive statistics}

Rangers reported 110 illegal crossings across 24 border cells (Table 2.2). Out of those 24 border cells, 16 cells were found to have one or more illegal 
entries, and 17 cells were found to have one or more exits. We found some overlap as 9 border cells contained both an entry and exit sites. Most border cells used by poachers contained only one illegal crossing. However, one particular cell contained half of all the illegal crossings $(n=55)$. Although statistically an outlier, we did not exclude this data point but discuss it as an important case-study. We describe this further in our analytic strategy. Descriptive statistics show the variation between the border cells with and without illegal crossings (Tables 2.3, 2.4). The distance to nearest rhino density was lower for border cells with illegal crossings, entries, and exits compared to cells without illegal crossings (Table 2.3). The average for road density outside the reserve was similar across the border cells with the highest density observed for cells with illegal entries and the lowest for cells with illegal exits (Table 2.3). On average, border cells with illegal crossings, entries, and exits were closer to power lines compared to cells without crossings (Table 2.3).

Buildings were present in 54\% of border cells with illegal crossings, while $41 \%$ of the cells without crossing contained buildings (Table 2.4). Phone signal was present in almost all border cells with crossings, entries, and exits (Table 2.4).

Table 2.2. Frequency table for the number of illegal border crossings between 2011 and 2016

\begin{tabular}{rr}
\hline Number of illegal crossings & Frequency \\
\hline 0 & 66 \\
1 & 11 \\
2 & 4 \\
3 & 2 \\
4 & 4 \\
5 & 1 \\
9 & 1 \\
55 & 1 \\
\hline
\end{tabular}




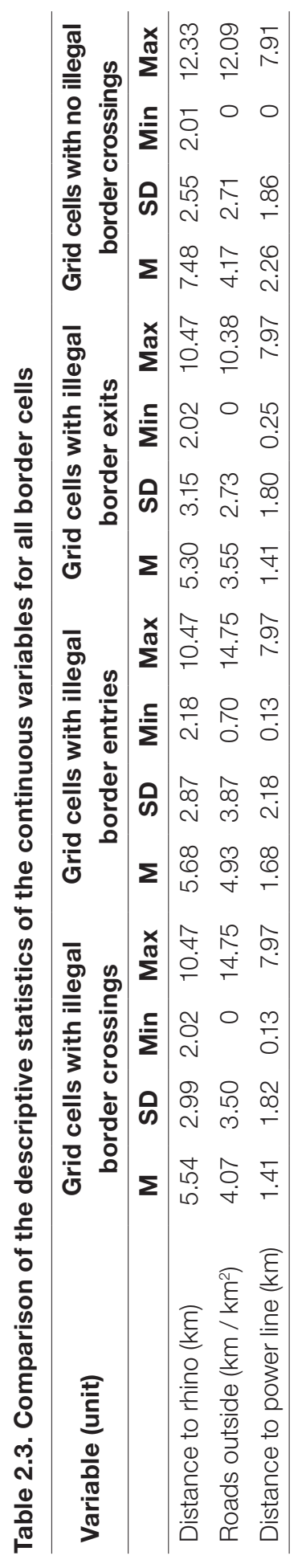


Table 2.4. Frequency table for the binary variables used in this chapter

\begin{tabular}{lrrrr}
\hline Variable & $\begin{array}{c}\text { Grid cells } \\
\text { with illegal } \\
\text { border } \\
\text { crossings }\end{array}$ & $\begin{array}{c}\text { Grid cells } \\
\text { with illegal } \\
\text { border } \\
\text { entries }\end{array}$ & $\begin{array}{c}\text { Grid cells } \\
\text { with illegal } \\
\text { border } \\
\text { exits }\end{array}$ & $\begin{array}{c}\text { Grid cells } \\
\text { with no } \\
\text { illegal border } \\
\text { crossings }\end{array}$ \\
\hline Buildings & 13 & 10 & 9 & 27 \\
No buildings & 11 & 6 & 8 & 39 \\
Phone signal & 22 & 14 & 16 & 57 \\
No phone signal & 2 & 2 & 1 & 9 \\
\hline
\end{tabular}

\section{ANALYTIC STRATEGY}

\section{Crime analysis of outlier}

The descriptive statistics showed that one border cell contained half of all the documented illegal crossings. Statistically, the high number of illegal crossings in a single cell is an outlier (Table 2.2). In general, researchers deal with outliers by either removing them from the analysis or by transforming the dependent variable. However, except when outliers are linked to a mistake in the research design, it is never appropriate to remove them from the analysis (Altman and Krzywinski 2016). From a crime analysis perspective, outliers like these are important to study because this allows us to break down a larger phenomenon into a specific problem on a local level (Clarke and Eck 2005; Poyner 1986). This enables law enforcement to use their resources more effectively. A successful intervention strategy aimed at outlier locations, disrupts crime opportunities and likely displaces poachers to other, sub-optimal areas. Therefore, rangers need to know where poachers are likely displaced to.

We examined this outlier in more detail to identify what caused the high number of illegal crossings. A general model based on the RCP would help us in explaining the overall distribution of illegal crossings. We built general models using logistic regression models and a quasi-Poisson distribution to explain illegal crossings by rhino poachers. The logistic regression models compare border cells with illegal crossings to the cells without crossings. By doing this, the outlier does not influence the results more than other border cells with illegal crossings. We also compared the counts to see how the 
outlier influence our results when it was included and excluded. The logistic regression and quasi-Poisson models are described below.

\section{Logistic regression models using penalised maximum likelihood estimation}

Logistic regression models are used for a dichotomous dependent variable. However, logistic regression modelling using a standard maximum likelihood estimation tends to be unreliable for small sample sizes (Long 1997; Pearce and Ferrier 2000). We considered the sample size of 90 border cells to be too small and therefore used a penalised maximum likelihood estimation. This method results in approximately unbiased estimates of coefficients even with small sample sizes and separation issues (Allison 2008; Firth 1993; Heinze and Schemper 2002). We built three separate models; the first model used all border crossing data by pooling both entry sites and exit sites, the second one used all entry crossings, and the third one used all exit crossings. Border length (in km) was included as an offset-term to account for unequal border length across the grid cells (see Figure 2.2). We used the logistf-package (Heinze et al. 2013) in R (R Core Team 2016) to estimate the models. The profile likelihood was used for the confidence intervals and P-values estimation to ensure consistency (Cole, Chu, and Greenland 2014; Zorn 2014).

\section{Quasi-Poisson models}

This dataset contained a low number of border cells with at least one illegal crossing. Most border cells contained no illegal crossings, resulting in a relatively large number of zeros (Table 2.2). The negative binomial distribution is appropriate for analysing count data with excess zeros. Most poaching datasets are characterised by a low sample mean, which causes the low mean problem (LMP). The LMP in a negative binomial distribution affects the dispersion parameter estimation (Lord 2006), especially when combined with small sample sizes (Zhang, Ye, and Lord 2007). Therefore, we used a quasi-Poisson model to correct the standard errors for overdispersion. It estimates a dispersion parameter, which is a multiplicative factor allowing the variance to be larger or smaller than the mean. We examined the effect of the outlier by estimating two models; the first used all illegal crossings, and a second excluded the outlier. Border length (in $\mathrm{km}$ ) was included as 
an offset-term as well (see Figure 2.2). We used R to estimate the quasiPoisson models (R Core Team 2016).

\section{Diagnostics and robustness checks}

A crucial element in the KDE is the bandwidth parameter selection, but there is no general consensus on how to set these (Hart and Zandbergen 2014). We used five different approaches: average distance to $K$ nearest neighbours, where $\mathrm{K}$ is the square root of the number of observations (Devroye, Györfi, and Lugosi 2013), cross validated bandwidth selection (Diggle 2003), the reference bandwidth (Calenge 2006), the method described by Vanek (2016) and a bandwidth used by the reserve based on visual assessments. The estimated bandwidths ranged from 1298 to $3861 \mathrm{~m}$. The five bandwidths for estimating rhino hot spots were used in the models separately, but did not affect the results. In the end, we used a bandwidth of $1298 \mathrm{~m}$ using the method described by Vanek (2016). This model had the lowest Akaike Information Criterion compared to the other models using different bandwidth estimators (Burnham and Anderson 2002).

We examined the data to see if it suffered from issues of multi-collinearity. The generalised Variance Inflation Factors (VIF) were estimated using the car-package (Fox and Weisberg 2011) and we found no variables with a VIF-value higher than 2.5. Using the Durbin-Watson test, we found that autocorrelation did not affect the residuals. The Moran's I test from the spdep-package (Bivand, Hauke, and Kossowski 2013; Bivand and Piras 2015) detected no spatial autocorrelation in the residuals. For this test, we defined neighbours as those cells that touch each other along the border.

\section{RESULTS}

\section{Explaining the high number of illegal crossings in a single border cell}

We found that 55 illegal crossings were documented in a single border cell; 27 entries and 28 exits. The nearest rhino hot spot was approximately 3.09 $\mathrm{km}$ from this location. Buildings and usable phone signal were present in the border cell as well. The outside road density was $5.68 \mathrm{~km} / \mathrm{km}^{2}$, the distance 
to nearest power line was $0.25 \mathrm{~km}$. However, the main difference between this border cell and the other cells was the presence of a bridge over a large river. This is the only bridge in this area that crosses the river and is accessible by people from the outside. Furthermore, the location where the bridge crosses the river into the reserve is unfenced. This provides poachers an easier access point to and from the reserve, because at all other areas they need to cross the fence. In the following sections, we show the results of analysing the overall distribution of illegal crossings.

\section{Logistic regression models}

The logistic regression model using all illegal crossings showed that 'proximity to rhino' was the only statistically significant predictor (Table 2.5). The likelihood of an illegal crossing was higher for border cells in close proximity to high rhino densities compared to cells further away; a one-unit increase in proximity to rhino increases the odds of an illegal crossing by a factor of 4.91. This finding is in line with the chapter's hypothesis. The other variables were not found to be statistically significant with regards to illegal crossings.

The logistic regression model using only illegal entries showed that the variables 'proximity to rhino' and 'outside roads' were statistically significant predictors (Table 2.6). A one-unit increase in proximity to rhino increases the odds of an illegal border entry by a factor of 3.41. A one-unit increase in outside road density increases the odds of an illegal entry by a factor of 1.28. Both findings were in line with the chapter's hypotheses. There was no statistically significant relationship between the other variables and illegal entries.

The logistic regression model using only illegal exits found that the variable 'proximity to rhino' was a statistically significant predictor (Table 2.7). A oneunit increase in proximity to rhino increases the odds of an illegal border exit by a factor of 5.15. This finding was in line with the chapter's hypothesis. There was no statistically significant relationship between the other variables and illegal exits. 
Table 2.5. Logistic regression model using penalised MLE using both entry and exit crossings

\begin{tabular}{lrrrr}
\hline Variable & Odds ratio & 95\% conf. interval & $\mathbf{X}^{2}$ \\
\hline Proximity to rhino & $4.91^{\star *}$ & 1.78 & 14.92 & 9.59 \\
Buildings & 1.46 & 0.52 & 4.13 & 0.52 \\
Phone signal & 1.97 & 0.43 & 12.89 & 0.71 \\
Roads outside & 1.12 & 0.92 & 1.40 & 1.42 \\
Distance to power lines & 0.74 & 0.47 & 1.04 & 0.09 \\
\hline
\end{tabular}

**P $<.01$

Table 2.6. Logistic regression model using penalised MLE using all illegal entry crossings

\begin{tabular}{lcccc}
\hline Variable & Odds ratio & 95\% conf. interval & $\mathbf{X}^{\mathbf{2}}$ \\
\hline Proximity to rhino & $3.51^{*}$ & 1.08 & 11.37 & 4.40 \\
Buildings & 2.60 & 0.82 & 9.10 & 2.64 \\
Roads outside & $1.28^{\star}$ & 1.03 & 1.62 & 5.05 \\
Distance to power lines & 0.84 & 0.54 & 1.18 & 0.88 \\
\hline
\end{tabular}

${ }^{*} \mathrm{P}<.05$

Table 2.7. Logistic regression model using penalised MLE using all illegal exit crossings.

\begin{tabular}{lrrrr}
\hline Variable & Odds ratio & $\mathbf{9 5 \%}$ conf. interval & $\mathbf{X}^{\mathbf{2}}$ \\
\hline Proximity to rhino & $5.15^{\star \star}$ & 1.72 & 17.03 & 8.73 \\
Buildings & 1.17 & 0.38 & 3.66 & 0.08 \\
Phone signal & 2.46 & 0.46 & 25.77 & 1.00 \\
Roads outside & 1.00 & 0.79 & 1.25 & 0.00 \\
Distance to power lines & 0.83 & 0.50 & 1.21 & 0.86 \\
\hline
\end{tabular}

${ }^{* * P}<.01$ 


\section{Quasi-Poisson models}

The quasi-Poisson model using all illegal crossing data, including the outlier, found no statistically significant effect for the predictor variables. This was related to the dispersion parameter, which the model estimated to be 49.26 . This means that the standard errors in this model are $\sqrt{ } 49.26 \approx 7$ times larger. When we excluded the outlier from the analysis, the model showed that proximity to rhino was the only statistically significant predictor variable (Table 2.8). The dispersion parameter was 3.22, suggesting that the outlier influenced the results. The closer the border cell was located to a rhino hot spot, the higher the number of illegal crossings. A one-unit increase in proximity to rhino increases the expected number of illegal crossing by a factor of 3.44 .

Table 2.8. Quasi-Poisson model using entry and exit crossings without the outlier of 55 illegal crossings.

\begin{tabular}{lccc}
\hline \multicolumn{1}{c}{ Variable } & Incidence rate ratio & \multicolumn{2}{c}{$\mathbf{9 5 \%}$ conf. interval } \\
\hline Proximity to rhino & $3.44^{*}$ & 1.33 & 8.92 \\
Buildings & 1.24 & 0.46 & 3.42 \\
Phone signal & 1.13 & 0.32 & 6.68 \\
Roads outside & 1.04 & 0.85 & 1.25 \\
Distance to power lines & 0.77 & 0.48 & 1.11 \\
\hline
\end{tabular}

${ }^{*} \mathbf{P}<.05$

\section{DISCUSSION}

\section{Outlier case study: bridge}

This chapter found that half of all illegal crossings occurred in a single border cell. This cell was different from the other border cells because it contains a bridge over a large river. Just as the reserve's fence is a barrier for poachers, the river can also be regarded in this way; Clare, Fernarndez, and Morgan (2009) found that large water bodies inhibit offender movements. The river in the reserve is a significant barrier and dangerous to cross. The bridge allows poachers to safely cross the river and gives them easier access to the reserve because this is an unfenced section. Parts of the river dry up during the dry season, making it easier to cross it at other places. Although we did not test how seasonality influenced the number of illegal crossings, 
poachers used the unfenced bridge consistently between 2011 and 2016. Hence, it is attractive for poachers to enter and exit the reserve, because it is a well-known and consistent opportunity to cross the river.

The high number of crossings could also be partly a reporting issue. Patrols do tend to visit areas in which they expect poaching is most likely to occur (Gavin et al. 2010). Their understanding of the spatial distribution of poaching often comes from past experiences and patrol observations. Unfortunately, ranger patrol routes were not recorded during our study period. Based on our communication with the reserve's management, we do not believe there were substantial large differences in patrol effort between the bridge border cell and other border cells with crossings.

\section{Potential solutions derived from the situational crime prevention techniques}

The unfenced bridge has the potential to become less attractive poachers by applying situational crime prevention techniques (Cornish and Clarke 2003). The most straightforward option is to fence off the bridge and increase the risks through formal surveillance. Ranger patrols can achieve this by physically monitoring the bridge or with technology such as security cameras. An alternative is to turn the bridge into an access control gate. The people working or living inside the reserve can still use the bridge in this way. However, both solutions still require a response team to follow-up on poacher detections or staff to be posted at the control gate, emphasising the need for human personnel to increase risks effectively. The reserve's management was keen on the idea of a permanent team to guard the bridge and protocols have been put in place to better secure this area.

\section{Risk and reward: proximity to rhino density}

Proximity to high rhino densities came up as a significant predictor in all logistic regression models and in the quasi-Poisson model with the outlier excluded. By entering and exiting near high rhino densities, poachers minimise the time spent inside the reserve. This would reduce the chances of encountering a patrolling ranger team, and hence reducing the poachers' risk of apprehension. This could be especially true for the journey from crime of successful poachers as they want to escape the reserve as quickly as 
possible after obtaining rhino horn. By choosing these sites, they increase the chance of encountering a rhino, and in turn increase the chance of obtaining high rewards.

While the finding is in line with Hypothesis 2a, it raises another question: "How do poachers know the locations of high rhino densities?" One explanation is that the poachers are experienced hunters who can read rhino activity signs to guide them to the nearest rhino. Poachers may also learn through previous experiences, since there were no major fluctuations in the spatial distribution of high rhino densities. Another, more worrisome, explanation is that somebody familiar with the reserve is involved in poaching by providing information to the poachers (Macleod 2012). Levels of corruption have been increasing in South Africa (Stone 2006) and it is likely to play a role in rhino poaching too. Future studies using arrest information and interviews might provide more insight as to how poachers plan their illegal crossing and uncover more about their target selection and the potential role of corrupt rangers or residents.

\section{Minimal risk: presence of buildings}

The results showed no support for Hypothesis 2b. Presence of buildings was not found to be a significant predictor for illegal crossings. This variable was used as a proxy measure for guardianship, assuming poachers would avoid areas with private homes and tourist lodges. The other guardians, rangers, might still influence the poacher's target selection. We did not study the effect of patrols because no such data were available before 2016. However, the reserve established updated data collection protocols, including GPS tracking of ranger movements. These data provide opportunities to update our analysis in future studies.

\section{Least effort: roads outside the reserve and phone signal}

Regarding effort, our results only found support for Hypothesis 3a. Outside roads had a statistically significant effect in the illegal entries model, while phone signal had no statistically significant effect. Roads facilitate movement to areas that would have otherwise been inaccessible or require more effort. Other studies found similar results and showed that the distance to roads was a strong predictor for levels of poaching (Blake et al. 2007), and that 
poachers use roads to penetrate into a national park (Blom et al. 2005). Outside roads can also facilitate drop-offs (Mulero-Pázmány et al. 2014; Snitch 2014; Spicer 2014). This suggests that poachers select entry sites that require minimal effort. This effect was not found for exit sites. A possible explanation is that a poacher has more time when deciding where to enter the fenced reserve, and can also decide not to enter at all, for example if he spots patrolling rangers. During the journey from crime, a poacher wants to exit quickly. Whether or not the exit site has good accessibility is less important. Even if poachers are unsuccessful, they probably have less control over where and when they exit the reserve, because this is dependent on their search inside the reserve.

Phone signal was not found to be a significant predictor for illegal exits. We measured phone signal in 2016 only, and applied this for all illegal crossings in previous years. It is most likely that phone coverage improved during our study period. We may have overestimated the phone signal distribution as a result. The reserve's updated data collection protocols now include phone signal measurements. In the future, it would be possible to study in more detail if and how phone signal influences the poacher's target selection.

\section{Navigation: distance to power lines}

We did not find any evidence that poachers were using power lines to navigate where they enter and exit the reserve. Power lines or other landmarks may still play a role during a hunt; however, it appeared not to be important for illegal entries or exits. Should information about poacher movements become available, it would be easier to study how the poachers navigate and whether such landmarks play any role.

\section{Limitations}

To study crime location choice, it is necessary to use spatial data, such as crimes reported to police by victims or bystanders. Spatial analyses of poaching activities are more difficult because animals cannot report crime. This 'silent victim' problem means quantifying true levels of crime is challenging (Lemieux 2014). Using patrol data to analyse crime location choice can be misleading because ranger patrols are biased towards certain areas (Gavin et al. 2010); they focus on areas where they expect 
the highest returns. Patrol teams are responsible for large areas, but often lack the resources to cover it on a regular basis. This results in an incomplete knowledge of crime levels and distributions, also known as the 'dark figure' (Biderman and Reiss 1967).

Overcoming these difficulties to study the poacher location choices is no easy task. However, fenced protected areas offer a unique opportunity to study specific stages of a poaching event. If a poacher wants to poach inside a fenced area, they have to find a way to enter it, and, after a certain amount of time, find a way to exit it. Regular fence patrols increase the probability of obtaining information on illegal crossings. We could not account for the spatial and temporal distribution of patrol effort because no such data were available before 2016. However, the reserve established updated data collection protocols, including GPS tracking of ranger movements. Future studies will be able to take patrol effort into account.

Another limitation of this research was the small sample size. This is explained by the reserve's size together with the relatively large grid cell sizes, but also because poaching is a rare event. It was not possible to determine the exact location of where poachers crossed the border because the illegal crossings were recorded at the grid-level. With the updated data collection protocols, crossings are now recorded at the exact location with GPS-coordinates.

\section{Future research}

This chapter's methodology could be replicated for other protected areas with similar data. Future research might focus poacher movements and what environmental features influence their decisions. These data can be collected when GPS-tracked rangers follow the exact trail the poachers used. Dense vegetation was not included in our analysis, but likely influences poacher movements on the micro-level. The location of rivers may also help to explain the entry and exit locations of poachers on the micro-level, and it should be able to identify them by analysing remote satellite imagery. In this chapter we neglected temporal elements that may influence poacher decision-making, but these should be studied in more detail to understand if spatial patterns are related to seasonal or monthly cycles. Arrest data 
and interviews would give more insight into how poachers plan their illegal crossing and uncover more about their modus operandi. Such detailed studies are useful for law enforcement to help with patrol planning.

\section{CONCLUSION}

This chapter contributes towards understanding illegal border crossings by rhino poachers into a fenced reserve in South Africa and can help law enforcement to identify risk locations. The descriptive results show that half of the observed crossings occurred at a single location, leading us to describe the special circumstances of this outlier. Next, we analysed the poacher's target selection in general. By breaking a poacher's trip into a journey to crime, and a journey from crime, it was possible to determine the similarities and differences between the two. Poachers go for the nearest way out of the reserve, by choosing exit sites near high rhino densities. The entry sites are also near high rhino densities, suggesting that poachers try to minimise time spent inside the reserve and have knowledge on rhino locations. Furthermore, poachers select sites with high road density outside the reserve. Roads outside the reserve facilitate the journey-to-crime by providing easier access to the reserve. The reward and risk aspects of the rational choice framework were found to be most strongly related to the rhino poacher's spatial preference for illegal border crossings. Effort was also found to be a significant predictor but not as strong as the reward and risk aspects, and only for entries. 


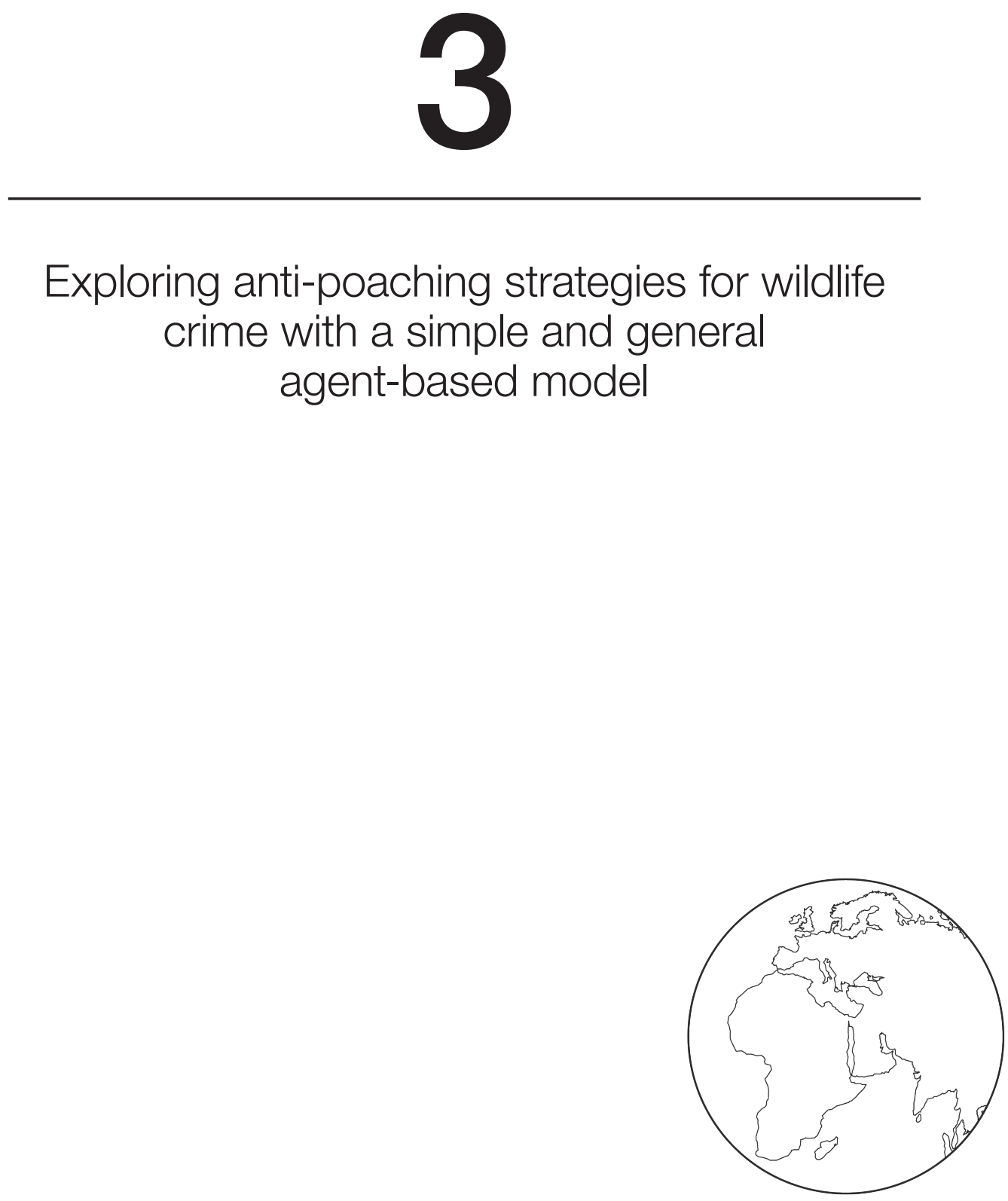


\section{ABSTRACT}

Understanding and preventing wildlife poaching is challenging because of the complex interdependencies between animals, poachers, and rangers. To tackle this complexity, this chapter introduces a simple, general agentbased model of wildlife poaching. The model is abstract and can be used to derive general conclusions about the emergence and prevention of wildlife poaching. It can also be tailored to create scenarios which allows researchers and practitioners to better understand the dynamics in specific cases. This was illustrated by applying the model to the context of rhino poaching in South Africa. A virtual park populated by rhinos, poachers and rangers was created to study how an increase in patrol effort for two different anti-poaching strategies affect the number of poached rhinos. The results show that fence patrols are more effective in preventing poaching than standard patrols. Strikingly, even increasing the number of ranger teams does not increase the effectiveness of standard patrols compared to fence patrols. ${ }^{3}$

3 A version of this chapter is published as: van Doormaal, N. 2017. 'Exploring Anti-Poaching Strategies for Wildlife Crime with a Simple and General Agent-Based Model'. Pp. 51-62 in Progress in Artificial Intelligence. EPIA 2017. Vol. 10423, Lecture Notes in Computer Science, edited by E Oliveira, J Gama, Z Vale, and H Lopes Cardoso. Cham: Springer. https://doi.org/10.1007/978-3319-65340-2_5. 


\section{INTRODUCTION}

The most common threats to plant and animal species worldwide are the destruction of their habitat and the over-exploitation of natural resources due to human activities like wildlife poaching and the illegal trade in wildlife products (Banks et al. 2008). Recently, criminologists have also started to study wildlife crime. Understanding the processes behind crime often leads to practical implications for crime prevention strategies to improve its effectiveness. These strategies are based upon opportunity theories, seeking to create interventions that reduce victimisation by removing or disrupting opportunities for crime. This includes increasing offender perceptions of risk and effort while minimising perceptions of reward (Clarke 1980).

A commonly used strategy to prevent wildlife crime inside a protected area is aimed at increasing the poacher's perception of risk. This is a data-driven approach that includes the analysis and mapping of poaching incidents (Maingi et al. 2012). Rangers are then deployed at poaching "hot spots" to either prevent or detect illegal activities. The downside of a data-driven approach is that it is heavily biased towards the spatial aspects of how the observation data was collected (Critchlow et al. 2015). Ranger patrols are often not able to cover the whole protected area on a regular basis, leading to an incomplete knowledge of where and when poaching activities occur (Gavin et al. 2010). This is also referred to as the 'dark figure of crime' (Biderman and Reiss 1967). Furthermore, when a new anti-poaching strategy has been put in place, rarely has it been evaluated in a standardised and systematic way.

As an alternative, wildlife crime can be studied as a complex and dynamic system. Its complexity does not only arise from the strategic interdependencies between animals and poachers. Poachers are also being tracked by rangers and seek to avoid interaction. This creates a second layer of strategic interdependence. To tackle the complexity of these systems, formal models allow researchers to study the implications of model assumptions. They help to understand why and under what conditions the models generate unexpected predictions (Epstein and Axtell 1996). Formal models allow researchers to explore the effectiveness of anti-poaching 
strategies even before they are implemented. They also allow to derive testable predictions about the conditions under which they are effective or not. For example, a successful strategy can turn ineffective at one moment, not because rangers failed to implement it, but simply because animals responded to changes in their environment. Subsequently, this motivates different poacher behaviour which makes the adopted anti-poaching strategy ineffective.

Agent-based modelling (ABM) is a prominent formal modelling technique and particularly suited to study wildlife crime. In an agent-based model, each individual agent makes autonomous decisions, reacting to its environment and the behaviour of other agents. AMB is a rigorous method, but hardly restricts the modeller in the choice of assumptions (Birks, Donkin, and Wellsmith 2008). ABM allows researchers to tailor models to specific settings, for example by applying their model to a specific protected area, endangered species, or anti-poaching strategy. Such information is not only relevant for practitioners, but also expands the application of ABM into new areas of wildlife crime.

\section{OBJECTIVE}

This chapter is aimed at exploring the dynamic interactions between the agents involved in wildlife crime using agent-based modelling. The objective was to develop a simple and general model that captures these dynamics under different anti-poaching scenarios. As an illustration, the model is demonstrated by applying it to the context of rhino poaching in South Africa.

\section{THE GENERAL MODEL: ANIMALS, POACHERS, AND RANGERS}

For most cases of wildlife crime, there are three types of agents: animals, poachers, and rangers. The interactions between these agents can be described as a triple foraging process (Lemieux 2014): "animals search for food, poachers search for animals, and rangers search for poachers". The model simulates a "world" with a population of animals where poachers go in and out to hunt for this species. The rangers try to disrupt and catch the poachers. 
The world is a simplified representation of a protected area, like a national park. This virtual park is divided into grid cells that contain information about the environment, like the amount of resources available to the animal, how long it takes to move through this cell and any signs of animal, poacher, or ranger presence. The advantage of using a simplified model of a park is that dynamics cannot be driven by idiosyncratic characteristics of a specific setting, allowing the modeller to derive general conclusions about the implications of model assumptions. Nevertheless, the model is formulated in such a way that many idiosyncrasies of real parks can be implemented, which allows the study of dynamics also in specific settings.

In this model, animals are distributed over the virtual park and individually make decisions on where to move next based on the characteristics of the surrounding grid cells, choosing cells that are most attractive. At the same time, animals also change their environment by consuming resources. The resources recover over time. While the animals move over the landscape, they leave signs that can be detected by poachers, influencing their movement as they search for a target. Poachers can also detect signs of ranger activity and try to avoid those areas. Hence, poachers make decisions based on, among others, signs of recent animal activity and ranger activity. Poachers always start and end their hunt at the border of the virtual park. If a poacher encounters an animal within his observation radius, he kills it and the poached animal is removed from the park. The poacher then returns to the park's border. When the poacher reaches the border, he successfully escaped and cannot be caught by rangers. Poachers remember the areas where they were successful, areas with high ranger activity and use that information to plan their subsequent incursions.

Rangers carry out patrols and search for signs of poaching. Just as poachers tend to go to areas with the highest animal activity, rangers tend to go to areas with the highest poaching activity. If a ranger detects a poacher within his observation radius, the ranger catches the poacher, removing him from the park. Rangers remember where they found poaching signs and tend to patrol those areas more frequently. Rangers can start either at a base camp inside the virtual park or at one of its borders. 
Dynamics are broken down to a sequence of discrete events. At each event, first all animals decide in a random order where to move, followed by the moving decisions of poachers, and rangers. Finally, the simulation program updates the resources available at each cell, taking into account the consumption by animals and resource recovery. The decision-making of all three agents is similar and can be easily adjusted by adding relevant variables for a particular problem. This can also be used to create specific scenarios or conditions.

\section{EXAMPLE: RHINO POACHING IN SOUTH AFRICA}

Rhino poaching in South Africa has surged since 2008, in response to significant increases in black market prices for rhino horn (Milliken and Shaw 2012). This has led to discussion among conservationists, law enforcement and governmental organisations about effective anti-poaching strategies. Protected areas often have limited resources available, and this forces ranger commanders to implement patrol strategies that are as efficient as possible. A standard anti-poaching strategy is to deploy ground based patrol teams around rhino locations and searching for poaching activity. Almost all protected areas in South Africa are fenced or partially fenced, and fence patrols play an important role in the early detection of illegal fence crossings.

The model was applied to study the interactions and dynamics of rhino poaching and two different patrol strategies in a virtual fenced park. The free software 'NetLogo' (Wilensky 1999) was used to program the virtual park and agents. The model, its code, and the used parameters are available online at: modelingcommons.org/browse/one_model/5016.

\section{Virtual park}

The virtual park consists of 100 by 100 grid cells. Time in the park is represented by discrete simulation events. In this example, the grid size and events are arbitrary measurements and do not map directly to real world size or time. During one event, all agents make decisions based on the surroundings and move to one of their neighbouring cells. The virtual park borders are considered to be outside of the park. The other cells represent areas inside the park and contain information about the environment with 
the most important ones being resource abundance, terrain roughness, rhino signs, poacher signs, and ranger signs. Resources are randomly distributed over the landscape, and a small number of cells do not contain any resources at all. Clusters of high resources were created around the cells with high resources. Cells increase their resources by $1 \%$ when there are no rhino visits within 100 events. The reserve also contains 'rough' grid cells; cells that take more time to pass through. Roughness is represented as values ranging from 1 to 5 , with 1 being easily accessible areas and 5 the most difficult areas to move through. The agents "skip several turns", depending on the roughness value of the cell they are in.

\section{Rhino agents}

Two rhino species still exist today in South Africa: the white rhinoceros and black rhinoceros. While both species suffer from poaching, here the white rhino was chosen to model the rhino agents after. This decision was based upon fact that black rhino populations are low compared to the white rhino population and hence white rhinos are poached more often. This virtual park is inhabited by 70 white rhinos which are randomly distributed over the landscape. Rhinos are territorial animals, so if two rhinos end up within a 10 cell radius of each other, one of them moves to another random spot. The rhinos move by checking which of its surrounding cells is the most attractive. The rhinos do this by checking each of those cells for several variables like, how many resources there are, the roughness, and the distance to other rhinos. Each variable is scaled from 0 to 1 with 1 representing the highest preference. Each variable has a weight assigned to it to prioritise certain variables over the other. Next, the variables are summed and divided by the sum of weights. This information is stored as 'attractiveness' and describes the likelihood that the rhino moves to that cell. Once the rhino has moved to a neighbouring cell, it consumes $1 \%$ of the resources and it includes that cell in its territory. To reduce the likelihood that a rhino enters another rhino's territory, the cell attractiveness that belong to other rhinos is divided by 10 . Finally, the rhino leaves signs at its current location. This probability was set at 0.5 and the signs remain visible for a certain number of events. This is a random number between 500 and 1000 events. At the start of each simulation run only the rhinos move around to establish their territory 
and to distribute rhino signs over the park. This setup duration is set to 1000 events.

\section{Poacher agents}

Poachers start with no recollection of hunting grounds or areas to avoid; this is an updated procedure based on what the poacher encounters during his hunts. Poachers start at a random grid cell along the border. While they at the border, they cannot be detected or caught by rangers. Before the poacher decides where to move to, he checks the neighbouring grid cells for the ranger presence. If so, the poacher abandons his current hunt, remembers this location as a 'failure site', and moves towards the nearest grid cell that is outside the park. While poachers are hunting, they have a similar decision-making rule as described for the rhinos. The variables that the poacher takes into account are the distance to the nearest ranger agent or camp, rhino activity signs, terrain roughness, and resources. Just as the rhino decision-making, each variable is scaled from 0 to 1 , summed and then divided by the sum of weights. This information is stored as 'attractiveness' and describes the likelihood that the poacher moves to that cell. Poachers also leave signs with a probability of 0.5 and remain visible for a random number between 100 and 200 events. A poacher kills a rhino when it is on a neighbouring grid cell of the poacher's location. A poached carcass is an important poaching sign and remains visible throughout the simulation run. Poachers remember the number of events he has spent inside the park. When it exceeds a specified threshold, the poacher moves to the nearest grid cell that is outside the park. Once the poacher is outside the park, he waits a certain number of events before his next attempt. The waiting time is set at twice the specified threshold plus a random number between 1 and 100. When the waiting time is over, the poacher chooses a new start location based on his recollection of any ranger encounters and signs, poached rhino locations, and rhino activity signs. If the poacher does not remember any good sites, he picks a random grid cell along the border of the virtual park.

\section{Ranger agents}

Ranger agents have a similar setup as the poacher agents. Rangers start at either a ranger camp or along the border of the virtual park. The camps 
are randomly distributed. All cells within a 10 cells radius around the camps do not contain any resources to avoid lingering rhinos around the camps. Rangers either perform standard patrols or fence patrols. Rangers on a standard patrol have a similar decision-making rule as poachers. While on patrol, rangers make decisions based on the distance to nearest camp or other ranger teams, rhino signs, terrain roughness, and poaching signs.

Just like the poacher decision-making, each variable is scaled from 0 to 1 , summed and then divided by the sum of weights. This information is stored as 'attractiveness' and describes the likelihood that the ranger moves to that cell. Ranger agents carrying out fence patrols do not make decisions; they always move along the border for a certain number of events. When a fence patrol encounters poaching signs, they carry out the so-called "follow up". The number of events that the ranger has been on patrol is then reset to 0 . This represents that a 'response team' takes over to follow the poacher's track. The ranger agent checks the neighbouring grid cells for other poacher signs and moves to the cell with the highest poacher activity. For the following actions, the decision-making is the same as the standard patrol until the agent reaches the patrol duration threshold. If a poacher is on a neighbouring cell of the ranger's location, he catches the poacher. The caught poacher is removed from the virtual park and the ranger ends his patrol. Rangers remember areas where they caught poachers and found poaching signs as risky sites, and tend to patrol those areas more. Rangers also leave signs with the same setup as for the poacher agents. Rangers remember the number of events they have been on patrol. When this exceeds the specified threshold, the ranger moves to the nearest grid cell outside the park or to the nearest camp, depending on which of the two is closest. Just like the poacher, ranger agents wait a certain number of events before going out on their next patrol. The ranger's waiting rule is the same as the poacher's waiting rule. Rangers choose a new start location for their patrols based on the memory of any poacher encounters and signs, poached rhino locations, and rhino activity signs. If the ranger does not remember any good sites, he picks a random border cell or a random camp. 


\section{SCENARIOS WITH DIFFERENT ANTI-POACHING STRATEGIES}

Having the agents in place, several scenarios or strategies can be simulated and compared in terms of how man rhinos have survived at the end of each simulation run. The different anti-poaching strategies were compared with a 'worst-case scenario': a virtual park without any ranger teams. For each patrol strategy, the number of ranger teams and the duration of their patrols were varied, in combination with different numbers of poachers. Ranger and poacher numbers were considered a categorical variable with three levels: 1,2 , and 4 poachers or rangers. Patrol duration was also considered as a categorical variable with three levels: 50, 100, and 200 events. The number of camps was set at 1 for all scenarios with rangers. Each simulation run lasts no longer than 10,000 events, but ends earlier if either all rhinos are killed, or all poachers are caught. The outcome variable was the number of surviving rhinos at the end of each run. Each combination of settings was ran 100 times.

The Shapiro-Wilk test was used to test for normality. Further analyses were performed with the Kruskal-Wallis test. A post hoc comparison using Dunn's test with the Bonferroni adjustment was performed if the Kruskal-Wallis showed significant differences between the groups (McKight and Najab 2010). These conservative non-parametric methods were applied to reduce the possibility of type I error.

\section{Standard patrols}

The effect of adding more ranger teams carrying out standard patrols was studied in a virtual park with 1 poacher, 2 poachers, and 4 poachers. The amount of time that the poachers and ranger teams are allowed to spend inside the park was fixed at 50 events. The number of surviving rhinos was significantly different between the number of poachers and number of ranger teams (Kruskal-Wallis test; $\mathrm{H}=567.99$; d.f. $=8$; $\mathrm{P}<0.001$ ). The number of surviving rhinos increased with increasing ranger team numbers (Figure 3.1a). There was no significant difference between one ranger or two ranger teams on the surviving rhino numbers when the poacher numbers were kept constant. The same applied for two rangers and four ranger teams for the same number of poachers. 
The effect of patrol duration was studied in a virtual park with 1 poacher, 2 poachers, and 4 poachers. The duration of a poacher's hunt was fixed to 50 events. The number of rangers was set to one. The number of surviving rhinos was significantly different between the number of poachers and patrol duration (Kruskal-Wallis test; $\mathrm{H}=680.58$; d.f. $=8$; $\mathrm{P}<0.001$ ). While the surviving rhino numbers decreases with increasing number of poachers, the results show no significant difference between the different patrol durations (Figure 3.1b).
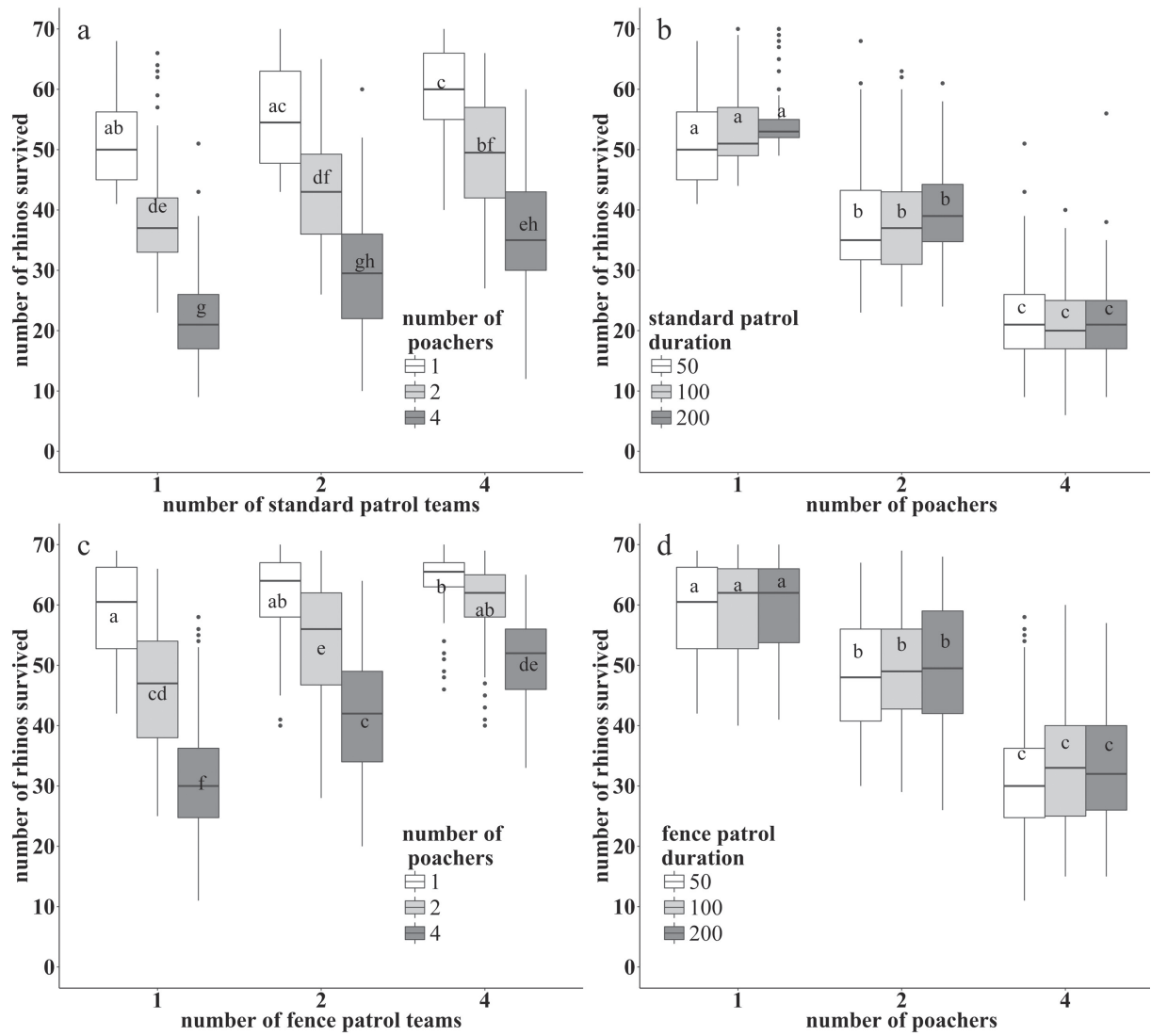

Figure 3.1. Scenario simulation results presented in boxplots. The upper row (a, b) shows the results for rangers using a standard patrol strategy. The lower row (c, d) shows the results of fence patrol teams. The left column $(a, c)$ shows the effect of adding more ranger teams. The right column (b, d) shows the effect of increasing patrol duration. The bars bearing the same letters are not significantly different at the $5 \%$ level. 


\section{Fence patrols}

The effect of adding more fence patrol teams was studied in a virtual park with 1 poacher, 2 poachers, and 4 poachers. The amount of time that the poachers and ranger teams are allowed to spend inside the park was fixed at 50 events. The number of surviving rhinos was significantly different between the number of poachers and number of fence patrol teams (Kruskal-Wallis test; $\mathrm{H}=515.58$; d.f. $=8 ; \mathrm{P}<0.001$ ). The number of surviving rhinos increases with an increase in number of fence patrol teams (Figure 3.1c). This effect was similar to the increase in rangers for the standard patrols.

The effect of fence patrol duration was studied in a virtual park with 1 poacher, 2 poachers, and 4 poachers. The duration of a poacher's hunt was fixed to 50 events. The number of rangers was set to one. The number of surviving rhinos was significantly different between the number of poachers and fence patrol duration (Kruskal-Wallis test; $\mathrm{H}=527.37$; d.f. $=8$; $\mathrm{P}<0.001$ ). While the number of surviving rhinos decreases with increasing number of poachers, the results show no significant difference between the different fence patrol duration (Figure 3.1d).

\section{Comparison of anti-poaching strategies}

The two anti-poaching strategies were compared with a 'worst-case scenario': a virtual park without any ranger teams. Two parks were created, one with one poacher, and one with four poachers. The duration of a poacher's hunt was fixed to 50 events. The comparison provides insight into how effective each patrol strategy is compared to a park without any patrols. The number of surviving rhinos was significantly different between the different patrol types and number of rangers in the park with one poacher (Kruskal-Wallis test; $\mathrm{H}=271.56$; d.f. = 6; $\mathrm{P}<0.001$; Figure 3.2a) and in the park with four poachers (Kruskal-Wallis test; $\mathrm{H}=451.35$; d.f. $=6$; $\mathrm{P}<$ 0.001; Figure 3.2b). As one might expect, the numbers of surviving rhinos was the lowest when four poachers were present. Still, when one poacher was present approximately half of the initial 70 rhinos survived. The average number of rhinos surviving was significantly higher when rangers were present and patrolling. In the virtual park with one poacher the difference between the two types of patrols decreases slightly with increasing rangers. 
Interestingly, the number of surviving rhinos was not significantly different between one fence patrol team and the two and four standard patrol teams in the one-poacher park. In the park with four poachers the differences between the patrol types are increasing with increasing ranger teams. The number of surviving rhinos was not significantly different between one fence patrol team and two and four standard patrol teams.
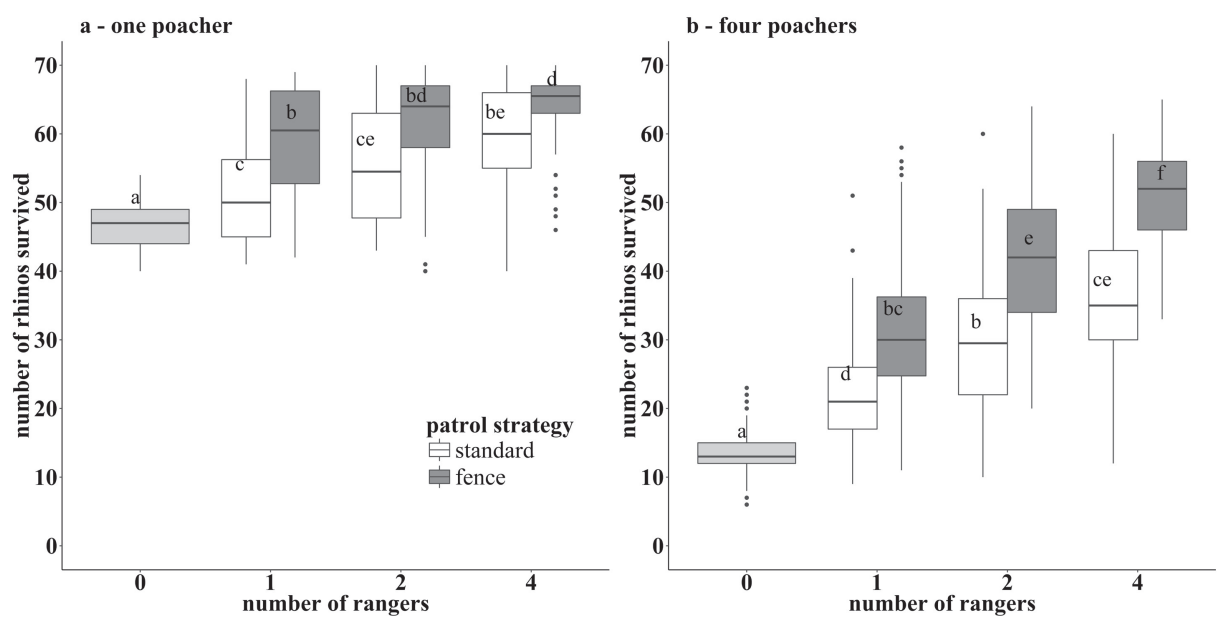

Figure 3.2. Results of the patrol strategy comparison presented in boxplots. The left plot shows the result of a virtual park with one poacher and the right plot shows the result of a park with four poachers. The bars bearing the same letters are not significantly different at the $5 \%$ level.

\section{DISCUSSION AND MODEL IMPROVEMENTS}

This chapter introduces an agent-based model to study the dynamic interactions between animals, poachers, and rangers. The model provides a general framework that can easily be applied to a specific setting or context. In this chapter, the model was applied to an abstract, virtually fenced park to explore the effect of an increase in ranger teams and an increase in patrol duration for standard patrols and fence patrols on the numbers of surviving rhinos.

The results show that the more rangers are being deployed, the less rhinos were poached. From a situational crime prevention perspective (Clarke 
1980), providing more 'boots on the ground' is a way to increase the risks for poachers. The increase in formal surveillance leads to a higher chance of getting detected and reduces the chances of success. The increase in ranger teams also means that a greater area can be covered or more frequently covered. This improves the knowledge on the spatial and temporal distribution of illegal activities, and hence uncovering the dark figure of crime (Biderman and Reiss 1967).

The general approach in building this model leads to the assumption that all ranger teams are equal: there are no differences in detection rate and in performance among the ranger agents, regardless of where or when it was deployed in the protected area. However, the effectiveness of one team and their ability to respond to a poaching event is heavily influenced by the amount of training they have received, and the equipment they carry on their patrol (Moreto 2013). The effect and efficiency of having more patrol teams is only possible when all rangers went through proper training and have adequate supplies of good anti-poaching equipment. The strength of a general model is that it can be easily adjusted. For example, one can introduce variation in the ranger's ability to detect poacher signs, or different levels of experiences. This can then lead into an analysis of the costs and returns for investing more in ranger teams, equipment, or perhaps in technology, like drones or GPS-transmitters for tracking animals. It also allows to test the proposed rule-of-thumb of 1 ranger per $20 \mathrm{~km}^{2}$ by Bell and Clarke (1986) This was not possible for the current chapter because the applied context was still a general approach with units that do not map directly to real world measurements.

When resources in protected areas are limited, a different strategy is to go on longer patrols to increase patrol area coverage. However, the results of this chapter showed that longer patrols were not more effective in protecting rhinos than shorter patrols. Rangers need special training to be able to survive under harsh conditions and in rough environments for an extended period of time. Hence, law enforcement commanders might prefer to send out their teams on shorter patrols, rather than longer ones if indeed they are not more effective. Another study by Nyirenda and Chomba (2012) found that shorter patrols of 2 to 8 days were more suitable for the Kafue National 
Park in Zambia, but stressed that this finding might not be applicable to other protected areas with different environments or in a different socialcultural context. Their statement also applies to the current model. In this chapter, only three levels of patrol duration were used in a virtual park where poachers only hunt for rhinos. Furthermore, the model also assumed that there are no changes in the ranger's ability to detect signs throughout their patrol. In other words, the model ignores the possible effect of fatigue on the ranger's ability. The longer waiting times between long patrols tries to take that into account, but also results in a lower frequency of patrols. This would also explain why no significant differences between patrol durations were found. The model can be further improved by creating a new variable that represents energy or fatigue of the ranger team and how it influences their detection rate.

The results showed that fence patrols were more effective in protecting rhinos than the standard patrols. More specifically, one fence patrol team was equally effective as two or four standard patrol teams. Fence patrols have a higher likelihood of picking up poacher signs, because poachers always start and end at the borders. In addition to that, while patrolling, the ranger agents also leave signs that influence the poacher's decision-making and likely deflects them. As stated by Eck and Weisburd (2015): "offenders avoid targets with evidence of high guardianship". Hence, offenders seek out new areas or time periods with low guardianship. This is referred to as crime displacement (Eck and Weisburd 2015). In the case of wildlife crime, poachers might be spatially displaced to other areas with low security, or temporally displaced by operating at different hours. Especially temporal displacement can be of concern when deploying fence patrols as those are much more linear and predictable compared to standard patrols. While spatial displacement can be observed from the current model, it does not explicitly measure it. Hence, it is still unknown if the observed spatial displacement in the model is a good representation of actual displacement. The model can be easily adjusted to study spatial and temporal displacement. For example, evidence suggests that poachers are more active around a full moon period (Eloff and Lemieux 2014), probably because the light allows them to move through the bush more easily or faster. If more teams are being deployed around these times, poachers 
eventually are displaced to other moon phases or perhaps even to times during the day. It would be interesting to use the model to study how ranger patrols displace poachers in time and space.

The suggestions mentioned above are just some possibilities to further improve the current model. However, before any of these suggestions are worked into the model, it is important to stress a few limitations. First, no sensitivity analysis was performed to see how each parameter influences the model outcomes. This is especially important when one is interested in studying the conditions under which systems can become critical. Ten Broeke, van Voorn, and Ligtenberg (2016) suggested the 'one-factorat-a-time' as a good starting point for a sensitivity analysis of an ABM. Furthermore, the current model was not calibrated to a specific protected area, but built around the general context of rhino poaching in South Africa. A true representation of the actual system requires more data on the agent's behaviour. In most cases, data on animal behaviour is widely available, however data on ranger and especially poacher behaviour is more difficult to collect. Such data usually comes from various sources, each with its own standards. This makes it challenging to create accurate rules for the ranger and poacher agents. However, the model can also be used to test different potential poacher strategies to see which one best reflects the observed behaviour. Once these limitations are accounted for, a next step can involve applying the model to a specific context or problem.

\section{CONCLUSION}

This chapter presented a general model to study the dynamic interactions between the three agents that are involved in wildlife crime. The general, abstract approach was done intentionally to keep the model from getting too complex, yet with rules that result in realistic behaviour of the animals, poachers, and rangers. The general framework of the model can easily be expanded to include more levels of complexity. When applied to rhino poaching under different anti-poaching strategies, the model provides some general insight as to how the different strategies influence the behaviour of rhino poachers. The results show that fence patrols are more effective in preventing wildlife crime than standard patrols. Strikingly, even deploying 
more ranger teams does not increase the effectiveness of standard patrols compared to fence patrols. The model presented here should be regarded as a first step to understand the complexity of wildlife crime and only benefits from further improvements and extensions. 



\section{4}

Understanding detection probabilities of wildlife poaching: a rigorous method for comparing patrol strategies using an experimental design

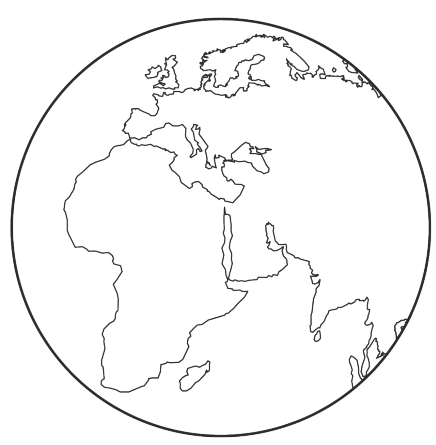




\section{ABSTRACT}

Many studies on poaching acknowledge the challenges of wildlife crime detection, but few address the issue. Wildlife crime data may be an inaccurate reflection of the true spatial distribution of events because of low detection rates. The deployment of conservation and law enforcement resources based on biased data can lead to unintended or unproductive outcomes. This chapter presents a rigorous methodology for estimating wildlife crime detection probabilities and for evaluating different patrol strategies. It illustrates the methodology with a case study in which fake snares were set in a private nature reserve in South Africa. By using an experimental design with a known spatial distribution of fake snares, it was possible to estimate the baseline detection probability by ranger teams and to evaluate three different patrol strategies: directed patrols, patrols with independent observers, and systematic search patterns. Although detection probabilities were generally low, most snares were detected when systematic search strategies were used. This chapter lays a foundation for understanding the detection probability of poacher snares, and presents a methodology that can be adjusted for other regions and other types of wildlife crimes. ${ }^{4}$

4 A version of this chapter is submitted to an international scientific journal. This chapter was coauthored by A.M. Lemieux, S. Ruiter, P.M.R.R. Allin, and C.R. Spencer. 


\section{INTRODUCTION}

Law enforcement needs to know where and when crime occurs to effectively design crime reduction strategies. Although the true distribution of crime is often unknown, police aim to accurately estimate this distribution from official crime data and victim reports. This set of data should be representative of all crimes if it is to be useful for estimating spatial-temporal crime patterns, monitoring trends, and making resource deployment decisions.

Although crime is generally hard to measure, obtaining a representative sample is particularly challenging for certain types of crime. For example, no victim reports exists for wildlife crimes because 'animals can't call the cops'; referred to as the 'silent victim' problem (Lemieux 2014). Most wildlife crimes can only be identified through proactive and reactive patrolling (Mosher, Miethe, and Hart 2010). The silent victim problem raises concerns about how many wildlife crimes go undetected and how well patrol-based data reflect the true spatial distribution of crime.

\section{Potential biases in wildlife crime data-driven}

Patrols in protected areas are unlikely to record all wildlife crimes. This does not necessarily pose a problem as long as the collected data are representative for the entire set of crimes. In reality, however, there are several reasons to expect that the recorded wildlife crime data are likely biased. The triple foraging process (Lemieux 2014) helps to understand why. It describes how opportunities for poaching and arrest are created through the movements of animals, poachers, and patrolling rangers: animals forage for food, poachers forage for animals, and rangers 'forage' for poachers. Because of the silent victim problem, whether or not poaching activity gets recorded depends on where rangers go on patrol. Rangers can only report poaching signs where they patrol while levels of poaching in unpatrolled areas remain unknown (Figure 4.1). Consequently, the recorded observations by rangers are a function of patrol rather than a function of where poaching occurs. Such biases are even strengthened if the observed wildlife crimes feed into future deployment decisions. Patrols would then repeatedly target areas where rangers have previously reported poaching activities, while other areas remain unpatrolled or only patrolled infrequently. The recorded 
information on where poaching occurs is unlikely a reliable reflection of the true distribution of crime, especially if certain areas are more frequently patrolled than others (Figure 4.1).
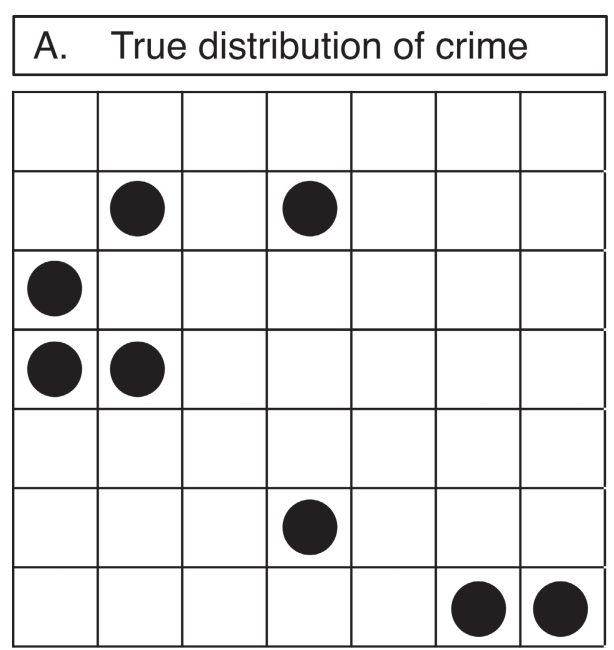

Poacher activity $\bigcirc \begin{aligned} & \text { Undetected } \\ & \text { crime }\end{aligned}$

\section{B. Recorded distribution}

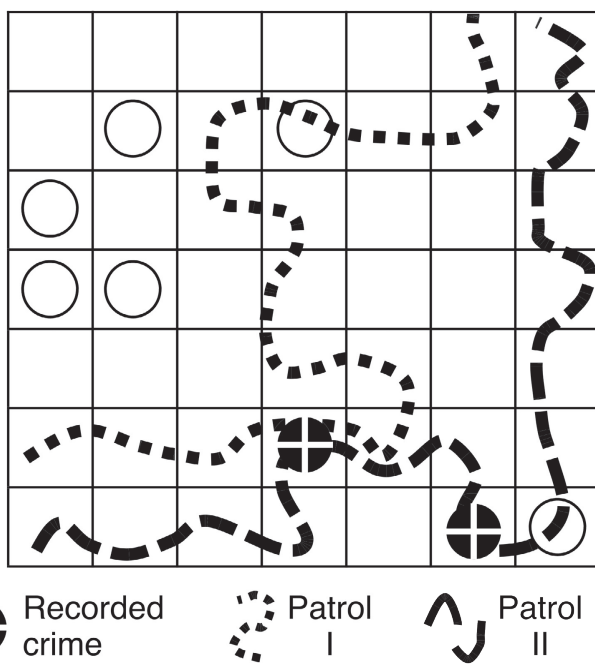

Figure 4.1. Hypothetical true spatial distribution of all crimes (A) and illustration of how patrol might bias the recorded distribution (B)

\section{Necessary steps for recording wildlife crime data}

To examine the potential biases in the recorded spatial distribution of wildlife crimes, the different steps in the data collection process need to be described (Figure 4.2). First, a ranger team is deployed somewhere inside the protected area to carry out a patrol. Given the limited resources available to enforcement teams and the large sizes of protected areas, patrols are unlikely to cover the entire area on a regularly basis. As a result, a number of wildlife crimes will remain undiscovered simply because rangers were not in close proximity to detect and report it.

If rangers patrol an area where a wildlife crime was committed, the next step for the rangers is to detect the crime (Figure 4.2). Ideally, rangers detect all poaching activities on their patrol. In reality however, the presence of a ranger team does not guarantee that all illegal activities will actually be detected. Previous studies have shown that detectability of wildlife crimes can vary 
substantially among different levels of experience, available information, landscapes, and seasons (Becker et al. 2013; Ibbett et al. 2020; O'Kelly et al. 2018; Rija 2017; Wato et al. 2006). In addition, some types of wildlife crimes are more easily detected than others. For example, a large carcass can be observed by an aerial patrol, whereas poacher snares or signs of illegal plant harvesting can often only be detected when rangers are in close proximity to those signs.

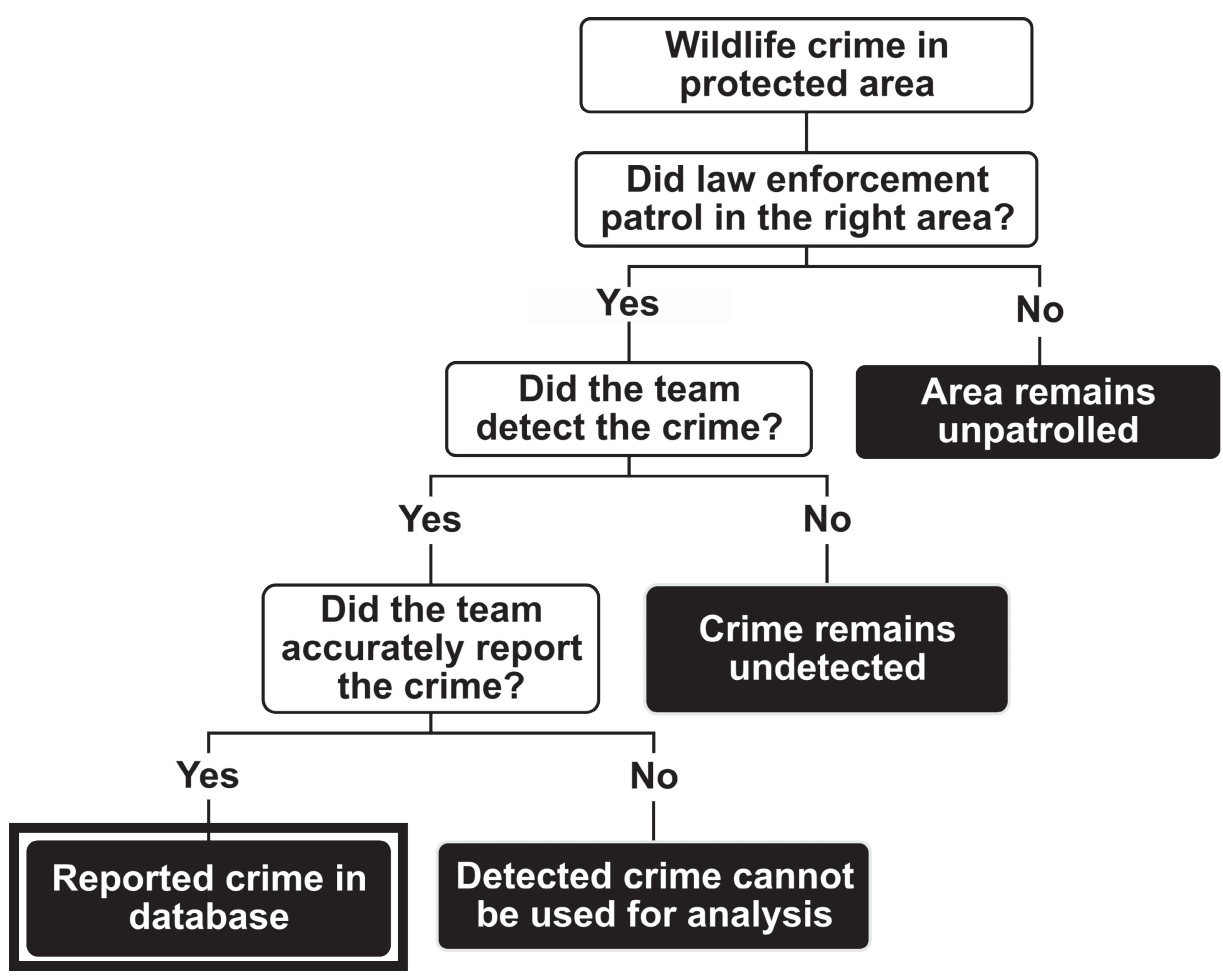

Figure 4.2. Flowchart of the necessary steps before a wildlife crime ends up recorded in a law enforcement database.

Lastly, rangers need to accurately report their observations. Several factors could influence adequate reporting of observations. Potential reasons for not reporting include equipment failure, inability to use the recording equipment correctly, forgetting to record observations, or collusion with poachers. Regardless of the reason, detected poaching activity might not always get recorded in official databases. In short, a database of recorded wildlife crimes is the end product of a chain of events related to the silent- 
victim problem, patrol deployment, detection, and reporting. Therefore, the information law enforcement have on where wildlife crimes occur will often be biased.

\section{Measuring detectability: a core component of evaluating patrol strategies}

Most studies on poaching acknowledge the challenges of detecting wildlife crimes (Becker et al. 2013; Lindsey, du Toit, and Mills 2004; Linkie et al. 2015; Wato et al. 2006; Watson et al. 2013), but few have estimated baseline detection probabilities or explored different strategies that may lead to increased performance. Recent patrol deployment research have focused on predicting the levels of poaching activities in unpatrolled or infrequently patrolled areas through mathematical modelling (Critchlow et al. 2015; Fang et al. 2017; Nguyen et al. 2016). These models can overcome some of the potential biases in crime data, but only under the assumption that the recorded crimes are a representative set of all crimes. This assumption, however, cannot be tested using only recorded poaching data and out-ofsample inferences are rarely justified. This makes estimating crime trends difficult, if not impossible. If the underlying biases behind recorded wildlife crime data are not properly understood, then the risk of misleading patrol deployments remains high.

Assessing effectiveness of patrol strategies is often not done with randomised controlled trials. A proper evaluation of new strategies or technologies will be impossible if the extent of the problem is unknown. For example, even if a particular strategy detects more poaching events, this does not necessarily mean it is indeed performing better. Other factors like rangers patrolling in an area with more poaching events, increase in patrol effort, or more resources available to law enforcement could also be responsible for the increase in recorded wildlife crimes. The evaluation of detection probabilities can only be done in scenarios with known spatial distributions of wildlife crime.

Creating scenarios with known spatial distributions of crime usually involves setting up field experiments. Field experiments are critical to better understand baseline detection probabilities of wildlife crimes, but 
also necessary to properly evaluate patrol strategies and interventions. Field experiments on wildlife crimes are, however, rarely undertaken because they require substantial investment and a collaborative relationship between academics and wildlife practitioners (Hulme 2014). It also creates ethical challenges when ongoing law enforcement operations are disrupted or by introducing harmful materials in protected areas. Only recently has a field experiment focused on the detection probabilities of wildlife crimes. O'Kelly et al. (2018) found that the detectability of wire snares varied between habitat type and snare type by setting fake snares in a tropical forest in Cambodia. Because the location of every fake snare was known, it was possible to calculate the proportion of detected snares and compare the detection probabilities among the different scenarios. Experimental designs like these are necessary to properly evaluate the context, mechanism, and outcomes of an implemented intervention but are largely absent from conservation literature focussing on wildlife crime (Kurland et al. 2017).

\section{Study objective}

This chapter outlines a methodology for estimating the detection probabilities of wildlife crime and presents a case study that uses the approach to compare different patrol strategies. It includes a preparation phase in which strategies that could potentially increase the detection probability were identified, as well as appropriate outcome measures. The strategies were tested in a field experiment in which the number and spatial distribution of 'fake' crimes were known.

\section{IMPROVING DETECTION STRATEGIES FOR WILDLIFE CRIMES}

To showcase the proposed methodology, one specific type of wildlife crime was chosen: snaring. The use of wire snares is a popular and widespread hunting technique in rural areas because they are inexpensive, effective, and easy to obtain, set and conceal (Becker et al. 2013). A wide variety of potential patrol strategies exists, but this chapter focused on those strategies with minimal or no changes to current law enforcement operations. The next section explains these strategies and how they could potentially increase the detection probability of wildlife crimes. 
Direct patrols

Local informant networks can provide crucial information or 'tip-offs' on where and when poaching activity might occur (Dudley, Stolton, and Elliott 2013; Linkie et al. 2015; Risdianto et al. 2016). This additional information can help law enforcement with directing resources towards high-risk areas. This can potentially increase the detection rate of wildlife crimes (Dudley et al. 2013). Other data-driven approaches can also lead to more directed patrols, but informant-driven patrols do not suffer as much from spatial-temporal biases. While verifying informant information has its own challenges, increased detection rates can be expected when rangers are directed towards areas based on informant data:

Hypothesis 1: Directed patrols based on informant data have a higher detection probability of wildlife crimes compared to the baseline detection probability.

\section{Independent observers}

Drawing from industrial psychology literature, observed individuals who perform a specific task may behave differently, simply because they know that they are being watched. This is also known as reactivity (Harvey et al. 2009). Studies have shown that reactivity could enhance human performance, industrial productivity, and health-related behaviours (Sibanda et al. 2016; Usichenko, Julich, and Wendt 2013). It has been speculated that the presence of an added observer or supervisor caused urban police officers to behave more proactively (Mastrofski, Parks, and McCluskey 2010; Spano 2007). We expect that the same holds for ranger teams:

Hypothesis 2: Patrols with independent observers have a higher detection probability of wildlife crimes compared to the baseline detection probability.

\section{Systematic search patterns}

Modern search theory was developed in the 1940s during wartime, primarily for naval use (Koopman 1946). It states that searching is a probabilistic process in which there is no guarantee of either success or failure. However, 
regardless the object of interest, an organised search pattern is more likely to succeed than randomly moving around. This is especially true when the target is small, mobile, or blends with its background (Frost and U.S. Coast Guard 1996), which often applies to wildlife crimes. Although rangers do not patrol in a haphazard or aimless way, a more systematic approach could yield better results for detecting wildlife crimes.

Hypothesis 3: Systematic search patterns have a higher detection probability of wildlife crimes compared to the baseline detection probability.

\section{METHODS}

\section{Study area}

This research was conducted in the buffer zone of Olifants West Nature Reserve (OWNR) in the Limpopo Province, South Africa. The climate is semi-arid savannah with an average annual rainfall of $454 \mathrm{~mm}$ (Peel 2014). The size of the buffer zone is $4.15 \mathrm{~km}^{2}$ and divided into two smaller areas: $1.28 \mathrm{~km}^{2}$ in the North and $2.87 \mathrm{~km}^{2}$ in the South. The buffer zone is officially part of OWNR, but is separated from the main reserve by a public road. It is completely fenced and no large predators were known to be present during this research (with the possible exception of leopards). Rangers patrol the buffer zone regularly and are generally tasked with looking for poacher snares. This type of patrol is referred to as a 'snare sweep'. The rangers do not follow fixed routes but focus instead on landscape features and environmental signs they believe would lead them to illegal activities. Ranger teams reported their observations, including the fake snares, through the reserve's patrol monitoring system. Rangers are equipped with a GPSdevice that automatically records their positions at approximately 10-second intervals. The sweeps were done in the early morning to avoid the heat of the day and took approximately 2 hours.

\section{Experimental design}

A thorough study of snare detection probabilities for different patrol strategies requires a field experiment in which the true spatial distribution of snares is known. This was done by setting fake snares throughout the study area. The fake snares resemble real poacher snares, but were set without the 
usual trigger mechanism. Hence, no animals could be captured or injured by the fake snares. The time and location of every fake snare placement was recorded using a handheld GPS. Each fake snare was marked with a small piece of black tape so that it could be distinguished from actual poacher snares. This minimised the likelihood that reported locations of fake snares negatively influenced future patrol deployment decisions. All fake snares were set in the last week of March 2019. Any undetected fake snares still left in the field were collected at the end of October 2019. The research design was approved by the relevant authorities of Olifants West and by the Ethics Committee for Legal and Criminological Research of the Vrije Universiteit Amsterdam.

\section{Baseline detection}

The first phase focused on estimating the baseline detection probability of snares under normal law enforcement operations. To answer this question, 166 fake snare were randomly distributed throughout the study area. This translated to a density of 40 snares $/ \mathrm{km}^{2}$. While the fake snares are randomly distributed, they are still set in a realistic way, for example along game trails. The number of fake snares was an estimated approximation of the true poacher snare densities in the area, based on the experiences from law enforcement.

The rangers were not informed about this research to minimise the impact on operations. Only the operations manager of the reserve was informed about the research. The manager did not know the exact locations of all fake snare placements, but was informed on how a fake snare could be recognised. All snare sweeps and observations recorded between May $1^{\text {st }}$ and August $12^{\text {th }}$ were used to estimate the baseline detection rate. The buffer zone was not always accessible during this time period because of hunting activities by the local landowners. Snare sweeps were planned around the hunting schedule as much as possible, but still resulted in infrequent snare sweeps especially in May-July.

\section{Directed patrols}

The baseline detection probability of snares was compared to the detection probability of directed patrols. This part of the research resembled a scenario 
in which law enforcement received information from a local informant. The remaining fake snares in the field were used to identify locations with a density of at least ten fake snares per $0.25 \mathrm{~km}^{2}$. This prevented that only the hard-to-find snares would remain in the field. These locations were then passed on to the operations manager. The manager decided on which of those locations the rangers should carry out a snare sweep. On the day of the sweep, the manager informed the ranger team where they should start their patrol. A map was often used to inform the rangers of the specified area they should sweep. The rangers were again not informed about the research. This phase took six weeks, between August $13^{\text {th }}$ and September $24^{\text {th }} 2019$.

\section{Independent observers}

For this part of the research two independent observers were asked to join the rangers every time a snare sweep was conducted. The observers were volunteers from a local non-profit organisation. The observers had little or no experience with snare sweeps, and their role was simply to join the rangers as an extra set of eyes looking for poaching activities. The observers were told not to interfere with the rangers' decision-making, but were free to interact with the rangers and ask them questions. Various people including volunteers, researchers, and journalists have joined the rangers on their patrols in the past and their daily operations did not change. The ranger teams were again not informed about the research. This phase took place in October 2019 and lasted approximately four weeks.

\section{Systematic search patterns}

We also examined two different search patterns: a zigzag and a quadrant search pattern. The zigzag pattern involved the team walking transects, usually North-South. The quadrant pattern was inspired by a snare survey from Watson et al. (2013). The quadrant pattern consists of two square patterns; an outer $(350 \times 350 \mathrm{~m}$.) and inner quadrant (175×175 m.). The team swept from corner to corner of the inner and outer quadrant. The team stopped at every corner, where the members split up and searched for snares in the vicinity for five minutes. 
The teams responsible for walking the zigzag and quadrant pattern consisted of four people. Three people were tasked with searching for snares. They maintained a spread of $5 \mathrm{~m}$. on both sides for the purpose of security and to reduce the likelihood that a fake snare would be missed (Wato et al. 2006). The fourth person was in charge and made sure that the others maintained their positions as much as possible. Every detected fake snare during the searches was recorded using a handheld GPS. The search patterns sweeps took approximately 2.5 hours. The team consisted of both researchers and volunteers from the same local NGO instead of rangers. Although involving rangers would be more realistic, it would disrupt their normal operations. Therefore, volunteers were used as a proxy so that the enforcement operations could continue as normal. The volunteers were informed about the research design and trained on walking transects in the field. The systematic search patterns were carried out between July $5^{\text {th }}$ and August $18^{\text {th }} 2019$ and between September $23^{\text {rd }}$ and October 30 2019.

\section{ANALYSIS}

\section{Survival analysis}

The Kaplan-Meier estimator was used to describe the overall probability of fake snares to remain undetected over time (Kaplan and Meier 1958). The Kaplan-Meier survival curve was estimated by pooling all data together to visualise when fake snares were reported over time. The start time was set to $4^{\text {th }}$ of April 2019, the date when the last fake snares were deployed. The end time was the date of detection or when the fake snare was removed from the field at the end of the research project, whichever came first. The survival analyses were done using the 'survival' and 'survminer' packages (Kassambara, Kosinski, and Biecek 2019; Therneau 2015) in R 3.5.2 (R Core Team, 2018).

\section{Bootstrap sampling}

To estimate the number of fake snares that were actually 'at risk' of being detected by a patrolling team, a $10 \mathrm{~m}$. buffer around the GPS-routes of the snare sweeps was used. The size of the buffer was based on a combination of how far away a fake snare can be visually seen and the inaccuracy of GPS pings. All fake snares within the detection buffer were considered 
detectable. This approach was also used for the systematic search patterns. The GPS data of the snare sweeps were used to estimate the duration of the sweep, distance walked, and area covered. The GPS-data were analysed using the 'sf' package (Pebesma 2018) in R 3.5.2 (R Core Team, 2018).

The number of reported fake snare was compared to the number of fake snares available for detection (e.g. within the $10 \mathrm{~m}$. around the GPS track of the patrol). We used non-parametric bootstrapping to estimate the variance in detection probabilities, because the number of reported snares were low, which precludes maximum likelihood estimation techniques. The basic idea behind non-parametric bootstrapping is that new samples of equal size are repeatedly drawn with replacement from the original collected data. Each original observation has an equal probability of being drawn into the new sample. Next, detection probabilities were calculated using the newly drawn sample. By repeating these steps 10,000 times for the baseline sample and every patrol strategy, the average detection probability and a 95\% confidence interval was calculated. The bootstrap resampling was done with the base functions in R 3.5.2 (R Core Team, 2018) and visualised with the 'ggplot2' package (Wickham 2016). The Fisher's exact test (Fay 2010) was used to compare the detection probabilities of every strategy to the baseline detection probability.

\section{RESULTS}

In total, 69 snare sweeps were conducted of which six had no recorded GPS tracks. The reason behind unrecorded tracks was either equipment failure or rangers forgetting to record their tracks. The final dataset included 63 recorded snare sweeps (39 ranger sweeps and 24 systematic searches), covering about $263 \mathrm{~km}$ over 132 patrol hours (Table 4.1). 
Table 4.1. Patrol effort for different strategies

\begin{tabular}{|c|c|c|c|c|c|}
\hline Patrol strategy & $\begin{array}{c}\mathrm{N} \\
\text { recorded } \\
\text { sweeps }\end{array}$ & $\begin{array}{c}\text { Total } \\
\text { distance } \\
\text { walked }(\mathbf{k m})\end{array}$ & $\begin{array}{c}\text { Total } \\
\text { duration } \\
\text { (hours) }\end{array}$ & $\begin{array}{c}\text { Total } \\
\text { coverage } \\
\left(\mathrm{km}^{2}\right)\end{array}$ & $\begin{array}{c}\text { Study area } \\
\text { covered } \\
(\%)\end{array}$ \\
\hline Baseline detection & 20 & 101.7 & 34h $01 \mathrm{~min}$ & 0.92 & 22 \\
\hline Directed patrols & 12 & 58.2 & 24h $40 \mathrm{~min}$ & 0.80 & 19 \\
\hline $\begin{array}{l}\text { Independent } \\
\text { observers }\end{array}$ & 7 & 24.8 & 10h 33 min & 0.38 & 9 \\
\hline Zigzag pattern & 12 & 45.5 & 26h $45 \mathrm{~min}$ & 0.67 & 16 \\
\hline Quadrant pattern & 12 & 50.9 & 36h 30 min & 0.55 & 13 \\
\hline Total & 63 & 263.6 & 132h 29 min & 2.27 & 54 \\
\hline
\end{tabular}

\section{Survival analysis}

All 63 recorded snare sweeps and their observations were combined to assess how many fake snares remained undetected over time. A total of 39 (23\%) out of the 166 fake snares were reported. The probability of survival at the end of the project (after 200 days) was approximately 0.77 (Figure 4.3). The dashed lines represent when the recorded sweeps were carried out (Figure 4.3). The first fake snares were reported after 77 days (approximately 2.5 months). The median survival time could not be estimated because more than half of all fake snares remained undetected during the study period.

\section{Detection probabilities of patrol strategies}

The baseline detection was estimated to be 19\% (Table 4.2; Figure 4.4). Approximately $15 \%$ of fake snares within the $10 \mathrm{~m}$. buffer of the directed patrols were reported, while detection was $27 \%$ for patrols with independent observers (Table 4.2; Figure 4.4). Systematic search patterns showed the highest detection probabilities. The largest number of fake snares were reported for the systematic search patterns. The zigzag search pattern resulted in $45 \%$ detection, while $42 \%$ of fake snares were reported for the quadrant search pattern (Table 4.2; Figure 4.4). The detection probability of the zigzag pattern was statistically significantly higher than the baseline detection probability (Fisher's exact test, $P=0.04$ ). The detection probability of the zigzag and quadrant search pattern combined (e.g. a systematic approach) was also statistically significantly higher than the baseline detection probability (Fisher's exact test, $\mathrm{P}=0.03$ ). The detection probability 
of the other strategies were not statistically significantly different from the baseline detection probability. Hypothesis 1 and 2 are thus falsified.

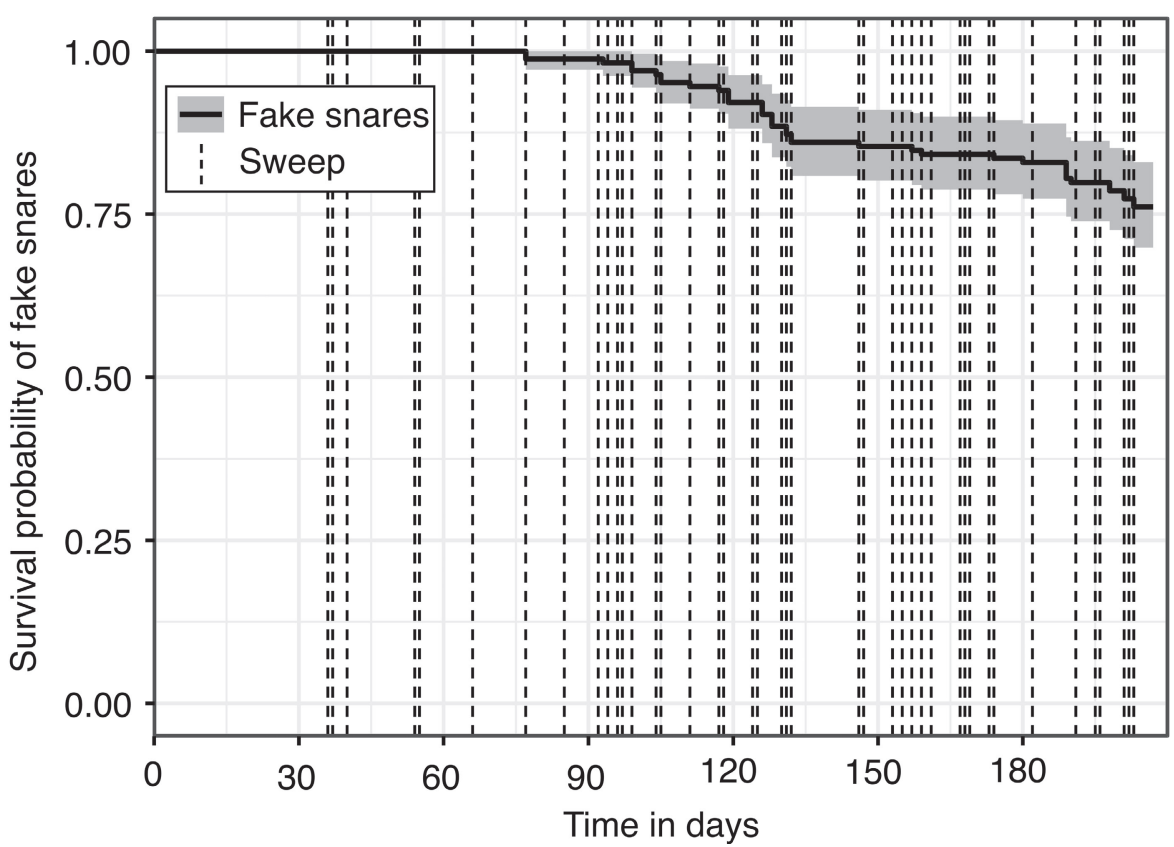

Figure 4.3. Kaplan-Meier survival curve of fake snares over time. The dashed lines show when snare sweeps were conducted.

Table 4.2. Number of detected fake snares and detection rates for the different snare sweep strategies

\begin{tabular}{|c|c|c|c|c|c|c|c|}
\hline Patrol strategy & $\begin{array}{c}\mathrm{N} \\
\text { recorded } \\
\text { sweeps }\end{array}$ & $\begin{array}{c}N \\
\text { fake } \\
\text { snares in } \\
\text { range }\end{array}$ & $\begin{array}{c}\mathbf{N} \\
\text { fake } \\
\text { snares } \\
\text { reported }\end{array}$ & $\begin{array}{c}\text { Estimated } \\
\text { detection } \\
\text { rate }\end{array}$ & $\begin{array}{r}\text { Boot } \\
95 \%\end{array}$ & $\begin{array}{l}\text { strap } \\
6 \mathrm{Cl}\end{array}$ & $\begin{array}{c}\text { Fisher's } \\
\text { exact } \\
\text { test* }^{\star}\end{array}$ \\
\hline Baseline detection & 20 & 26 & 5 & 0.19 & 0.08 & 0.31 & - \\
\hline Directed patrols & 12 & 27 & 4 & 0.15 & 0.04 & 0.26 & 0.79 \\
\hline $\begin{array}{l}\text { Independent } \\
\text { observers }\end{array}$ & 7 & 11 & 3 & 0.27 & 0.09 & 0.54 & 0.44 \\
\hline Zigzag pattern & 12 & 31 & 14 & 0.45 & 0.32 & 0.61 & 0.04 \\
\hline Quadrant pattern & 12 & 31 & 13 & 0.42 & 0.29 & 0.58 & 0.06 \\
\hline
\end{tabular}

${ }^{*}$ Tested against the baseline detection rate 


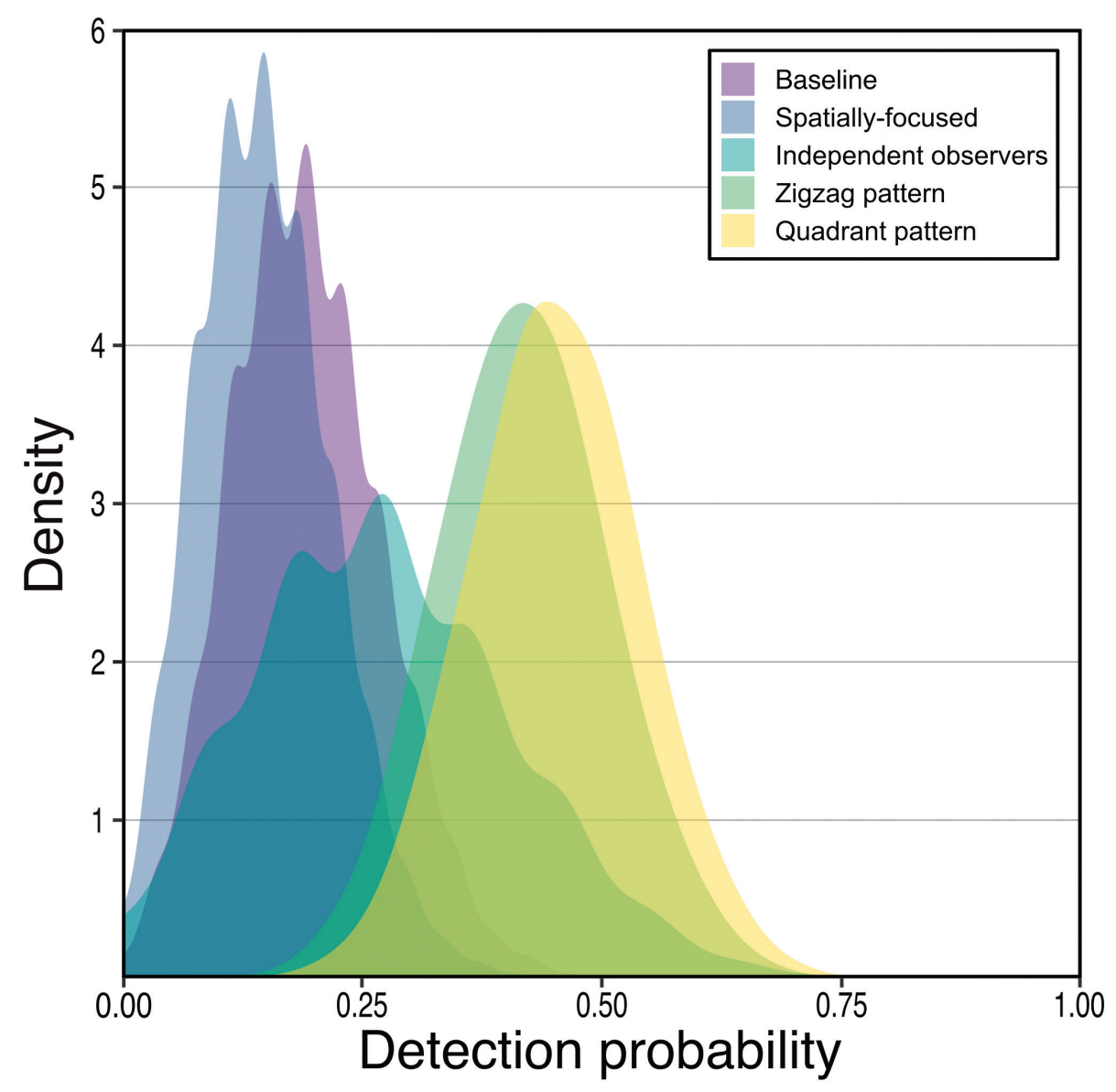

Figure 4.4. Density plot of detection probabilities by patrol strategies from 10.000 bootstrap resamples.

\section{DISCUSSION}

The detection of wildlife crimes is challenging and could potentially lead to a biased understanding of the true spatial distributions. This chapter outlined a methodology for estimating detection probabilities of wildlife crimes and evaluating different patrol strategies by using snares as a case study. Detection experiments like the one presented here are rarely conducted, but can provide evidence for what strategies might work for a particular problem. While not possible for every problem, this chapter has shown how it can be done for understanding the detection probabilities of snares. 
The experimental design included a baseline measure of detection probabilities before different strategies were implemented. The results showed that approximately $7 \%$ of the 166 fake snares were found by rangers at the end of the project. Most fake snares were never detected during the study period. From a conservation perspective this highlights the threat of actual poacher snares; even snares that were set several months ago can still be harmful to local wildlife (Hunter et al. 2007). Although detection probabilities were generally low, most snares were detected when systematic search strategies were used.

\section{Limitations}

The study area was small in size, but a relatively high densities of fake snares was used $\left(40\right.$ fakes $\left./ \mathrm{km}^{2}\right)$. Despite the relative high densities of fake snares, the detection probabilities were generally low. The estimated detection probabilities were based on the available fake snares within the $10 \mathrm{~m}$ buffer around patrol routes as opposed to all fake snares in the study area. By only considering those fake snares available for detection, the estimated detection rates were likely inflated.

The fake snares were set at the end of the wet season with still some relatively dense vegetated areas. From that moment until the last fake snares were retrieved in October, the study area received very little rain. Hence, the landscape gradually got drier and consequently vegetation cover gradually decreased. The estimated detection probabilities in this chapter are therefore more reflective for dry season conditions in similar semi-arid landscapes. It is expected that detection probabilities of snares during the wet season are even lower because of increased vegetation cover. The way in which the field experiment was designed does allow to empirically test how vegetation density influences the detection probability.

The rangers were not informed about this research to minimise our impact on their behaviour. However, the researchers received signs in October 2019 that the rangers were in fact aware about the project and the fake snares. It was suspected that the rangers first learned about the project at the beginning of August. The patrol effort around that time was examined and a small increase in hours and distance of sweep were observed. After 
approximately two weeks, patrol efforts decreased and were similar to ones observed in June and July 2019.

Another limitation was the people involved in the different sweeps. In this research, volunteers were used to walk the systematic patterns because involving rangers would disrupt their normal operations. It is implausible to expect that the volunteers were actually better at detecting snares than rangers. This chapter could not control for this factor, but a potential reason could be related to morale. Many of the volunteers specifically visited the reserve to gain bush experience and enjoyed walking outside. The rangers on the other hand have been carrying out patrols and sweeps for numerous years. While they are much more experienced than the volunteers, the novelty has worn off and may have resulted in lower morale. The differences in morale have contributed to the increased detection rate of the systematic search patterns.

\section{Interpretation of findings}

The detection probability of the systematic searches were approximately twice as high compared to the baseline estimate. This could not be attributed to differences in patrolling effort because the time spent patrolling and the area coverage was generally equal among the different patrol strategies. A potential explanation on why the systematic searches were outperforming may be related to how patrol effort was distributed across an area. By systematically combing an area, patrol effort is more concentrated, whereas the effort of the other patrol strategies is more diffused. The trade-off is that it takes more time to eventually cover the area of interest. A hybrid model in which systematic searches are combined with regular snare sweeps are potentially a balanced option in practice. A ranger team starts patrolling as they normally would, until the first snare or signs of illegal activity are found. The team can then switch to a systematic strategy to comb the area for more signs. This approach does assume that poachers tend to set their snares close together, rather than trying to distribute them evenly.

The context of the current research was searching for snares in a semiarid environment. While systematic searches were outperforming the other strategies, this does not necessarily imply that a zigzag search would be 
equally effective in a different environment or when searching for different objects. For example, a zigzag pattern might not be suitable when searching for people or animals. Similarly, the zigzag strategy might not work in a different environments. For example, O'Kelly et al. (2018) related the higher detectability of snares in evergreen forest to the difficult terrain and fewer existing trails. In those environments, a suitable approach could involve systematically sweeping along those trails. The exact systematics could be different depending on the context, but approaching snare sweeps in a more systematic way could be a practical alternative to standard snare sweeping.

Implementing a systematic approach may require additional resources in the beginning to make the right adjustments to the current law enforcement operations. If the decision is made that a particular strategy is going to be part of the operations, formal supervisors may have to join the rangers on their patrol to ensure that the strategy is properly implemented. The reported observations are still a sample of all wildlife crimes, however, and are still related to patrol effort. This should always be taken into account for estimating spatial-temporal patterns, monitoring trends, and deployment strategies.

\section{Future research}

This research is a first step to better understand the detection probabilities of poacher snares for different patrol strategies. The methodology outlined in this chapter can be repeated to other areas to obtain a baseline detection probability of snares and compare other patrol strategies. The first step is to start with the preparation phase. Here, the strategies that could potentially increase the detection probability are identified, as well as appropriate outcome measures. The hypotheses on those strategies can derived from relevant literature. Only after deciding on the outcome measures and strategies, should one start with designing the field experiment. Data on baseline detection probabilities are often not available, but are should be collected first to understand the starting point for the different strategies in relation to the outcome measures. Finally, the different strategies can be implemented and evaluated. 
A next step to further develop our understanding of detection probabilities would be by incorporating landscape features such as terrain and vegetation, which can be derived from satellite imagery. Analysing how these features influence the detection probability can also help in identifying what the best patrol strategy might be given a certain environment. In fact, landscape features may also be predictive of where rangers will patrol, or even where poachers go.

\section{Conclusion}

This chapter lays a foundation for understanding the detection probability of poacher snares, and presents a methodology that can be adjusted for other regions and other types of wildlife crimes. By using an experimental design with a known spatial distribution of fake snares, it was possible to estimate the baseline detection probability by ranger teams and to evaluate different patrol strategies. Although detection probabilities were generally low, most snares were detected when systematic search strategies were used. Future studies can build upon these findings by using a similar design to explore other factors such as seasonality and vegetation. 
Understanding detection probabilities of wildlife poaching 

Corruption and the shadow of the future: a generalization of an ABM with repeated interactions

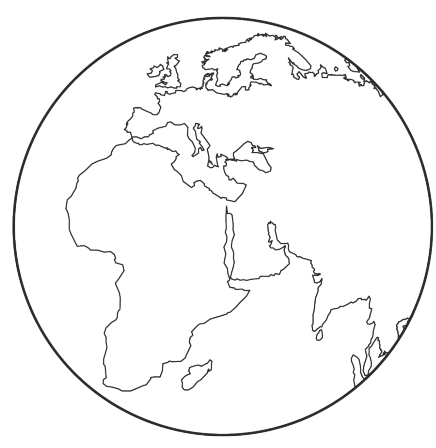




\section{ABSTRACT}

Corruption is a widespread, complex phenomenon with detrimental impacts on social and economic development around the world. To tackle the complexity of corruption and deterrence, agent-based models can be used to study corruption in an artificial society and explore conditions that lead to lower levels of corruption. This chapter expanded upon the work of Hammond (2000) to test the theory of general deterrence and the role of certainty of punishment on controlling corruption in an artificial environment. Our stylised fact, that certainty of punishment is a necessary component for the general deterrence of crime, was only replicated for oneshot interactions. Repeat interactions between agents reduces the certainty of punishment and corruption is therefore more likely to persist inside the artificial society. This led us to suggest that the certainty of punishment is indeed an important component of general deterrence theory. The general framework of the model can be easily expanded to explore different elements and conditions for the deterrence of corruption. ${ }^{5}$

5 This chapter was co-authored by S. Ruiter and A.M. Lemieux. A version of this chapter is accepted for publication as: van Doormaal, N., S. Ruiter, and A. M. Lemieux. 'Corruption and the Shadow of the Future: A Generalization of an ABM with Repeated Interactions'. In Agent-Based Modelling for Criminological Theory Testing and Theory Development, edited by C. Gerritsen and H. Elffers, Routledge. 


\section{INTRODUCTION}

Corruption is a widespread, complex phenomenon with detrimental impacts on social and economic development around the world (Banuri and Eckel 2012; Transparency International 2019; Warf 2016). High levels of corruption lead to unfair distributions of resources and income, while undermining democracy and the rule of law. Corruption manifests itself in a variety of ways including individual acts such as accepting bribes, and grand larceny on an organised, institutional scale (Transparency International 2019; Warf 2016). Ultimately, a better understanding of the effects and causes of corruption has the potential to inform corruption control and anti-corruption campaigns. Policies that seek to deter corruption can be directed at influencing individual behaviour and perception through penalties, public relations campaigns, or organisational structures and procedures. Such policies have the potential to increase the perceived costs for engaging in corrupt activities and deter potential offenders.

\section{Deterrence of corrupt behaviour}

Early modern deterrence theorists argued that people weigh costs and benefits in their decision-making process (Becker 1968). Assuming rational decision-making, individuals can be deterred from crime if the costs outweigh the benefits. This model of deterrence is known as the "economic model of rational deterrence" (Becker 1968). The theory does not differentiate between criminals and non-criminals, and states that every individual has their own cost-benefit assessment for committing crimes (Paternoster 2010).

Deterrence theory divides the costs of committing a crime into three components related to punishment: severity, certainty, and celerity (Nagin 2013). The severity of punishment needs to be strong enough to sufficiently reduce the benefits of a particular crime. Certainty applies to the likelihood of receiving punishment, whereas celerity applies to the timing of imposing punishment. Empirical studies on the deterrence of crime show mixed results regarding the severity and celerity of punishment. The certainty of punishment, however, is often found to have a play an important role in crime deterrence (Nagin 2013). 
Deterrence is general or specific. We refer to specific deterrence when an individual is deterred from committing future crimes through the experience of punishment. General deterrence refers to the idea that individuals respond to the threat of punishment; the punishment of those who commit crimes will also serve as an example to potential offenders among the general population.

Most forms of corruption are interactions between at least two individuals or groups. Choosing to behave corruptly will yield the highest rewards that the individual otherwise would not be able to get. Although the rewards of corruption are generally higher than for following the rules, the rewards could be counterbalanced by high costs. According to deterrence theory, the costs of corruption could be increased by increasing the perceived severity, certainty or celerity of punishment. Empirical studies commonly find the costs of crime can be increased by increasing the likelihood of punishment (Nagin 2013).

\section{Modelling corruption and deterrence}

The level of corruption in a society is the aggregate-level outcome of all individual decisions. The associated costs of corruption are perceived differently among individuals and it is the perception on the severity, certainty, and celerity of punishment that matters (Paternoster 2010). The conditions to deter someone from corruption can vary depending on the individual's perception of punishment. The reciprocal relationships among these three components and its effect on deterrence complicates our understanding of what leads to higher or lower levels of corruption. To tackle the complexity of corruption and deterrence, agent-based models can be used to assess these conditions.

Agent-based modelling is a simulation technique in which the behaviour and decision-making of autonomous individuals are modelled to identify relevant factors for the entire system (Epstein and Axtell 1996). It allows researchers to study complex systems and problems in an abstract environment, without them being influenced by specific characteristics of certain locations, and without the need of direct observations in the real world. Corruption is a widespread, complex phenomenon and difficult to observe directly in the 
real world. Therefore, agent-based modelling can be used to study the dynamics of corruption and its deterrence in an abstract environment.

Studies on corruption have used agent-based models or similar bottom-up approaches to explore the mechanisms, drivers (Farjam et al. 2015; Ye et al. 2011; Zausinová et al. 2019) and emergence of corruption (Kim, Zhong, and Chun 2013; Situngkir and Khanafiah 2006; Voinea 2013). Hammond (2000) modelled corruption as a game-theoretic interaction between two agent populations and showed the effects of general deterrence on corruption levels in an artificial society. His model showed that the effect of general deterrence or "fear of enforcement" can spread rapidly throughout the society and can lead to a transition from a high corrupt society to a low corrupt one. The simulation results showed that the transition from a corrupt society to an honest one can happen endogenously. Hammond's (2000) findings contradict existing political economy and economics literature which assumes these transitions are the result of an exogenous force like a new election, government policy, or economic shock (Di Vita 2007; Goel and Nelson 2005).

\section{Improving corruption research}

Hammond's model offered an alternative explanation for how general deterrence can cause transitions in a corrupt society. However, his model was based on a specific instance of corruption. The interactions between agents were modelled as one-shot, random encounters. Certain scenarios can indeed be regarded as a one-time random interaction, for example citizens declaring taxes or applying for a drivers' licence. However, not all interactions involving corruption can be represented with one-shot interactions. Some types of interactions involving corruption are improperly captured with one-shot interactions or even a disconnected series of one-time interactions among individuals. For example, a supplier and a purchasing agent often interact with each other multiple times and over an extended time, as do corrupt police officers that facilitate the work of local criminal groups. To better understand those forms of corruption, assuming repeated interactions between the same individuals would better reflect reality than one-shot interactions. 
A key element that is omitted in one-shot interactions is some form of reciprocity (Dal Bó and Fréchette 2011; Gossner and Tomala 2015). Corrupt individuals working together operate in a risky environment. Interaction is based on the expectation that cooperation will be beneficial to both sides (Dal Bó and Fréchette 2011; Gossner and Tomala 2015). If one individual does not hold up his or her end of the bargain, then it is likely that the other side will not cooperate in the future. Repeated interaction favours a solid base for mutual trust, and this will also have an impact on the certainty of apprehension. An individual's cooperation in social situations depends strongly on the degree to which others cooperate, which is why offenders are more likely to co-offend with family, long-time friends, and other confidants (Kleemans and de Poot 2008). In terms of deterrence theory, repeated interactions and mutual trust can reduce the certainty of punishment as long as both parties hold up his or her end of the bargain. Previous studies human decision-making in exchange relationships have noted that the possibility of there being future interactions can hold important consequences for understanding cooperation (Axelrod 1984; Balliet, Mulder, and Van Lange 2011).

\section{OBJECTIVE}

In this chapter we focus on the theory of general deterrence and the certainty of punishment. The work of Hammond (2000) showed the effect of general deterrence on the spread of corruption in an artificial society, but was based on a specific instance of corruption with one-shot interactions. Repeated interactions, on the other hand, likely reduces the certainty of punishment and hence should lead to higher levels of corruption. Our stylised fact is therefore that certainty of punishment is a necessary component for the general deterrence of crime. We extend the original model by Hammond (2000) to examine if and how repeated interactions change the ability of high corrupt societies to transition into low corrupt societies. We explore several scenarios in which we systematically vary the likelihood of punishment to better understand the conditions that lead to higher or lower levels of corruption. 
The following sections provide an overview of the modelling framework, and describe how we generalised Hammond's model to include repeated interactions between agents.

\section{MODEL FRAMEWORK}

\section{Payoff structures}

We first explain the model from a purely game-theoretic perspective. Every player can choose one of two strategies: "Corrupt" or "Honest". Their decision is based on the expected payoff of that strategy (Table 5.1). We assume that the corrupt action yields the highest payoff $(x)$, but only if both players choose "Corrupt". A game-theoretic analysis shows that choosing "Corrupt" results in a strict Nash equilibrium because no one has an incentive to change their decision; the outcome with both players choosing "Corrupt" is better than all other outcomes. If one or both players choose "Honest", then they both receive the lowest payoff $(y)$. Choosing "Honest" leads to a weak Nash equilibrium. Neither player can do better by choosing "Corrupt" if the other player chooses "Honest" because both options yield the low payoff $y$.

Table 5.1. The $2 \times 2$ corruption game payoff structure

\begin{tabular}{lccc} 
& & \multicolumn{2}{c}{ Player 2 } \\
\cline { 3 - 4 } & & Corrupt & Honest \\
\hline Player $\mathbf{1}$ & Corrupt & $\mathrm{x}, \mathrm{x}$ & $\mathrm{y}, \mathrm{y}$ \\
& Honest & $\mathrm{x}, \mathrm{x}$ & $\mathrm{y}, \mathrm{y}$ \\
\hline $\mathbf{x}>\mathbf{y}$ & & &
\end{tabular}

Note: ' $x$ ' and ' $y$ ' are the payoffs for choosing that particular strategy

\section{Agent-based modelling approach}

Although the decisions in the game are straightforward, it is still an oversimplification of decision making. No two persons in reality are the same, and each individual has a unique set of values that affects their perception. Furthermore, people's decisions are not only influenced by their own set of values, but also by the behaviour of others, especially friends and family. Therefore, individuals will perceive the payoffs for engaging 
in corruption differently and make different decisions. The game can be played by a heterogeneous population to better reflect reality, but would also be difficult to solve under the traditional game-theoretic framework. The behaviour of heterogeneous players in a dynamic environment is difficult to predict with game theory alone, but can be captured and quantified with agent-based models. Agent-based modelling allows for heterogeneous and autonomous agents capable of exhibiting human-like behaviours, for example, corrupt behaviours.

\section{AGENT CHARACTERISTICS AND BEHAVIOUR}

\section{Morality and perceived payoff}

Based on the offender motivation literature, we assume that agents possess some intrinsic core values on how to behave (McMurran and Ward 2004; Ryan and Deci 2000). We refer to this as an agent's 'morality' (Hammond (2000) labelled it as 'Honesty'). It influences how the agent perceives the payoffs for choosing "Corrupt". An agent that scores high on morality gains little from a corrupt interaction, while only an agent with the lowest morality score gains the full benefits. Increasing levels of morality thus decrease the perceived payoff of corruption. Morality takes a random value between 0 and 1 and is assigned to every agent before a simulation run starts. The assigned morality value is fixed throughout the simulation run. The perceived payoff for acting corrupt (xi) is calculated as: $x_{i}=(1-$ morality $) x$

\section{Networks}

Every agent has its own network of other agents (Hammond (2000) referred to the agents within a network as 'friends'). The size of an agent's network is fixed and set by the modeller at the start of the simulation. Every agent creates an undirected link with a number of other random agents until it reaches the specified network size. Agents can be part of multiple networks but will never exceed the specified network size. The size of the network is fixed and set by the modeller at the start of the simulation. We are uncertain if our network setup is the same as the one described by Hammond because little information was provided. Hammond (2000) described it as follows: "These networks are of fixed (standard) size, but the specific contents of each agent's network is randomly assigned during initialisation". 
The agent has access to certain information of other agents within its network. The agent can observe the most recent actions of the members within its network ("Honest" or "Corrupt"), and observe which members are suspended.

\section{Agent decision-making}

Each agent first calculates the perceived payoffs for acting corrupt $\left(x_{i}\right)$. Next, every agent estimates the probability of encountering a corrupt agent as follows:

The agent keeps track of the actions chosen by the agents it interacted with in previous rounds and will remember those actions for a certain period of time. This is referred to as the agent's "memory". The size of memory (i.e. the number of past interactions the agent can remember) is set by the modeller at the start of the simulation and is fixed throughout the simulation run. The agent examines its memory to count the number of corrupt partners it has encountered in previous interactions. The agent calculates the probability of encountering a corrupt agent as: $A=\frac{n}{N}$, in which $\boldsymbol{n}$ is the number of corrupt partners encountered in $\boldsymbol{N}$ previous interactions.

Every agent also estimates the probability of apprehension for acting corrupt in this round. The agent does this by examining the behaviour and status of other agents in its social network. Every agent can only observe the most recent action chosen by all network members, and observe which network members are suspended. The probability of apprehension is calculated based on the number of suspended network members and the number of corrupt network members in the last round. The probability of apprehension for a corrupt action in a round is calculated as: $B=\frac{m}{M^{\prime}}$ in which $\boldsymbol{m}$ is the number of suspended network members and $\boldsymbol{M}$ the number of corrupt network members in the previous round.

Finally, agents know the length of suspension $\boldsymbol{k}$. Suspended agents are removed from play for the duration of $k$. The decision rule for each agent to act corrupt is then: $(1-B)\left[A x_{i}+(1-A) y\right]+B[y-k y]>y$ 
The cost of being suspended is $\boldsymbol{k} \boldsymbol{y}$. The partner of the suspended agent will randomly choose another agent as its new partner. Suspended agents and agents that already have a partner cannot be chosen. It is possible that no agents will be available, because some are suspended and others already have a partner. If so, then the agent without partner will not interact and wait until agents become available again.

\section{Compare actions with partner}

Every agent randomly chooses a partner to interact with. Only agents who are not suspended and do not have a partner at that moment can be selected. If no other agent is available as a partner, then the agent will remain without a partner until other agents become available. Depending on the model settings, the interaction between the agent and its partner may only last one round (one-shot interaction) or multiple interactions over a longer period of time (repeated interactions). Each agent decides between the two actions ("Corrupt" and "Honest") immediately before each interaction by using the decision-rule outlined before.

Next, the agents compare their actions, which leads to one of three possible outcomes (Figure 5.1):

1. Honest interaction: both agents act honest and will receive the lowest payoff.

2. Mismatch: a corrupt agent meets an honest agent. Both agents will receive the lowest payoff and the honest agent will "report" the corrupt agent. If the number of reports reaches a certain threshold, then the corrupt agent will be temporarily suspended.

3. Collusive corruption: both agents act corrupt and will receive the highest payoff. 

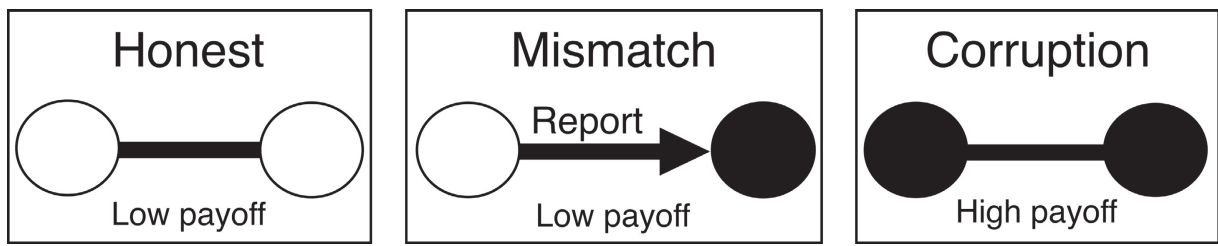

Figure 5.1. Diagram visualising the three potential outcomes of two agents interacting

\section{Enforcement}

Just as in Hammond's model, a punishment component will be triggered if a corrupt agent meets an honest agent. The model keeps track of how many reports every agent has received for acting corrupt throughout the simulation run. If an agent has been reported a certain number of times, then the reported agent will be suspended temporarily. Suspended agents cannot interact with other players and therefore cannot gain payoffs. The agent is allowed to interact with other agents again and able to gain payoffs after serving the suspension time. An agent's decision-making is unaltered after being suspended.

The agents in the model are aware that it is possible to get suspended for acting corrupt and do know the length of the suspension term. The length of suspension is set during the model initialisation and can be specified by the user. Agents take the length of suspension $\mathrm{k}$ into account when deciding between acting corrupt or honest. However, the agents themselves do not know how many reports they have received or how many reports are required to get suspended. The next section will describe the decisionmaking process of the agents in the model.

A model round can be summarised as follows:

1. Select agent: every round, an agent will be randomly paired with another agent.

2. Select strategy: each agent decides simultaneously to act corrupt or honestly. The decision rule is based on the agent's bounded rationality.

3. Receive payoff: Acting corrupt yields the highest payoff $(x)$, but only if the other agent also chooses the corrupt strategy. If both agents chose to act honest, they both receive the lowest payoff $(y)$. If only one of two 
agents acts corrupt, the honest agent reports the corrupt agent and both receive the lowest payoff $(y)$.

4. Suspend agents: If an agent is reported a predefined number of times, the agent will be suspended for a period of time. A suspended agent cannot interact with other agents or gain payoffs.

5. Release agents: After serving the suspension time, agents are allowed to interact with other agents again.

\section{From random one-shot to repeated interactions}

In Hammond's original model, an agent was randomly paired with another available agent. Hammond did not explore if the transition from a high to low corrupt state can be reached when the same pair of agents interact for consecutive rounds. Our model extension is aimed at changing the current one-shot interaction to repeated interactions between the same agents. The decision-making of agents and model processes described earlier still work in the same way. The only difference is that agents will interact with the same agent over multiple rounds. The number of interactions can be specified by the user and applies to all agents. The number of repeated interactions will never be longer than specified, but can end earlier if one of the agents gets suspended.

\section{Agent interactions and memory weights}

We expect that the length of memory will play an important role in scenarios with repeated interactions. The agent's memory in the original model reflect the different choices by the other players. The agent uses its memory to assess the likelihood of encountering a corrupt agent in the next round. However, when pairs of agents interact with each over multiple consecutive rounds, their memory will mostly consist of interactions with that particular agent. The agent's challenge is then to assess the likelihood that its current partner will choose the corrupt action in the next round, rather than assessing the likelihood of encountering a corrupt agent in the entire population. We incorporate this by assigning a weight to the most recent interaction of the agent's memory. The higher the weight, the larger the influence of the most recent interaction on the agent's estimation of encountering a corrupt agent. When the weight is 100\%, the agent will only include the most recent interaction in the decision-making for estimating 
the likelihood of encountering a corrupt agent and disregard all other, older memories. Our extension is built in such a way that when no additional weight is assigned to the most recent interaction, the model reflects the original model by Hammond.

\section{SCENARIO SIMULATIONS}

Scenarios with repeated interactions were compared with scenarios with Hammond's original one-shot model settings. We run scenarios with agents repeatedly interacting with each other for two to eight consecutive rounds. We run these scenarios in combination with situations in which no addition weight, $50 \%$ and $100 \%$ weight was assigned to the most recent interaction of the agent's memory (Table 5.2). All other parameters in the model were kept constant throughout all simulation runs (Table 5.3). Each simulation run lasts no longer than 2.000 time units (called ticks in the model). The model keeps track of the number of honest and corrupt agents throughout the simulation run. The outcome variable was the number of corrupt agents at the end of each simulation run. We also recorded when a transition from high corruption to low corruption took place. This was recorded as the moment when the number of honest agents exceeded the number of corrupt agents. Each combination of settings was run 150 times.

Table 5.2. Overview of the corruption model's defaults setting based on Hammond (2000)

\begin{tabular}{|c|c|c|}
\hline Parameter & Description & $\begin{array}{l}\text { Default } \\
\text { value }\end{array}$ \\
\hline Morality & $\begin{array}{l}\text { Agent variable to reflect an inherent propensity for } \\
\text { 'doing good'. Increasing levels of morality decrease the } \\
\text { perceived payoff of corruption. }\end{array}$ & $\begin{array}{l}\text { Randomly } \\
\text { distributed } \\
{[0,1]}\end{array}$ \\
\hline $\begin{array}{l}\text { Corruption } \\
\text { payoff }\end{array}$ & $\begin{array}{l}\text { Benefit an agent receives for a successful collusive } \\
\text { corrupt action. Corruption payoff is always the highest } \\
\text { payoff. }\end{array}$ & 20 \\
\hline Honest payoff & $\begin{array}{l}\text { Benefit that an agent receives for choosing honest } \\
\text { actions. Both players receive the honest payoff in a } \\
\text { mismatch. }\end{array}$ & 1 \\
\hline Reports & Number of reports required to get suspended. & 2 reports \\
\hline
\end{tabular}


Table 5.2. Continued.

\begin{tabular}{lll}
\hline Parameter & Description & $\begin{array}{l}\text { Default } \\
\text { value }\end{array}$ \\
\hline $\begin{array}{l}\text { Suspension } \\
\text { term }\end{array}$ & $\begin{array}{l}\text { Number of rounds an agent will be suspended from } \\
\text { interaction with other players. }\end{array}$ & 4 rounds \\
Memory & $\begin{array}{l}\text { Every agent remembers a certain number of actions } \\
\text { chosen by the other players it interacted with in previous } \\
\text { rounds. }\end{array}$ & 5 rounds \\
Network & $\begin{array}{l}\text { Represents the number of 'friends' that every agent has. } \\
\text { Agents are randomly assigned to a network. }\end{array}$ & 10 agents \\
& $\begin{array}{l}\text { Total number of agents in every simulation round. } \\
\text { Population }\end{array}$ & 300 agents \\
\hline
\end{tabular}

Table 5.3. Overview of the corruption model's defaults setting based on Hammond (2000)

\begin{tabular}{lll}
\hline $\begin{array}{l}\text { Parameter introduced to } \\
\text { the original model }\end{array}$ & Description & Values \\
\hline Interactions & $\begin{array}{l}\text { The number of times an agent consecutively } \\
\text { interacts with the same agent before being }\end{array}$ & $1-8$ \\
& matched with a different agent & \\
Weight & $\begin{array}{l}\text { Percentage of weight assigned to the most } \\
\text { recent interaction in agent's memory. The higher } \\
\end{array}$ & the weight the larger its influence on the agent's \\
& estimation of encountering a corrupt agent & \\
\hline
\end{tabular}

We used the software 'NetLogo' version 6.1.0 (Wilensky 1999), building upon an earlier implementation of Hammond's original model (Lonsdale 2017). Our model and code are published online at: http://modelingcommons.org/ browse/one_model/6210.

The Shapiro-Wilk test was used to test for normality. Further analyses were performed with the Kruskal-Wallis test. A post hoc comparison using Dunn's test with the Bonferroni adjustment was performed if the Kruskal-Wallis showed statistical differences between the groups. These conservative non-parametric methods were applied to reduce the possibility of a type I error. 


\section{RESULTS}

\section{One-shot vs. repeated interactions}

The effect of repeated interactions was compared with the one-shot interactions based on the original model. All other model parameters were kept constant throughout the simulation runs (Table 5.3). The number of corrupt agents at the end of a simulation was statistically significantly different between the different number of repeated interactions (KruskalWallis test; $\mathrm{H}=550.96$; d.f. $=7 ; \mathrm{P}<0.001$ ). The number of corrupt agents was the lowest for one-shot interactions, and the two and three repeated interactions (Figure 5.2). The scenario with three repeated interactions showed more variation in the number of corrupt agents but it was not statistically significantly different from single and double-shot interactions. The outliers in the one-shot and two-shot repeated interactions showed that the transition from high to low levels of corruption does not always happen; $11 \%(n=16)$ of the simulation runs with one-shot interactions and $13 \%(n=20)$ of the simulations with two repeated interactions did not result in a transition to low levels of corruption.

The scenarios with three and four repeated interactions showed more variation in the number of corrupt agents than the other scenarios (Figure 5.2). The majority of these runs still resulted in a transition from high to low levels of corruption as indicated by the low median of corrupt agents (45 and 58 corrupt agents for the three repeated and four repeated scenarios respectively). For the simulation runs with three repeated interactions, 26\% $(n=39)$ did not result in a transition to low levels of corruption. For four repeated interaction runs, this was $47 \%(n=71)$.

The number of corrupt agents at the end of every simulation run was higher when agents repeatedly interacted for five rounds or more compared to the other scenarios (Figure 5.2). In 78\% ( $n=117$ ) of the runs with five repeated interactions, the levels of corruption remained high and did not show a transition to low levels. Simulation runs with seven and eight repeated interactions showed the highest level of corrupt agents. A transition to low levels of corruption was observed on one occasion only for scenarios with seven- and eight repeated interactions. 


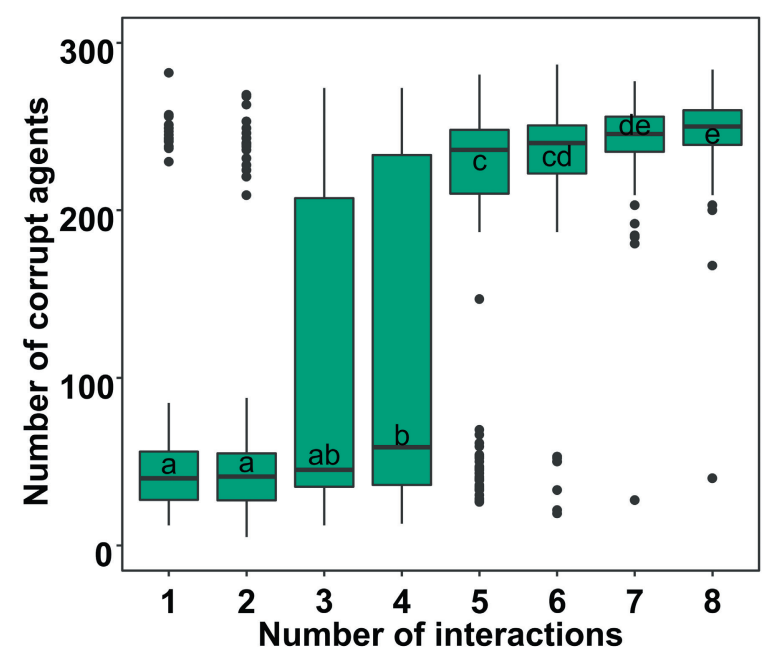

Figure 5.2. Simulation results for the effect of repeated interactions on the number of corrupt agents at the end of each simulation run. No weights to the agents' memory were assigned. For statistical comparisons, a Kruskal-Wallis test was conducted followed by a Dunn's post-hoc test. The plots bearing the same letters are not statistically significantly different at the $5 \%$ level

\section{Weight to memory}

Weights were assigned to the agents' most recent interaction to explore their effect on the transition from a high corrupt society to a low one. The higher the weight, the larger the influence of the most recent interaction on the agent's estimation of encountering a corrupt agent. The results for adding weights to the agent's memory resulted in statistically significant, but small differences in the number of corrupt agents at the end of each simulation run (Kruskal-Wallis test; $H=1088.5$; d.f. $=15 ; \mathrm{P}<0.001$ ). When the weight parameter was set to 50 , the results were similar to scenarios with zero weight; the number of corrupt agents was the lowest for the one-shot interactions (Figure 5.3). The three repeated interactions scenario showed more variation in the number of corrupt agents as well. The majority of those runs $(55 \%, n=83)$ showed a transition from high to low levels of corruption. The number of corrupt agents at the end of the simulation runs was highest for scenarios with five or more repeated interactions. Only one transition from a high level of corruption to a low level was observed for the six repeated interactions scenario, while no transition was observed for seven or eight repeated interaction scenarios. 
When the weight was set to $100 \%$, the agent will only include its most recent interaction in the decision-making for estimating the likelihood of encountering a corrupt agent and disregard all other, older memories. For these scenarios, the results look similar to the scenarios with no addition weights and 50\% weights; the number of corrupt agents at the end of the simulation runs was highest for scenarios with six or more repeated interactions (Figure 5.3). Scenarios with the weight value set to $100 \%$ showed that a high variability in the number of corrupt agents for the two repeated interactions. Just over half of all the simulation runs resulted in a transition from high to low corruption levels $(53 \%, n=79)$. Three times a transition from high levels of corruption to low levels occurred for the six repeated interactions scenario. No transition was observed for the seven or eight repeated interaction scenarios.

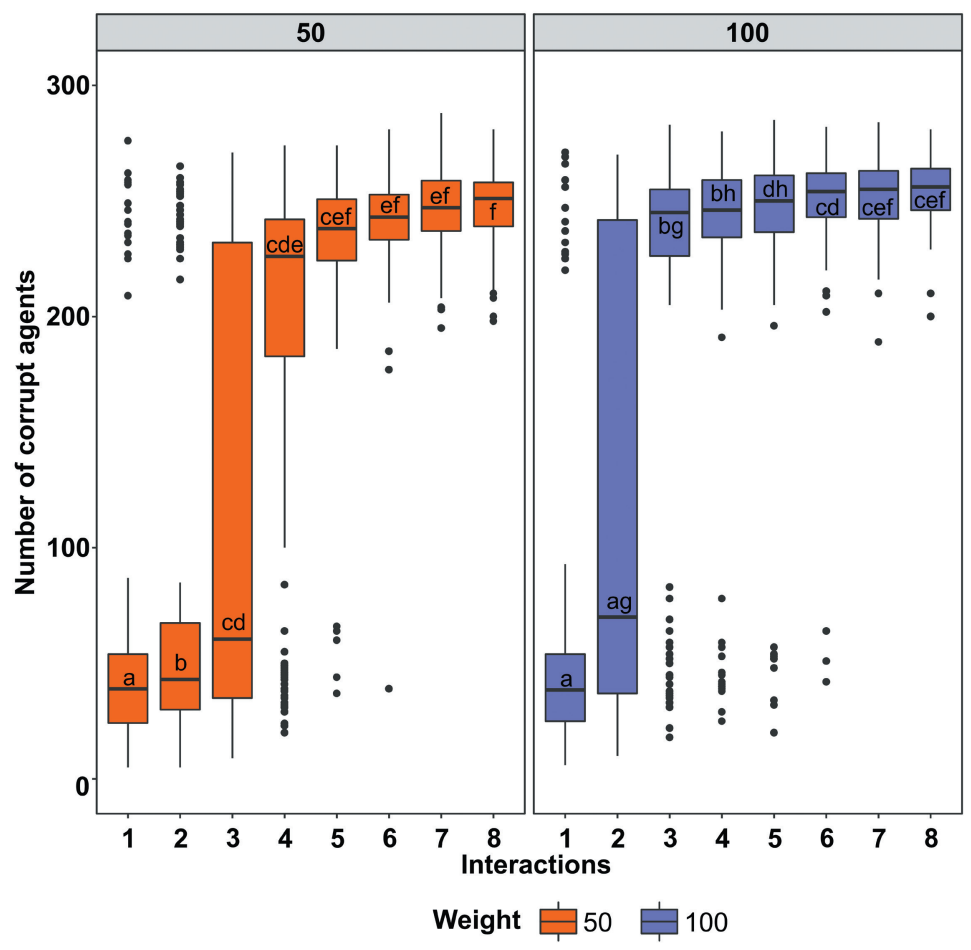

Figure 5.3. Simulation results for the effect of repeated interactions together with assigning weights to agent's memory on the number of corrupt agents at the end of each simulation run. For statistical comparisons, a Kruskal-Wallis test was conducted followed by a Dunn's post-hoc test. The plots bearing the same letters are not statistically different at the $5 \%$ level 


\section{Time until transition}

We also explored the time until transition for the different number of repeated interactions. When no weight was assigned to the agent's memory, transitions from high to low levels of corruption tend to happen earlier for scenarios with one-shot interactions, followed by scenarios with two, three and four repeated interactions (Figure 5.4). The median 'survival' time for a high corrupt state was 32 ticks for scenarios with one-shot interactions. For the repeated interactions, this was 71 ticks, 457 ticks, and 1459 ticks for the two, three and four repeated interactions respectively (Table 5.4). For the scenarios with five or more repeated interactions not enough transitions from high to low corruption were observed to estimate a median survival time.

In scenarios with weights assigned to the agent's memory, the scenarios with two and three repeated interactions were affected most (Figure 5.5A). The median 'survival' time for a high corrupt state in the two repeated interaction scenarios and a weight of $50 \%$ was 120 ticks. When the weight parameter was set to $100 \%$, the number of ticks increased to 762 (Table 5.4). For the three repeated interactions scenario, this was 1100 ticks for the $50 \%$-weights. When the weight parameter was set to $100 \%$, not enough transitions occurred to estimate the median 'survival' time (Figure 5.5B). The two weight values did not influence the one-shot interactions because both median survival times (respectively 33 and 22 ticks) were similar to one without the weight parameter (32 ticks).

Table 5.4. Summary of the median time until transition for the different scenarios

\begin{tabular}{lrrr}
\hline & \multicolumn{3}{c}{ Median survival time (ticks) } \\
\hline Number of interactions & No weight & $\mathbf{5 0}$ weight & $\mathbf{1 0 0}$ weight \\
1 & 32 & 33 & 22 \\
2 & 71 & 120 & 762 \\
3 & 457 & 1100 & - \\
4 & 1459 & - & - \\
$5-8$ & - & - & - \\
\hline
\end{tabular}

To get a better understanding of how our model behaves under different parameter settings, we ran scenarios with varying parameters for corrupt payoff, honest payoff, suspension term, and memory size. These results 
are summarised in Table 5.5. Our results for the corruption and honest payoffs, and suspension terms in the one-shot scenarios were in line with the findings form Hammond (2000).

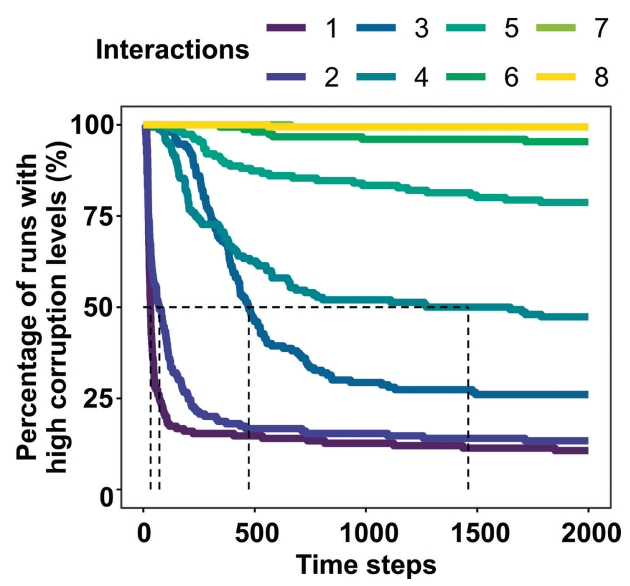

Figure 5.4. Survival curves for duration until transition from high levels to low levels of corruption for simulation runs with one and multiple repeated interactions. Each coloured line represents a different number of interactions. No weights were assigned to agent's memory. The dashed lines show the median survival time for that scenario Model sensitivity to parameter settings

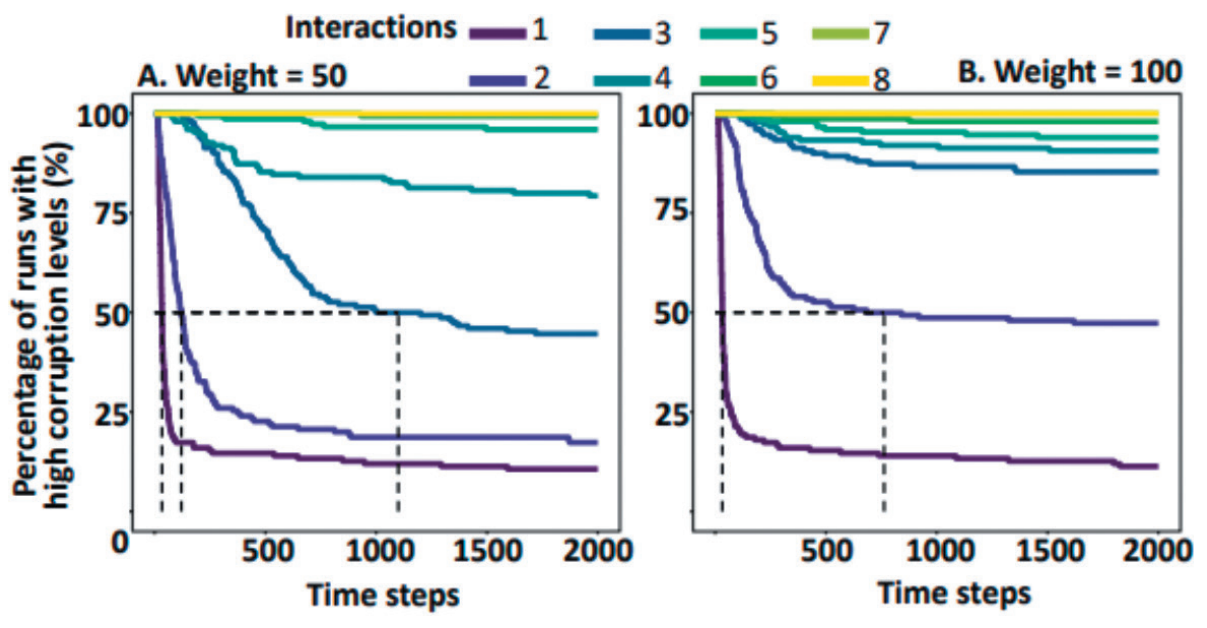

Figure 5.5. Survival curves for duration until transition from high levels to low levels of corruption for simulation runs with one and multiple repeated interactions. Each coloured line represents a different number of interactions. The left graph $(A)$ shows scenarios with the weight parameter set to $50 \%$, the right graph (B) has weight set to $100 \%$. The dashed lines show the median survival time for that scenario 
Table 5.5. Summary of the scenario runs with varying values of corruption payoff, honest payoff, and suspension term

\begin{tabular}{|c|c|c|}
\hline Parameter & One-shot interaction & Repeated interaction \\
\hline $\begin{array}{l}\text { Corruption } \\
\text { payoff }\end{array}$ & $\begin{array}{l}\text { Transition to low corruption } \\
\text { less likely with increasing } \\
\text { payoffs, but still occurs } \\
\text { regularly. The transitions } \\
\text { that do happen take longer }\end{array}$ & $\begin{array}{l}\text { Higher corruption payoffs decreases the } \\
\text { likelihood of a transition to low corruption } \\
\text { even further. From } 6 \text { or more repeated } \\
\text { interactions, also low payoffs do not show } \\
\text { a transition most of the time. }\end{array}$ \\
\hline Honest payoff & $\begin{array}{l}\text { Increased payoffs for honest } \\
\text { behaviour always resulted in } \\
\text { a transition to low corruption } \\
\text { and transitions happen } \\
\text { almost immediately. }\end{array}$ & $\begin{array}{l}\text { Increased payoffs for honest behaviour } \\
\text { always resulted in a transition to low } \\
\text { corruption, but transitions do take longer } \\
\text { to occur with increasing numbers of } \\
\text { repeated interactions. }\end{array}$ \\
\hline $\begin{array}{l}\text { Suspension } \\
\text { term }\end{array}$ & $\begin{array}{l}\text { For suspension term }=3 \text {, a } \\
\text { transition rarely occurred. } \\
\text { When this parameter was } \\
\text { set to } 4 \text { and } 5 \text {, a transition } \\
\text { occurred in most runs. }\end{array}$ & $\begin{array}{l}\text { For suspension term }=3 \text {, a transition never } \\
\text { occurred. When set to } 4 \text {, transitions only } \\
\text { occurred in scenarios with four or less } \\
\text { repeated interactions. Transitions often } \\
\text { occurred when suspension term was set } \\
\text { to } 5 \text { in all repeated interactions. }\end{array}$ \\
\hline Memory & $\begin{array}{l}\text { Transition to low corruption } \\
\text { were observed for the } \\
\text { majority of runs for both } \\
\text { small and large sizes of } \\
\text { memory. }\end{array}$ & $\begin{array}{l}\text { Dynamics for both small and large sizes } \\
\text { of memory start to shift from around 3-4 } \\
\text { repeated interactions. From } 5 \text { repeated } \\
\text { interactions onwards, a transition to low } \\
\text { levels of corruption was not observed for } \\
\text { the majority of runs of both small and large } \\
\text { sizes of memory }\end{array}$ \\
\hline
\end{tabular}

\section{DISCUSSION}

This chapter introduces an extension of an agent-based model for corruption originally developed by Hammond (2000). The original model represents a specific instance of corruption, that of one-shot interactions. By also studying repeated interactions between agents, we could evaluate our stylised fact. Our stylised fact was based on the empirical regularity that certainty is an important component for the general deterrence of crime. Our expanded model shows that high levels of corruption were more likely to persist in scenarios with repeated interactions compared to one-shot scenarios. Transitions from high to low levels of corruption rarely occurred in 
scenarios with increasing number of repeated interactions. The time it took for a transition to occur also increased with increasing number of repeated interactions. We were able to reproduce our stylised fact only for the oneshot interactions and therefore found support that certainty is indeed an important component of general deterrence.

While we were able to reproduce our stylised fact, we weren't able to exactly replicate Hammond's original findings. According to Hammond, all agents would eventually decide to behave honest, until all agents within the population are honest. Our results from the one-shot interactions are similar to those described by Hammond (2000), but none of our simulation runs eventually led to population with only honest agents. We found that some corrupt agents persisted even while the society was in a low-corrupt state. Furthermore, $11 \%$ of the simulations runs did not resulted in a transition. It is unclear what caused these differences in results, because the original code of Hammond's model was unfortunately not published or made available elsewhere. His model was described in great detail, but still information on certain elements were missing from his description. We took NetLogo implementations of Hammond's model published by others as our starting point and were forced to make our own assumptions, for example on the exact network configuration and reporting system.

\section{Deterrence and repeated interactions}

In our model, the number of corrupt agents remained high with repeated interactions and often a transition to low levels of corruption did not happen. We interpret this result as the certainty of punishment diminishing with increasing numbers of repeated interactions. When an agent has "learned" that its partner is willing to act corrupt, the most optimal decision is to act corrupt as well. Learning that your other partner is corrupt, removed the certainty of punishment. From that moment onwards, agents have no incentive to report their partner and no one will get suspended. The results of this is then signalled throughout the society via the social networks of the agents. Agents use their own network to get a subjective estimate of how likely it is to get caught for a corrupt act in the future. If no one inside the network is suspended, then a corrupt agent has no incentive to change its strategy. The agent feels certain to encounter another corrupt agent, 
and believes he will not get caught for acting corrupt. Similarly, honest agents are tempted to choose the "Corrupt" strategy because none of the corrupt agents inside the network are receiving punishment. Hence, repeated interactions reduces the certainty of punishment and with it the effect of general deterrence dissolves.

This chapter focused on the theory of general deterrence. The theory states that the interplay of severity, certainty, and celerity of punishment can deter crime. In our model, we only varied the certainty of punishment, while the severity and celerity were held constant. Deterrence theorists argue that at least certainty of punishment is important for the deterrence of crime (Nagin 2013; Paternoster 2010). Empirical studies show that the effect of severity and celerity on crime are still not well understood (Nagin 2013; Paternoster 2010). Therefore, we did not fully explore the interactive effects between severity and certainty. Our simulation runs does suggest that some level of severity may be required for certainty of punishment to be effective. A similar suggestion has been proposed by other researchers (Engel and Nagin 2015; Stafford et al. 1986). The results in this chapter suggest that at least certainty plays an important role in the deterrence of corruption. Our model can be used to explore these components further to detect if a particular severitythreshold is indeed needed to effectively deter corruption.

\section{One-shots to increase certainty}

Our results are in line with the current literature on behaviour in repeated interactions; cooperation becomes more likely if there is "a shadow of the future" (Axelrod 1984; Sabater and Sierra 2005). Cooperation, in our model, refers to two agents successfully colluding together in a corrupt act. In the example of corrupt officers working together with local criminal groups, the officers routinely work together with offenders for longer periods of time. By working together, they can get a higher payoff and reduce the certainty of getting caught. To increase the perceptions of certainty of punishment, one should aim to create a setting that mimics a one-shot scenario or fewer repeated interactions. These scenarios should represents situations in which individuals do not learn about the behaviour of their partner. An example to approach this is through the introduction of rotation schemes. Abbink (2004) showed that the number of bribery attempts, and their volume is cut 
by approximately half when an agent is paired with another random agent in every round. Staff rotation schemes have the potential to reduce levels of collusive corruption in organisational or institutional settings.

\section{Model assumptions and improvements}

The general approach in extending the model leads to two important assumptions related the enforcement and reporting system. The strength of this general model is that these scenarios can be easily incorporated in the current model.

In our model, the model has perfect information on all agents. Although the individual agents do not keep track of the number of reports they received, the model will automatically remove a corrupt agent from the game when that agent received a certain number of reports. This assumption is related to the certainty of apprehension in deterrence theory. Our results show that even when one has perfect information, high levels of corruption can still persist if agents repeatedly interact with one another. Only through mismatches in which an honest agent reports a corrupt agent will the system know who is corrupt. Our model can be extended further to compare with different enforcement systems. For example, a new enforcement system in which agents are randomly inspected for corrupt behaviour or by focussing only on agents who were apprehended in the past.

For simplicity, we assumed that an honest agent will always report a corrupt agent. An agent may decide not to report a corrupt agent under certain circumstances. For example, an honest agent might not blow the whistle if the reporting agent was involved in corrupt practices in the past. A possible extension would be to relate the likelihood of reporting a corrupt agent to an agent's morality, or to the number of corrupt acts in the past. These potential model extensions can provide more insights into how whistle-blowing could affect levels of corruption over time.

\section{CONCLUSION}

This chapter improved upon the work of Hammond (2000) to test the theory of general deterrence and the role of certainty of punishment on controlling 
corruption in an artificial environment. Our stylised fact, that certainty of punishment is a necessary component for the general deterrence of crime, was only replicated for one-shot interactions. Repeat interactions between agents reduces the certainty of punishment and corruption is therefore more likely to persist inside the artificial society. This led us to suggest that the certainty of punishment is indeed an important component of general deterrence theory. The general framework of the model can be easily expanded to explore different elements and conditions on deterring corruption. The model presented here should be regarded as a theoretical exploration to better understand the complexity of corruption and deterrence. 



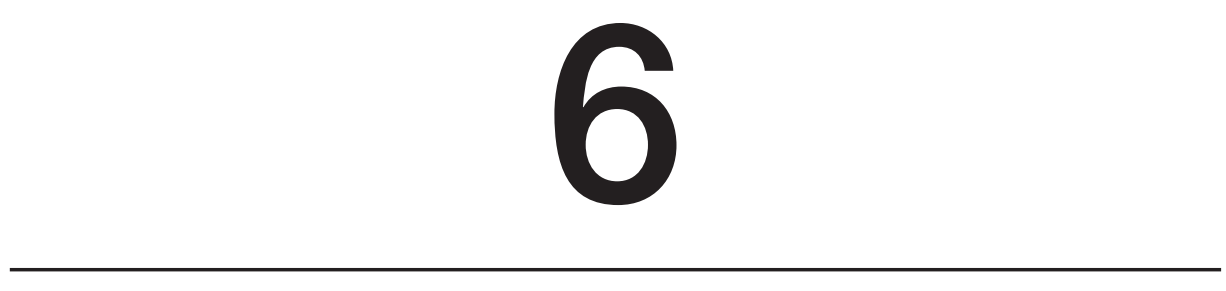

Nederlandse samenvatting

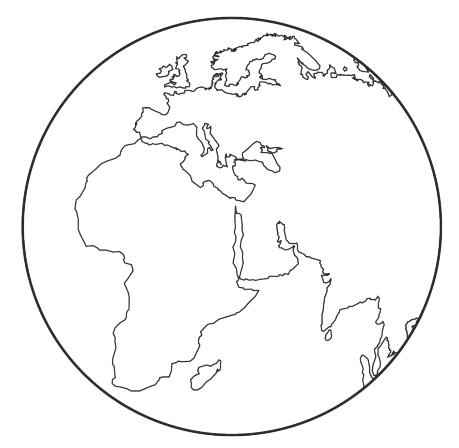




\section{INTRODUCTIE}

De illegale handel in flora en fauna is een van de grootste illegale markten in de wereld. Deze markt wordt veelal gevoed door stroperij, het illegaal bemachtigen van wilde dieren en planten uit de natuur. Met name beschermde gebieden zoals nationale parken en natuurreservaten worden getroffen door stroperij. Vanwege de grote gevolgen van stroperij voor flora, fauna, en ecosystemen krijgt deze vorm van criminaliteit groeiende aandacht van ecologen, natuurbeschermingsorganisaties, overheden, maar ook van criminologen. Stroperij is immers een strafbaar feit en kan dus ook vanuit een criminologisch oogpunt worden bestudeerd.

Om stroperij tegen te gaan, worden vaak rangers ingezet die door middel van patrouilles de natuurgebieden trachten te beschermen. Vanwege de omvang van deze gebieden, maar ook door een gebrek aan beschikbare middelen voor de rangers, dekken deze patrouilles echter vaak maar een klein gedeelte van de natuurgebieden. Om de beperkte middelen zo optimaal mogelijk te kunnen benutten, helpt het als rangers zo precies mogelijk weten waar de plekken binnen een natuurgebied zijn met de grootse kans op stroperij. Rangers kunnen deze plekken vervolgens beter beschermen wanneer ze begrijpen waarom juist deze plekken kwetsbaar zijn. Deze manier van criminaliteit bestrijden kent daarmee overeenkomsten met de wijze waarop de politie in steden te werk gaan. 'Hot spot policing' is het langdurig aanpakken van plekken, zoals een straatsegment of huizenblok,. Met een hoge criminaliteit intensiteit. Bij het bekijken van dit soort plekken, worden politiemeldingen en statistische informatie meestal gebruikt om hotspots te bepalen. In tegenstelling tot bij stedelijke criminaliteit, zijn er bij stroperij geen slachtoffer- of ooggetuigenverklaringen: dieren en planten melden zich niet bij de politie. Dit 'probleem van het stille slachtoffer' kan leiden tot een potentieel grote hoeveelheid ongeregistreerde criminaliteit en geeft mogelijk een vertekend beeld van waar en wanneer illegale activiteiten plaatsvinden.

In het afgelopen decennium, hebben criminologen zich ook ingezet om stroperij beter te begrijpen. Tot zover hebben zij dit voornamelijk gedaan met kwalitatieve en verkennende studies. Er is echter nog weinig aandacht 
geweest voor vragen die gericht zijn op het beter leren begrijpen van het gedrag van stropers en rangers. De antwoorden op deze vragen kunnen bijdragen om stroperij te begrijpen inclusief de stappen voor en nadat stroperij heeft plaatsgevonden.

\section{Onderzoeksdoel}

In dit proefschrift staat de volgende vraag centraal: 'Wat voor invloed hebben de keuzes van stropers en rangers op de bescherming van natuurgebieden?' We bekijken deze vraag vanuit een criminologisch oogpunt. Daarnaast heeft dit proefschrift ook als doel om methodes en technieken te ontwikkelen om de huidige strategieën voor rangers beter te begrijpen, waarmee teven een bijdrage wordt geleverd aan het verbeteren ervan. In dit proefschrift maken we gebruik van surveillancedata, agent-based modeling (ABM) technieken en een veldexperiment. Ook combineren we inzichten uit de ecologie en kunstmatige intelligentie samen met die uit de criminologie om drie verschillende problemen nader te bestuderen: neushoornstroperij, het opsporen van valstrikken, en corruptie onder rangers.

\section{BEVINDINGEN}

In hoofdstuk 2 van dit proefschrift zijn de ruimtelijke keuzes van neushoornstropers onderzocht. We bestudeerden de plekken waar de stropers een beschermd en afgegrendeld natuurreservaat zijn binnengedrongen om beter te begrijpen waarom de stroper juist deze plek heeft gekozen. Er is nog weinig aandacht geweest voor vragen die gericht zijn op het beter leren begrijpen van het keuzegedrag van stropers. De antwoorden op deze vragen kunnen bijdragen om stroperij te begrijpen, inclusief hoe stropers te werk gaan en hoe hun gedrag wordt beïnvloed door hun omgeving. De hypotheses van dit hoofdstuk zijn gebaseerd op het rationele-keuze perspectief; stropers zullen de meest efficiënte manier en middelen kiezen om hun doel te verwezenlijken. In dit hoofdstuk maken we gebruik van surveillancedata. Met deze data konden we achterhalen of de stroper de plek gebruikte om het natuurreservaat binnen te dringen of te ontsnappen. Dit soort data is bijzonder omdat het meestal moeilijk is om te verzamelen en wordt daarom maar zelden gebruikt in criminologische studies. In dit hoofdstuk was het echter mogelijk, door middel van de 
surveillancedata, om de inbraak- en ontsnappingsplekken van stropers te bestuderen en met elkaar te vergelijken.

De resultaten lieten zien dat de helft van alle gerapporteerde inbraken in het natuurreservaat op vrijwel dezelfde plek hebben plaatsgevonden. Deze plek is nader onderzocht en het blijkt dat hier een onafgeschermde brug over een grote rivier te vinden is. De stropers maakten waarschijnlijk gebruik van deze brug om zo gemakkelijk de rivier over te steken. Daarnaast zien we ook dat zowel de inbraak- als ontsnappingsplek dichtbij locaties zijn waar regelmatig veel neushoorns te vinden zijn. Dit suggereert dat de stropers al weten waar ze neushoorns kunnen vinden vóórdat ze bij het reservaat inbreken. Tevens suggereert het dat de stropers zo kort mogelijk in het reservaat verblijven. Ten slotte lieten de resultaten ook zien dat stropers plekken kiezen die gemakkelijk toegankelijk zijn wanneer ze het reservaat proberen binnen te dringen. Een soortgelijk verband was niet gevonden voor de ontsnappingsplekken van de stropers.

In hoofdstuk 3 van dit proefschrift gebruikten we agent-based mode/s (ABM) om de interacties tussen stropers en rangers beter te begrijpen. Het gedrag van stropers en rangers kan worden gezien als een soort kat-enmuisspel waarin beide partijen op het gedrag van de ander reageren. Zo heeft een stroper heeft meer kans op succes als hij goed kan voorspellen waar en wanneer de rangers gaan patrouilleren. Andersom kunnen de rangers een natuurgebied beter beschermen wanneer zij in staat zijn om nauwkeurig te voorspellen waar de stropers zullen toeslaan. Beide partijen leren van hun ervaringen waardoor ze gaandeweg beter worden in het maken van voorspellingen. Zo passen ze hun gedrag of strategie steeds aan in de hoop om de ander te slim af te zijn. Om de complexiteit van de stropers en rangers beter te begrijpen, hebben we een computermodel ontwikkeld waarin we het gedrag van stropers en rangers simuleren. Het computermodel is een abstracte weerspiegeling van een natuurreservaat in Zuid-Afrika met een populatie neushoorns, een groep stropers, en een aantal rangerteams. In het model worden twee verschillende patrouillestrategieën gesimuleerd: verkenningspatrouilles en grenspatrouilles. Deze strategieën worden door middel van de simulaties met elkaar vergeleken om er achter te komen welke van de twee het effectiefst is in het bestrijden van stroperij. 
De computersimulaties laten zien dat stroperij beter kan worden tegengegaan wanneer er meer rangerteams worden ingezet. De simulaties laten echter ook zien dat de patrouillestrategie van de rangers net zo belangrijk is om stroperij tegen te gaan als de hoeveelheid rangerteams. Rangers konden het virtuele reservaat beter beschermen met grenspatrouilles dan met verkenningspatrouilles. Sterker nog, de grenspatrouilles waren twee keer zo effectief als verkenningspatrouilles. Door het gebruikt van dit ABM waren we in staat om de complexe interacties tussen stropers en rangers te bestuderen, en deze kunnen bijdragen aan de ontwikkeling van hypotheses voor vervolgonderzoek in de werkelijke wereld.

In hoofdstuk 4 richten we ons op het beter begrijpen van verschillende zoekstrategieën van rangers om valstrikken op te sporen. De valstrikken worden door de stropers gezet om wilde dieren te vangen, zoals antilopes en wilde zwijnen, en deze te slachten voor het vlees. Rangers vaak speciaal getraind in het opsporen van valstrikken, maar het blijt zeer moeilijk om deze te vinden. Eerder onderzoek naar stropers en valstrikken erkennen dit probleem, maar er zijn nog maar weinig studies die het probleem hebben gekwantificeerd. In dit hoofdstuk introduceren we een methode om de detectiekans van valstrikken in kaart te brengen door middel van een veldexperiment. In het experiment hebben we nep-valstrikken uitgezet in een natuurreservaat in Zuid-Afrika en gemarkeerd met een GPS. Deze data wordt gecombineerd met de GPS-data van de rangpatrouilles en zo kunnen we precies achterhalen welke valstrikken worden gevonden en welke over het hoofd worden gezien. Deze methode is toepast op een aantal verschillende zoekstrategieën om zo de detectiekans in kaart te brengen en met elkaar te vergelijken. De onderzochte strategieën zijn doelgerichte patrouilles, patrouilles met vrijwilligers die mee gaan als onafhankelijke observanten, en systematisch zoektechnieken.

Uit het experiment bleek dat de systematisch zoektechniek het meest succesvol was in het vinden van valstrikken. Zelfs met deze techniek was echter de kans dat een valstrik gevonden wordt erg klein en de meeste nep-valstrikken werden helemaal niet gevonden gedurende het experiment. Dit suggereert ook dat het inzetten van rangerteams misschien niet de meest effectieve manier is om het zetten van valstrikken tegen te gaan. De 
manier waarop wij de verschillende rangerstrategieën hebben bestudeerd kan echter wel gemakkelijk worden toegepast in andere natuurreservaten, en om de detectiekans van andere vormen van stroperij te bestuderen.

In hoofdstuk 5 bestudeerden we de rol van corruptie onder rangers en de invloed hiervan op de beveiliging van beschermde natuurgebieden. De eerdere hoofdstukken van dit proefschrift zijn met name gericht op het begrijpen van rangerstrategieën. Hierbij zijn we er vanuit gegaan dat de rangers zich niet corrupt gedragen, maar helaas is corruptie onder rangers een vrij veelvoorkomend probleem. Het is echter niet gemakkelijk om corruptie direct te observeren, maar agent-based models (ABM) kunnen worden gebruikt als een alternatief. In de meeste computermodellen worden de interacties tussen twee individuen vaak geprogrammeerd als een éénmalige en willekeurige gebeurtenis. In het geval van rangers is dit echter niet realistischer omdat met meerderen in teams werken en over een langere periode. Het is daarom realistischer om deze interacties te programmeren als herhaalde interacties in plaats van éénmalige en willekeurige interacties. In dit hoofdstuk maken we gebruik van een al eerder ontwikkeld computermodel over corruptie dat een virtuele samenleving simuleert waarin individuen continue een rationele afweging maken tussen corrupt en eerlijk gedrag. Dit doen ze door de kosten en baten tegen elkaar af te wegen, en deze worden ook beïnvloed door hun omgeving. Dit model werd verder uitgebreid zodat het ook herhaalde interacties tussen dezelfde individuen bevat, naast de eenmalige interacties. Het doel van dit model was om te bestuderen wat de invloed is van éénmalige en herhaalde interacties tussen de individuen op het algehele corruptie-niveau in de virtuele samenleving.

De resultaten van het computermodel lieten zien dat herhaaldelijke interacties tussen dezelfde individuen meestal leidt tot een corrupte samenleving, ook al gedroegen de meeste individuen zich eerlijk aan het begin van de simulatie. Dit verklaren we als volgt: wanneer er twee individuen herhaaldelijk met elkaar omgaan, wordt ook de kans om gepakt te worden voor corrupt gedrag vermindert. Zodra een individu in het model heeft 'geleerd' dat zijn partner bereid is om zich corrupt te gedragen, dan is de meeste optimale keuze om ook voor corrupt gedrag te gaan. Met andere woorden, er achter komen dat je partner corrupt is heeft als gevolg dat je ook niet gepakt kan worden 
voor corrupt gedrag. De resultaten laten ook zien dat éénmalige interacties tussen individuen meestal wel leidt tot een eerlijke samenleving met weinig corruptie. Om de corruptie in de werkelijke wereld tegen te gaan, zouden we dus een situatie kunnen creëren die de éénmalige interacties nabootst, bijvoorbeeld door middel van het invoeren van rotatieschema's. Ook al zijn de resultaten van dit hoofdstuk gebaseerd om een simpel computermodel, ze kunnen alsnog bijdragen aan het begrijpen en tegengaan van corruptie onder rangers.

\section{WETENSCHAPPELIJKE IMPLICATIES}

Eerdere studies naar stroperij hebben met name onderzocht wat de correlaties zijn tussen landschapskenmerken en de locaties van gestroopte dieren in beschermde natuurgebieden. Het gedrag en keuzes van stropers in de aanloop naar het daadwerkelijk stropen van dieren heeft nog maar weinig aandacht gekregen. In dit proefschrift richten we ons daarom op de context waarin stropers en rangers keuzes maken en gebruiken daarvoor het rationele-keuze perspectief. Door dit perspectief te gebruiken, verschuift de focus van het bestuderen van enkel de locaties van gestroopte dieren naar het bestuderen van het gehele criminele proces inclusief alle handelingen en keuzes van stropers. We waren in staat om te achterhalen waarom de stropers bepaalde keuzes maakten tijdens het binnendringen in en ontsnappen uit een afgegrendeld natuurreservaat. Tot op heden zijn er nog maar weinig criminologische studies die in staat waren om inbraakpogingen en ontsnappingspogingen met elkaar te vergelijken. Het is meestal moeilijk is om dit soort data te verzamelen en wordt daarom maar zelden gebruikt in criminologische studies. Daarnaast hebben maar weinig studies zich gericht op het bestuderen en beter begrijpen van de interacties tussen stropers en rangers. Dit soort informatie helpt bij het ontwikkelen en evalueren van nieuwe rangerstrategieën omdat we dan beter kunnen voorspellen hoe stropers op de nieuwe strategie vermoedelijk zullen reageren. Idealiter zouden alle nieuwe strategieën moeten worden geëvalueerd met veldexperimenten om nauwkeurig te beschrijven wat wel en niet werkt voor een bepaald probleem en het identificeren van de onderliggende mechanismes en de achterliggende factoren. Helaas worden dit soort experimenten nog maar weinig opgezet en uitgevoerd 
binnen de criminologie vanwege de ethische en logistieke moeilijkheden die hiermee gepaard gaan. Dit proefschrift laat echter zien dat het mogelijk is voor het begrijpen van stroperij en legt het grondwerk voor het bestuderen van rangerstrategieën door middel van methodes die ook kunnen worden toegepast in andere natuurgebieden en voor andere vormen van stroperij.

\section{AANBEVELINGEN VOOR PRAKTIJK EN VERVOLGONDERZOEK}

Op basis van de resultaten van dit proefschrift zijn er een aantal aanbevelingen voor de praktijk, maar ook voor vervolgonderzoek. Het gedrag van stropers kan strategisch worden beïnvloed met behulp van specifieke omgevingskenmerken om zo het stropen meer risicovol te maken of door ervoor te zorgen dat stroperij minder oplevert. Er zijn echter nog veel vragen onbeantwoord omtrent het gedrag van stropers. Een systematische literatuuronderzoek naar het gedrag van stropers kan helpen om met te begrijpen welke aspecten van stroperij en het gedrag van stropers nog onderbelicht zijn. Daarnaast zijn er ook veel rangerstrategieën en interventies zodanig opgezet dat ze moeilijk of niet goed te evalueren zijn. Een goed doordachte evaluatie hoort ook de relevante mechanismes, bemiddelaars, implementatie, en kosten te bestuderen in plaats van alleen de effectiviteit van de interventie te beoordelen. Het opzetten van zulke evaluaties is geen gemakkelijke taak, maar recentelijk zijn er verschillende hulpmiddelen en richtlijnen ontwikkeld die hierbij kunnen helpen. Naast het beter begrijpen van stroperij, kunnen vervolgonderzoeken en evaluaties ook gericht worden op de rol van corruptie. In hoofdstuk 5 van dit proefschrift gaven we als aanbeveling om rotatieschema's te introduceren als een potentiële manier om corruptie onder rangers tegen te gaan. Onafhankelijke observanten zouden wellicht hetzelfde effect teweeg kunnen brengen, maar deze twee manieren zijn nog niet onderzocht in de context van corruptie onder rangers. Het is belangrijk om dit eerst goed te bestuderen zodat we eventuele onbedoelde en negatieve gevolgen kunnen voorkomen.

De bevindingen van dit proefschrift geeft een kritische reflectie over het gebruik en nut van rangerpatrouilles. Rangers en de patrouilles zijn belangrijk voor het opsporen van stroperij, maar het blijft kwestieus hoe effectief deze 
zijn in het tegengaan van stroperij en het beïnvloeden van het gedrag van stropers. Als uit verdere onderzoeken blijkt dat rangerpatrouilles maar een beperkte invloed hebben op het tegengaan van een specifiek stroperijprobleem, dan is het nodig om kritische te kijken naar een andere manier van aanpakken. Hierbij kunnen goed doordachte en wetenschappelijke evaluaties helpen om precies te achterhalen wat voor invloed de rangerpatrouilles hebben op het gedrag van stropers.

\section{CONCLUSIE}

Het bestuderen van stroperij is geen gemakkelijke taak, maar door inzichten en onderzoeksmethoden te combineren vanuit verschillende disciplines als de criminologie, natuurbehoud, en kunstmatige intelligentie waren we in staat dit onderzoek uit te voeren. In dit proefschrift stond de volgende onderzoeksvraag centraal: 'wat voor invloed hebben de keuzes van stropers en rangers op de bescherming van natuurgebieden?' We gebruikten het rationele-keuze perspectief om de keuzes en het gedrag van stropers en rangers beter te begrijpen. Dit perspectief was voorheen met name gebruikt voor stedelijke criminaliteit, maar dit proefschrift laat zien dat het ook toepasbaar is voor het begrijpen van verschillende vormen van stroperij in beschermde natuurgebieden. Met de beschikbare data konden we achterhalen waarom de stropers bepaalde keuzes maakten tijdens het binnendringen in en ontsnappen uit een afgegrendeld natuurreservaat. Dit soort informatie is belangrijk voor het ontwikkelen van rangerstrategieën om stroperij tegen te gaan. Dit proefschrift laat ook zien dat de wijze waarop de beperkte middelen van rangers strategisch worden ingezet, net zo belangrijk is voor de bescherming van de natuurgebieden als de hoeveelheid beschikbare middelen. We hebben verschillende onderzoeksmethoden ontwikkeld die kunnen helpen om rangerstrategieën beter te leren begrijpen, te ontwerpen, en te evalueren. Deze methoden kunnen ook breder worden toegepast in andere natuurgebieden en voor andere vormen van stroperij. 



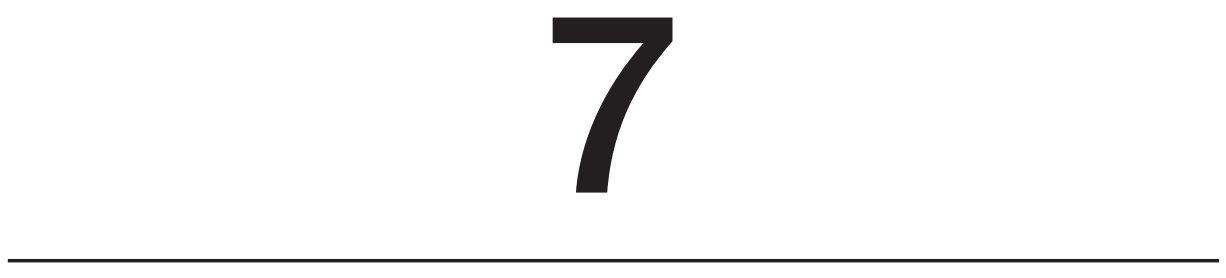

References

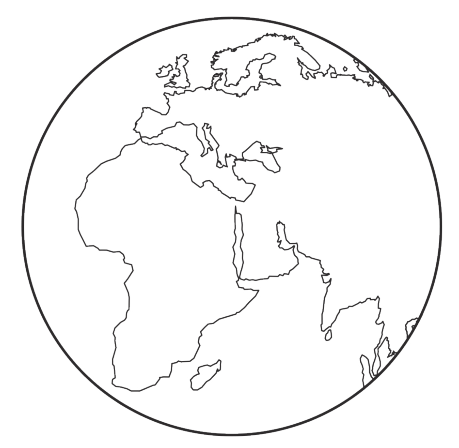


Abbink, Klaus. 2004. 'Staff Rotation as an Anti-Corruption Policy: An Experimental Study'. European Journal of Political Economy 20(4):887-906.

Allison, Paul D. 2008. 'Convergence Failures in Logistic Regression'. in SAS Global Forum. Vol. 360.

Altman, Naomi, and Martin Krzywinski. 2016. 'Points of Significance: Analyzing Outliers: Influential or Nuisance?' Nature Methods 13(4):281-82.

Axelrod, R. 1984. The Evolution of Cooperation. New York: Basic Books.

Ayling, Julie. 2013. 'What Sustains Wildlife Crime? Rhino Horn Trading and the Resilience of Criminal Networks'. Journal of International Wildlife Law and Policy 16(1):57-80.

Balliet, Daniel, Laetitia B. Mulder, and Paul A. M. Van Lange. 2011. 'Reward, Punishment, and Cooperation: A Meta-Analysis'. Psychological Bulletin 137(4):594-615.

Banks, Debbie, Charlotte Davies, Justin Gosling, Julian Newman, Mary Rice, Jago Wadley, and Fionnuala Walravens. 2008. Environmental Crime: A Threat to Our Future. London: Environmental Investigation Agency.

Banuri, Sheheryar, and Catherine Eckel. 2012. 'Experiments in Culture and Corruption: A Review". Pp. 51-76 in New Advances in Experimental Research on Corruption, edited by D. Serra and L. Wantchekon. Emerald Group Publishing Limited.

Baylis, Kathy, Jordi Honey-Rosés, Jan Börner, Esteve Corbera, Driss Ezzine-de-Blas, Paul J. Ferraro, Renaud Lapeyre, U. Martin Persson, Alex Pfaff, and Sven Wunder. 2016. 'Mainstreaming Impact Evaluation in Nature Conservation'. Conservation Letters 9(1):58-64.

Becker, Gary S. 1968. 'Crime and Punishment: An Economic Approach'. Journal of Political Economy 76(2):169-217.

Becker, Matthew, Rachel McRobb, Fred Watson, Egil Droge, Benson Kanyembo, James Murdoch, and Catherine Kakumbi. 2013. 'Evaluating Wire-Snare Poaching Trends and the Impacts of by-Catch on Elephants and Large Carnivores'. Biological Conservation 158:26-36.

Belecky, M., R. Singh, and William D. Moreto. 2019. Life on the Frontline 2019: A Global Survey of the Working Conditions of Rangers.

Bell, R. H. V., and J. E. Clarke. 1986. 'Funding and Fiancial Control'. Pp. 543-556 in Conservation and Wildlife Management in Africa, edited by R. H. V. Bell and E. McShaneCaluzi. Washington: US Peace Corps.

Bennett, Elizabeth L. 2011. 'Another Inconvenient Truth: The Failure of Enforcement Systems to Save Charismatic Species'. Oryx 45(4):476-79.

Bernasco, Wim. 2009. 'Foraging Strategies for Homo Criminalis: Lessons from Behavioral Ecology'. Crime Patterns and Analysis 2(1):5-16.

Bernasco, Wim, and Paul Nieuwbeerta. 2005. 'How Do Residential Burglars Select Target Areas? : A New Approach to the Analysis of Criminal Location Choice'. British Journal of Criminology 45(3):296-315.

Biderman, Albert D., and Albert J. Reiss. 1967. 'On Exploring the "Dark Figure” of Crime'. The Annals of the American Academy of Political and Social Science 374(1):1-15. 
Birks, Daniel J., Susan Donkin, and Melanie Wellsmith. 2008. 'Synthesis over Analysis: Towards an Ontology for Volume Crime Simulation'. Pp. 160-92 in Artificial Crime Analysis Systems: Using Computer Simulations and Geographic Information Systems. IGI Global.

Bivand, Roger, Jan Hauke, and Tomasz Kossowski. 2013. 'Computing the Jacobian in Gaussian Spatial Autoregressive Models: An Illustrated Comparison of Available Methods'. Geographical Analysis 45(2):150-79.

Bivand, Roger, and Gianfranco Piras. 2015. 'Comparing Implementations of Estimation Methods for Spatial Econometrics'. Journal of Statistical Software 63(18):1-36.

Blake, Stephen, Samantha Strindberg, Patrick Boudjan, Calixte Makombo, Inogwabini BilaIsia, Omari llambu, Falk Grossmann, Lambert Bene-Bene, Bruno De Semboli, Valentin Mbenzo, Dino S'hwa, Rosine Bayogo, Liz Williamson, Mike Fay, John Hart, and Fiona Maisels. 2007. 'Forest Elephant Crisis in the Congo Basin'. PLoS Biology 5(4):945-53.

Blom, Allard, Robert Van Zalinge, Ignas M. A. Heitkönig, and Herbert H. T. Prins. 2005. 'Factors Influencing the Distribution of Large Mammals within a Protected Central African Forest'. Oryx 39(4):381-88.

Borrion, Hervé, Amin Amiri, Dorothea Delpech, and A. M. Lemieux. 2019. 'Experimental Assessment of the Viability of Using Ground Penetrating Radar for Metal Wire-Snare Detection'. Crime Science 8(1):9.

Braga, Anthony A., Andrew V. Papachristos, and David M. Hureau. 2014. 'The Effects of Hot Spots Policing on Crime: An Updated Systematic Review and Meta-Analysis'. Justice Quarterly 31(4):633-63.

Braga, Anthony A., Brandon S. Turchan, Andrew V. Papachristos, and David M. Hureau. 2019. 'Hot Spots Policing and Crime Reduction: An Update of an Ongoing Systematic Review and Meta-Analysis'. Journal of Experimental Criminology 15(3):289-311.

Brantingham, P. J., and P. L. Brantingham. 2008. 'Crime Pattern Theory'. Pp. 78-93 in Environmental Criminology and Crime Analysis, edited by R. Wortley and L. Mazerolle. Willan.

Brantingham, P. L., and P. J. Brantingham. 1981. 'Notes on the Geometry of Crime'. Environmental Criminology 27-54.

ten Broeke, Guus, George van Voorn, and Arend Ligtenberg. 2016. 'Which Sensitivity Analysis Method Should i Use for My Agent-Based Model?' JASSS 19(1).

Brown, B. B., and I. Altman. 1982. Territoriality and Residential Crime: A Conceptual Framework. Thousand Oaks: Sage.

Bruch, Elizabeth, and Jon Atwell. 2015. 'Agent-Based Models in Empirical Social Research'. Sociological Methods \& Research 44(2):186-221.

Bühren, Christoph. 2020. 'Staff Rotation as an Anti-Corruption Policy in China and in Germany: An Experimental Comparison'. Jahrbücher Für Nationalökonomie Und Statistik 240(1):1-18.

Burnham, K. P., and D. R. Anderson. 2002. 'Information and Likelihood Theory: A Basis for Model Selection and Inference'. Pp. 49-97 in Model Selection and Multimodel Inference: A Practical Information-Theoretic Approach. Springer-Verlag New York. 
Calenge, Clément. 2006. 'The Package "Adehabitat" for the R Software: A Tool for the Analysis of Space and Habitat Use by Animals'. Ecological Modelling 197(3-4):516-19.

CEE. 2013. 'Guidelines for Systematic Review and Evidence Synthesis in Environmental Management'. Version 4.2. Environmental Evidence. Retrieved 21 June 2020 (http:// www.environmentalevidence.org/wp-content/uploads/2014/06/Review-guidelinesversion-4.2-final.pdf).

Chalfin, Aaron, and Justin McCrary. 2017. 'Criminal Deterrence: A Review of the Literature'. Journal of Economic Literature 55(1):5-48.

Challender, Daniel W. S., and Douglas C. MacMillan. 2014. 'Poaching Is More than an Enforcement Problem'. Conservation Letters 7(5):484-94.

Chapman, A. D., and Olivier Grafton. 2008. Guide to Best Practices for Generalising Sensitive Species-Occurrence Data. Copenhagen.

Clare, Joseph, John Fernandez, and Frank Morgan. 2009. 'Formal Evaluation of the Impact of Barriers and Connectors on Residential Burglars' Macro-Level Offending Location Choices'. Australian and New Zealand Journal of Criminology 42(2):139-58.

Clarke, Ronald V. 1980. '“Situational” Crime Prevention: Theory and Practice'. The British Journal of Criminology 20(2):136-47.

Clarke, Ronald V. 1983. 'Situational Crime Prevention: Its Theoretical Basis and Practical Scope'. Crime and Justice 4:225-56.

Clarke, Ronald V, and Derek B. Cornish. 1985. 'Modeling Offenders' Decisions: A Framework for Research and Policy'. Crime and Justice 6:147-85.

Clarke, Ronald V., and J. E. Eck. 2005. Crime Analysis for Problem Solvers in 60 Small Steps. Washington DC.

Clarke, Ronald V., and M. Felson. 1993. Routine Activity and Rational Choice. New Brunswick, NJ: Transaction Press.

Cohen, Lawrence E., and Marcus Felson. 1979. 'Social Change and Crime Rate Trends: A Routine Activity Approach'. American Sociological Review 44(4):588.

Cole, Stephen R., Haitao Chu, and Sander Greenland. 2014. 'Maximum Likelihood, Profile Likelihood, and Penalized Likelihood: A Primer'. American Journal of Epidemiology 179(2):252-60.

Cornish, D. B., and Ronald V. Clarke. 1987. 'Understanding Crime Displacement: An Application of Rational Choice Theory'. Criminology 25(4):933-48.

Cornish, Derek B. 1994. 'The Procedural Analysis of Offending and Its Relevance for Situational Prevention'. Crime Prevention Studies 3:151-96.

Cornish, Derek B., and Ronald V. Clarke. 2003. 'Opportunities, Precipitators and Criminal Decisions: A Reply to Wortley's Critique of Situational Crime Prevention'. Crime Prevention Studies 16:41-96.

Critchlow, R., A. J. Plumptre, M. Driciru, A. Rwetsiba, E. J. Stokes, C. Tumwesigye, F. Wanyama, and C. M. Beale. 2015. 'Spatiotemporal Trends of Illegal Activities from Ranger-Collected Data in a Ugandan National Park'. Conservation Biology 29(5):145870.

Dal Bó, Pedro, and Guillaume R. Fréchette. 2011. 'The Evolution of Cooperation in Infinitely Repeated Games: Experimental Evidence'. American Economic Review 101(1):411-429. 
Devroye, Luc, László Györfi, and Gábor Lugosi. 2013. A Probabilistic Theory of Pattern Recognition. Berlin: Springer Science \& Business Media.

Dezember, Amy, Megan Stoltz, Lina Marmolejo, L. Caitlin Kanewske, Kate Doyle Feingold, Sean Wire, Lauren Duhaime, and Carl Maupin. 2020. 'The Lack of Experimental Research in Criminology-Evidence from Criminology and Justice Quarterly'. Journal of Experimental Criminology.

Di Vita, Giuseppe. 2007. 'A Note on Exogenous Changes in Incentives for and Deterrence of Corruption'. European Journal of Law and Economics 24(1):15-27.

Diggle, P. 2003. Statistical Analysis of Spatial Point Patterns. London: Edward Arnold.

Dudley, Nigel, Sue Stolton, and Wendy Elliott. 2013. 'Wildlife Crime Poses Unique Challenges to Protected Areas'. Parks 19(1):7-12.

Eck, John, and David L. Weisburd. 2015. Crime Places in Crime Theory. Vol. 3. 4. University of Chicago Press.

Eloff, C., and Andrew M. Lemieux. 2014. 'Rhino Poaching in Kruger National Park, South Africa.' Pp. 18-43 in Situational Prevention of Poaching, edited by A. M. Lemieux. Oxon: Routledge.

Emslie, Richard H. 2012. 'Ceratotherium Simum. The IUCN Red List of Threatened Species 2012: E.T4185A45813880'.

Engel, Christoph, and Daniel Nagin. 2015. 'Who Is Afraid of the Stick? Experimentally Testing the Deterrent Effect of Sanction Certainty'. Review of Behavioral Economics 2(4):405-34.

Epstein, Joshua M. 2006. Generative Social Science: Studies in Agent-Based Computational Modeling. Princeton University Press.

Epstein, Joshua M., and Robert L. Axtell. 1996. Growing Artificial Societies: Social Science from the Bottom Up. Vol. 1. Brookings Institute Press.

Fajardo del Castillo, Teresa. 2016. 'The European Union's Approach in the Fight against Wildlife Trafficking: Challenges Ahead'. Journal of International Wildlife Law and Policy 19(1):1-21.

Fang, Fei, Thanh H. Nguyen, Robert Pickles, Wai Y. Lam, Gopalasamy R. Clements, Bo An, Amandeep Singh, Brian C. Schwedock, Milind Tambe, and Andrew Lemieux. 2017. 'PAWS - A Deployed Game-Theoretic Application to Combat Poaching'. Al Magazine 38(1):23-36.

Farjam, Mike, Marco Faillo, Ida Sprinkhuizen-Kuyper, and Pim Haselager. 2015. 'Punishment Mechanisms and Their Effect on Cooperation: A Simulation Study'. Journal of Artificial Societies and Social Simulation 18(1).

Farrington, David P. 2013. 'Longitudinal and Experimental Research in Criminology'. Crime and Justice 42(1):453-527.

Fay, Michael P. 2010. 'Confidence Intervals That Match Fisher's Exact or Blaker's Exact Tests'. Biostatistics (Oxford, England) 11(2):373-74.

Firth, David. 1993. 'Bias Reduction of Maximum Likelihood Estimates'. Biometrika 80(1):27.

Foo, Patrick, William H. Warren, Andrew Duchon, and Michael J. Tarr. 2005. 'Do Humans Integrate Routes into a Cognitive Map? Map- Versus Landmark-Based Navigation of Novel Shortcuts'. Journal of Experimental Psychology: Learning Memory and Cognition 31(2):195-215. 
Fox, John, and Sanford Weisberg. 2011. An R Companion to Applied Regression. 2nd ed. Thousand Oaks: SAGE Publications.

Frith, Michael J., Shane D. Johnson, and Hannah M. Fry. 2017. 'Role of the Street Network in Burglars' Spatial Decision-Making'. Criminology 55(2):344-76.

Frost, J. R., and U.S. Coast Guard. 1996. The Theory of Search: A Simplified Explanation. 96-F-HNG040. Fairfax: Soza \& Company Ltd.

Gavin, Michael C., Jennifer N. Solomon, and Sara G. Blank. 2010. 'Measuring and Monitoring Illegal Use of Natural Resources'. Conservation Biology 24(1):89-100.

Gerritsen, Charlotte. 2015. 'Agent-Based Modelling as a Research Tool for Criminological Research'. Crime Science 4(1):2.

Goel, Rajeev K., and Michael A. Nelson. 2005. 'Economic Freedom versus Political Freedom: Cross-Country Influences on Corruption'. Australian Economic Papers 44(2):121-33.

Gossner, Olivier, and Tristan Tomala. 2015. 'Repeated Games with Complete Information'. Pp. 7616-30 in Encyclopedia of Complexity and Systems Science. Springer.

Gottschalk, Petter. 2016. 'Explaining White-Collar Crime: An Empirical Study of Convenience Theory'. International Journal of Corporate Governance 7(3):274.

Haas, Timothy C., and Sam M. Ferreira. 2015. 'Federated Databases and Actionable Intelligence: Using Social Network Analysis to Disrupt Transnational Wildlife Trafficking Criminal Networks'. Security Informatics 4(1):2.

Haas, Timothy C., and Sam M. Ferreira. 2016. 'Conservation Risks: When Will Rhinos Be Extinct?' IEEE Transactions on Cybernetics 46(8):1721-34.

Haines, Aaron M., David Elledge, Lucas K. Wilsing, Matt Grabe, Michael D. Barske, Nolan Burke, and Stephen L. Webb. 2012. 'Spatially Explicit Analysis of Poaching Activity as a Conservation Management Tool'. Wildlife Society Bulletin 36(4):685-92.

Hammond, R. 2000. 'Endogenous Transition Dynamics in Corruption: An Agent-Based Computer Model'. 1-18.

Hart, Timothy, and Paul Zandbergen. 2014. 'Kernel Density Estimation and Hotspot Mapping: Examining the Influence of Interpolation Method, Grid Cell Size, and Bandwidth on Crime Forecasting'. Policing 37(2):305-23.

Harvey, Steven A., Paredes Maribel Olórtegui, Elli Leontsini, and Peter J. Winch. 2009. “"They'll Change What They're Doing If They Know That You're Watching”: Measuring Reactivity in Health Behavior Because of an Observer's Presence - A Case from the Peruvian Amazon'. Field Methods 21(1):3-25.

Heinze, Georg, and Michael Schemper. 2002. 'A Solution to the Problem of Separation in Logistic Regression'. Statistics in Medicine 21(16):2409-19.

Heinze, George, Meinhard Ploner, D. Dunkler, and H. Southworth. 2013. 'Logistf: Firth's Bias Reduced Logistic Regression'.

Hilborn, Ray, Peter Arcese, Markus Borner, Justin Hando, Grant Hopcraft, Martin Loibooki, Simon Mduma, and Anthony R. E. Sinclair. 2006. 'Effective Enforcement in a Conservation Area'. Science 314(5803):1266.

Hill, Joanna F. 2015. 'A Systems Thinking Perspective on the Motivations and Mechanisms That Drive Wildlife Poaching'. Pp. 189-219 in Green Harms and Crimes. Palgrave Macmillan UK. 
Hill, Joanna F., Shane D. Johnson, and H. Borrion. 2014. 'Potential Uses of Computer Agent-Based Simulation Modelling in the Evaluation of Wildlife Poaching'. Pp. 120-53 in Situational Prevention of Poaching, edited by A. M. Lemieux. Oxon: Routledge.

Hollis-Peel, Meghan E., Danielle M. Reynald, Maud van Bavel, Henk Elffers, and Brandon

C. Welsh. 2011. 'Guardianship for Crime Prevention: A Critical Review of the Literature'. Crime, Law and Social Change 56(1):53-70.

Hötte, Michiel H. H., Igor A. Kolodin, Sergei L. Bereznuk, Jonathan C. Slaght, Linda L. Kerley, Svetlana V. Soutyrina, Galina P. Salkina, Olga Y. Zaumyslova, Emma J. Stokes, and Dale G. Miquelle. 2016. 'Indicators of Success for Smart Law Enforcement in Protected Areas: A Case Study for Russian Amur Tiger (Panthera Tigris Altaica) Reserves'. Integrative Zoology 11(1):2-15.

Hübschle, Annette. 2016. 'A Game of Horns: Transnational Flows of Rhino Horn'. Universität Köln.

Hulme, Philip E. 2014. 'Bridging the Knowing-Doing Gap: Know-Who, Know-What, Know-

Why, Know-How and Know-When'. Journal of Applied Ecology 51(5):1131-36.

Hunter, L. T. B., K. Pretorius, L. C. Carlisle, M. Rickelton, C. Walker, R. Slotow, and J. D. Skinner. 2007. 'Restoring Lions Panthera Leo to Northern KwaZulu-Natal, South Africa: Short-Term Biological and Technical Success but Equivocal Long-Term Conservation'. Oryx 41(2):196-204.

Ibbett, Harriet, E. J. Milner-Gulland, Colin Beale, Andrew D. M. Dobson, Olly Griffin, Hannah

O'Kelly, and Aidan Keane. 2020. 'Experimentally Assessing the Effect of Search Effort on Snare Detectability'. Biological Conservation 247:108581.

Jachmann, Hugo. 2008. 'Monitoring Law-Enforcement Performance in Nine Protected Areas in Ghana'. Biological Conservation 141(1):89-99.

Jackson, Michelle, and D. R. Cox. 2013. 'The Principles of Experimental Design and Their Application in Sociology'. Annual Review of Sociology 39(1):27-49.

Johnson, Shane D., Nick Tilley, and Kate J. Bowers. 2015. 'Introducing EMMIE: An Evidence

Rating Scale to Encourage Mixed-Method Crime Prevention Synthesis Reviews'. Journal of Experimental Criminology 11(3):459-473.

Kaplan, E. L., and Paul Meier. 1958. 'Nonparametric Estimation from Incomplete Observations'. Journal of the American Statistical Association 53(282):457-81.

Kassambara, A., A. Kosinski, and P. Biecek. 2019. 'Survminer: Drawing Survival Curves Using "Ggplot2"'. Retrieved (https://CRAN.R-project.org/package=survminer).

Kim, Yushim, Wei Zhong, and Yongwan Chun. 2013. 'Modeling Sanction Choices on Fraudulent Benefit Exchanges in Public Service Delivery'. Journal of Artificial Societies and Social Simulation 16(2).

Kimanzi, Johnstone K., Roy A. Sanderson, Stephen P. Rushton, and Mware J. Mugo. 2015. 'Spatial Distribution of Snares in Ruma National Park, Kenya, with Implications for Management of the Roan Antelope Hippotragus Equinus Langheldi and Other Wildlife'. Oryx 49(2):295-302.

Kleemans, Edward E., and Christianne J. de Poot. 2008. 'Criminal Careers in Organized Crime and Social Opportunity Structure'. European Journal of Criminology 5(1):69-98. 
Koopman, Bernard O. 1946. A Theoretical Basis for Methods of Search and Screening. Washington DC.

Kozyukov, A. 2014. 'Signal Monitoring: GSM Field Test'. GSM Field Test - Tool for Creating Coverage Map. Retrieved 23 May 2016 (http://signalmonitoring.com/en/gsm-field-test).

Kruger National Park. 2016. 'Rhino Poaching Update - Rhino Poaching Update March 2016'. Retrieved 11 November 2016 (http://www.krugerpark.co.za/krugerpark-timese-6-rhino-poaching-update-25237.html).

Kurland, Justin, and Stephen F. Pires. 2017. 'Assessing U.S. Wildlife Trafficking Patterns: How Criminology and Conservation Science Can Guide Strategies to Reduce the Illegal Wildlife Trade'. Deviant Behavior 38(4):375-91.

Kurland, Justin, Stephen F. Pires, and Nerea Marteache. 2018. 'The Spatial Pattern of Redwood Burl Poaching and Implications for Prevention'. Forest Policy and Economics 94:46-54.

Kurland, Justin, Stephen F. Pires, Sara C. McFann, and William D. Moreto. 2017. 'Wildlife Crime: A Conceptual Integration, Literature Review, and Methodological Critique'. Crime Science 6(1):4.

Lemieux, Andrew M. 2014. 'Introduction'. Pp. 1-17 in Situational Prevention of Poaching. Oxon: Routledge.

Lindsey, Peter A., Johan du Toit, and Michael Mills. 2004. 'The Distribution and Population Status of African Wild Dogs (Lycaon Pictus) Outside Protected Areas in South Africa'. African Journal of Wildlife Research 34:143-151.

Linkie, Matthew, Deborah J. Martyr, Abishek Harihar, Dian Risdianto, Rudijanta T. Nugraha, Maryati, Nigel Leader-Williams, and Wai Ming Wong. 2015. 'Safeguarding Sumatran Tigers: Evaluating Effectiveness of Law Enforcement Patrols and Local Informant Networks' edited by M. Hayward. Journal of Applied Ecology 52(4):851-60.

Long, John Scott. 1997. 'Binary Outcomes: The Linear Probability, Probit, and Logit Models'. Pp. 63-73 in Regression Models for Categorical and Limited Dependent Variables. Thousand Oaks: SAGE Publications Inc.

Lonsdale, Charles. 2017. 'Creating an Agent-Based Model of Hammond's Model of Social Inequality Using Netlogo'. Retrieved 9 January 2019 (http://charleslonsdale.co.uk/ portfolio/advanced-2.php).

Lord, Dominique. 2006. 'Modeling Motor Vehicle Crashes Using Poisson-Gamma Models: Examining the Effects of Low Sample Mean Values and Small Sample Size on the Estimation of the Fixed Dispersion Parameter'. Accident Analysis and Prevention 38(4):751-66.

Lu, Yongmei. 2003. 'Getting Away with the Stolen Vehicle: An Investigation of Journey-afterCrime'. Professional Geographer 55(4):422-33.

Lynch, Michael J., Kimberly L. Barrett, Paul B. Stretesky, and Michael A. Long. 2017. 'The Neglect of Quantitative Research in Green Criminology and Its Consequences'. Critical Criminology 25(2):183-98.

Macleod, Fiona. 2012. 'SANParks Tenders Probed'. Mail \& Guardian. Retrieved 24 November 2016 (https://mg.co.za/article/2012-02-17-sanparks-tenders-probed/). 
Maingi, John K., Joseph M. Mukeka, Daniel M. Kyale, and Robert M. Muasya. 2012. 'Spatiotemporal Patterns of Elephant Poaching in South-Eastern Kenya'. Wildlife Research 39(3):234-49.

Mammen, S. 2015. 'Making Sense of Signal Strength/Signal Quality Readings for Cellular Modems'. Retrieved 26 September 2016 (http://blog.industrialnetworking.com/2014/04/ making-sense-of-signal-strengthsignal.html).

Marteache, Nerea, and Stephen F. Pires. 2019. 'Choice Structuring Properties of Natural Resource Theft: An Examination of Redwood Burl Poaching'. Deviant Behavior 41(3):311-28.

Mastrofski, Stephen D., Roger B. Parks, and John D. McCluskey. 2010. 'Systematic Social Observation in Criminology'. Pp. 225-247 in Handbook of Quantitative Criminology. Springer New York.

McFann, Sara C., and Stephen F. Pires. 2020. 'Taking Stock in Wildlife Crime Research: Trends and Implications for Future Research'. Deviant Behavior 41(1):118-35.

McKight, Patrick E., and Julius Najab. 2010. 'Kruskal-Wallis Test'. in The Corsini Encyclopedia of Psychology, edited by I. B. Weiner and W. E. Craighead. John Wiley \& Sons, Inc.

McMurran, Mary, and Tony Ward. 2004. 'Motivating Offenders to Change in Therapy: An Organizing Framework'. Legal and Criminological Psychology 9(2):295-311.

Milliken, Tom, Richard H. Emslie, and Bibhab Talukdar. 2009. 'African and Asian Rhinoceroses-Status, Conservation and Trade'. in IUCN Species Survival Commission (IUCN/SSC) African and Asian Rhino Specialist Groups and TRAFFIC to the CITES Secretariat pursuant to Resolution Conf. Vol. 9.

Milliken, Tom, and Jo Shaw. 2012. The South Africa-Viet Nam Rhino Horn Trade Nexus: A Deadly Combination of Institutional Lapses, Corrupt Wildlife Industry Professionals and Asian Crime Syndicates. Johannesburg.

Moreto, William D. 2013. 'To Conserve and Protect: Examining Law Enforcement Ranger Culture and Operations in Queen Elizabeth National Park, Uganda.' Rutgers University Graduate School: Newark.

Moreto, William D., Rod K. Brunson, and Anthony A. Braga. 2017. "'Anything We Do, We Have to Include the Communities": Law Enforcement Rangers' Attitudes towards and Experiences of Community-Ranger Relations in Wildlife Protected Areas in Uganda'. British Journal of Criminology 57(4):924-44.

Moreto, William D., and Jacinta M. Gau. 2017. 'Deterrence, Legitimacy, and Wildlife Crime in Protected Areas'. Pp. 45-58 in Conservation Criminology. Chichester, UK: John Wiley \& Sons, Ltd.

Moreto, William D., and Andrew M. Lemieux. 2015. 'From CRAVED to CAPTURED: Introducing a Product-Based Framework to Examine Illegal Wildlife Markets'. European Journal on Criminal Policy and Research 21(3):303-20.

Moreto, William D., Andrew M. Lemieux, A. Rwetsiba, N. Guma, M. Driciru, and H. Kulu Kirya. 2014. 'Law Enforcement Monitoring in Uganda: The Utility of Official Data and Time/Distance-Based Ranger Efficiency Measures'. Pp. 82-101 in Situational Prevention of Poaching, edited by A. M. Lemieux. Oxon: Routledge. 
Mosher, C. J., T. D. Miethe, and T. C. Hart. 2010. 'Introduction: The Pervasiveness (and Limitations) of Measurement'. Pp. 1-29 in The mismeasure of crime, edited by C. J. Mosher, T. D. Miethe, and T. C. Hart. Thousand Oaks: SAGE Publications.

Mulero-Pázmány, Margarita, Roel Stolper, L. D. Van Essen, Juan J. Negro, and Tyrell Sassen. 2014. 'Remotely Piloted Aircraft Systems as a Rhinoceros Anti-Poaching Tool in Africa' edited by H. Suleman. PLoS ONE 9(1):e83873.

Nagin, Daniel S. 2013. 'Deterrence in the Twenty-First Century'. Crime and Justice 42(1):199263.

Nguyen, Thanh H., Arunesh Sinha, Shahrzad Gholami, Andrew Plumptre, Lucas Joppa, Milind Tambe, Margaret Driciru, Fred Wanyama, Aggrey Rwetsiba, Rob Critchlow, and Colin M. Beale. 2016. 'CAPTURE: A New Predictive Anti-Poaching Tool for Wildlife Protection'. Pp. 767-75 in Proceedings of the International Joint Conference on Autonomous Agents and Multiagent Systems, AAMAS.

Nolte, Christoph. 2016. 'Identifying Challenges to Enforcement in Protected Areas: Empirical Insights from 15 Colombian Parks'. Oryx 50(2):317-22.

Nyirenda, Vincent R., and Chansa Chomba. 2012. 'Field Foot Patrol Effectiveness in Kafue National Park, Zambia'. Journal of Ecology and the Natural Environment 4(6):163-72.

O'Kelly, Hannah J., J. Marcus Rowcliffe, Sarah Durant, and E. J. Milner-Gulland. 2018. 'Experimental Estimation of Snare Detectability for Robust Threat Monitoring'. Ecology and Evolution 8(3):1778-85.

Paternoster, Raymond. 2010. 'How Much Do We Really Know about Criminal Deterrence?' The Journal of Criminal Law and Criminology 100(3):765-824.

Pearce, Jennie, and Simon Ferrier. 2000. 'An Evaluation of Alternative Algorithms for Fitting Species Distribution Models Using Logistic Regression'. Ecological Modelling 128(23):127-47.

Pebesma, E. 2018. 'Simple Features for R: Standardized Support for Spatial Vector Data'. The $R$ Journal 10(1):439-46.

Peel, Michael. 2014. Ecological Monitoring: Association of Private Nature Reserves (Timbavati, Umbabat, Klaserie and Balule). Nelspruit: Animal Production Institute.

Phelps, J., and Edward L. Webb. 2015. "'Invisible” Wildlife Trades: Southeast Asia's Undocumented Illegal Trade in Wild Ornamental Plants'. Biological Conservation 186:296-305.

Pires, Stephen, and Ronald V. Clarke. 2012. 'Are Parrots Craved? An Analysis of Parrot Poaching in Mexico'. Journal of Research in Crime and Delinquency 49(1):122-46.

Pires, Stephen F., and Rob. T. Guerette. 2014. 'Does Opportunity Make the Poacher? An Analysis of Neo-Tropical Illicit Parrot Markets'. Pp. 44-61 in Situational Prevention of Poaching, edited by A. M. Lemieux. Oxon: Routledge.

Poyner, B. 1986. 'A Model for Action'. Pp. 25-39 in Situational Crime Prevention From Theory to Practice, edited by K. Heal and G. Laycock. London: Her Majesty's Stationary Office.

Pyke, G. H., H. R. Pulliam, and E. L. Charnov. 1977. 'Optimal Foraging: A Selective Review of Theory and Tests'. The Quarterly Review of Biology 52(2):137-54. 
Ramsay, Scott. 2014. 'Full Interview with Kruger's Anti-Poaching Chief General Johan Jooste'. Retrieved 22 May 2016 (https://africageographic.com/stories/interview-withkrugers-anti-poaching-chief/).

Ratcliffe, Jerry H., Travis Taniguchi, Elizabeth R. Groff, and Jennifer D. Wood. 2011. 'The Philadelphia Foot Patrol Experiment: A Randomized Controlled Trial of Police Patrol Effectiveness in Violent Crime Hotspots*'. Criminology 49(3):795-831.

Reuter, Kim E., Marni Lafleur, and Tara A. Clarke. 2017. 'Endangered Species: Illegal Lemur Trade Grows in Madagascar'. Nature 541(7636):157.

Rifaie, Farid, Jito Sugardjito, and Yuli Sulistya Fitriana. 2015. 'Spatial Point Pattern Analysis of the Sumatran Tiger (Panthera Tigris Sumatrae) Poaching Cases in and around Kerinci Seblat National Park, Sumatra'. Biodiversitas 16(2):311-19.

Rija, Alfan Abeid. 2017. 'Spatial Pattern of Illegal Activities and the Impact on Wildlife Populations in Protected Areas in the Serengeti Ecosystem'. Doctor of Philosophy, University of York.

Ripple, William J., Christopher Wolf, Thomas M. Newsome, Matthew G. Betts, Gerardo Ceballos, Franck Courchamp, Matt W. Hayward, Blaire Van Valkenburgh, Arian D. Wallach, and Boris Worm. 2019. 'Are We Eating the World's Megafauna to Extinction?' Conservation Letters 12(3):e12627.

Risdianto, Dian, Deborah J. Martyr, Rudijanta T. Nugraha, Abishek Harihar, Hariyo T. Wibisono, Iding A. Haidir, David W. Macdonald, Neil D'Cruze, and Matthew Linkie. 2016. 'Examining the Shifting Patterns of Poaching from a Long-Term Law Enforcement Intervention in Sumatra'. Biological Conservation 204:306-12.

Rossmo, D. Kim. 1999. Geographic Profiling. Boca Raton: CRC Press.

Rowland, Richard, and Timothy Coupe. 2014. 'Patrol Officers and Public Reassurance: A Comparative Evaluation of Police Officers, PCSOs, ACSOs and Private Security Guards'. Policing and Society 24(3):265-84.

Ryan, Richard M., and Edward L. Deci. 2000. 'Self-Determination Theory and the Facilitation of Intrinsic Motivation, Social Development, and Well-Being'. American Psychologist 55(1):68-78.

Sabater, Jordi, and Carles Sierra. 2005. 'Review on Computational Trust and Reputation Models'. Artificial Intelligence Review 24(1):33-60.

Schoener, T. W. 1971. 'Theory of Feeding Strategies'. Annual Review of Ecology and Systematics 2(1):369-404.

Sherman, Lawrence W. 2013. 'Targeting, Testing and Tracking Police Services: The Rise of Evidence-Based Policing, 1975-2025'. Pp. 377-451 in Crime and Justice in America. Vol. 43, edited by M. Tonry. Chicago: University of Chicago Press.

Sherman, Lawrence W., Dennis P. Rogan, Timothy Edwards, Rachel Whipple, Dennis Shreve, Daniel Witcher, William Trimble, The Street Narcotics Unit, Robert Velke, Mark Blumberg, Anne Beatty, and Carol A. Bridgeforth. 1995. 'Deterrent Effects of Police Raids on Crack Houses: A Randomized, Controlled Experiment'. Justice Quarterly 12(4):755-81.

Sherman, Lawrence W., and David Weisburd. 1995. 'General Deterrent Effects of Police Patrol in Crime "Hot Spots": A Randomized, Controlled Trial'. Justice Quarterly 12(4):625-48. 
Sibanda, Mbulisi, Timothy Dube, Victor M. Bangamwabo, Onisimo Mutanga, Cletah Shoko, and Webster Gumindoga. 2016. 'Understanding the Spatial Distribution of Elephant (Loxodonta Africana) Poaching Incidences in the Mid-Zambezi Valley, Zimbabwe Using Geographic Information Systems and Remote Sensing'. Geocarto International 31(9):1006-18.

Situngkir, Hokky, and Deni Khanafiah. 2006. 'Theorizing Corruption through Agent-Based Modeling'. Pp. 561-64 in Proceedings of the 9th Joint Conference on Information Sciences, JCIS 2006. Vol. 2006. Atlantis Press.

Skogan, Wesley G., and Kathleen Frydl. 2004. Fairness and Effectiveness in Policing: The Evidence. Washington, D.C.: National Academies Press.

Smith, David. 2015. 'Thousands of Rhinos, 500 Poachers; Grim Toll in the Hunt for Prized Horns'. The Guardian. Retrieved 19 June 2018 (https://www.theguardian.com/ environment/2015/oct/18/rhino-horn-boom-impoverished-african-poachers).

Snitch, Thomas. 2014. 'Poachers Kill Three Elephants an Hour. Here's How to Stop Them'. The Telegraph. Retrieved 22 May 2016 (https://www.telegraph.co.uk/news/earth/ environment/conservation/10634747/Poachers-kill-three-elephants-an-hour.-Hereshow-to-stop-them.html).

Spano, Richard. 2007. 'How Does Reactivity Affect Police Behavior? Describing and Quantifying the Impact of Reactivity as Behavioral Change in a Large-Scale Observational Study of Police'. Journal of Criminal Justice 35(4):453-65.

Spicer, Kelly. 2014. 'South African Police Officer Held over Attempted Rhino Poaching'. International Business Times. Retrieved 20 May 2016 (https://www.ibtimes.co.uk/southafrican-police-officer-held-over-attempted-rhino-poaching-1461778).

Stafford, Mark C., Louis N. Gray, Ben A. Menke, and David A. Ward. 1986. 'Modeling the Deterrent Effects of Punishment'. Social Psychology Quarterly 49(4):338.

Stokes, Emma J. 2010. 'Improving Effectiveness of Protection Efforts in Tiger Source Sites: Developing a Framework for Law Enforcement Monitoring Using MIST'. Integrative Zoology 5(4):363-77.

Stone, Christopher. 2006. Crime, Justice, and Growth in South Africa: Toward a Plausible Contribution from Criminal Justice to Economic Growth. RWP06-038.

Struhsaker, Thomas T., Paul J. Struhsaker, and Kirstin S. Siex. 2005. 'Conserving Africa's Rain Forests: Problems in Protected Areas and Possible Solutions'. Biological Conservation 123(1):45-54.

Synnott, John, David Canter, Donna Youngs, and Maria loannou. 2016. 'Variations in the Journey from Crime: Examples from Tiger Kidnapping'. Journal of Investigative Psychology and Offender Profiling 13(3):239-52.

't Sas-Rolfes, Michael, Daniel W. S. Challender, Amy Hinsley, Diogo Veríssimo, and E. J. Milner-Gulland. 2019. 'Illegal Wildlife Trade: Scale, Processes, and Governance'. Annual Review of Environment and Resources 44(1):201-28.

Therneau, T. 2015. 'A Package for Survival Analysis in S'. Retrieved (https://cran.r-project. org/web/packages/survival/index.html). 
Tonkin, Matthew, Jessica Woodhams, John W. Bond, and Trudy Loe. 2010. 'A Theoretical and Practical Test of Geographical Profiling with Serial Vehicle Theft in a U.K. Context'. Behavioral Sciences and the Law 28(3):442-60.

Transparency International. 2019. Corruption Perception Index 2018. Transparency International.

United Nations. 2019. ‘Goal 15: Sustainable Development Knowledge Platform'. Retrieved 2 March 2020 (https://sustainabledevelopment.un.org/sdg15).

UNODC. 2016. World Wildlife Crime Report: Trafficking in Protected Species. New York: United Nations Office on Drugs and Crime.

UNODC. 2017. Addressing Corruption and Wildlife Crime. Berlin: United Nations Office on Drugs and Crime.

Usichenko, T., A. Julich, and M. Wendt. 2013. "“Yes We Can” Utilize the Hawthorne Effect to Improve Postoperative Analgesia'. British Journal of Anaesthesia 110(4):659.

Vandeviver, Christophe, Tijs Neutens, Stijn van Daele, Dirk Geurts, and Tom Vander Beken. 2015. 'A Discrete Spatial Choice Model of Burglary Target Selection at the House-Level'. Applied Geography 64:24-34.

Vanek, John P. 2016. 'Find the Appropriate Smoothing Factor (h) for Kernel Densities in R'. Retrieved 23 June 2017 (https://johnpvanek.wordpress.com/2016/05/02/find-theappropriate-smoothing-factor-h-for-kernel-densities-in-r/).

van Velden, Julia, Kerrie Wilson, and Duan Biggs. 2018. 'The Evidence for the Bushmeat Crisis in African Savannas: A Systematic Quantitative Literature Review'. Biological Conservation 221:345-56.

Voinea, Camelia. 2013. 'Bribery-Scape: An Artificial Society-Based Simulation Model of Corruption's Emergence and Growth'. European Quarterly of Political Attitudes and Mentalities-EQPAM 2(1):27-54.

Wain, N., and B. Ariel. 2014. 'Tracking of Police Patrol'. Policing 8(3):274-83.

Wangchuk, P., and A. Olsen. 2010. 'Risk Factors for the Sustainability of Medicinal Plants in Bhutan in: Asian Medicine Volume 6 Issue 1 (2010)'. Asian Medicine 6(1):123-36.

Warchol, Greg, and Michael Harrington. 2016. 'Exploring the Dynamics of South Africa's Illegal Abalone Trade via Routine Activities Theory'. Trends in Organized Crime 19(1):21-41.

Warchol, Greg, and Dale Kapla. 2012. 'Policing the Wilderness: A Descriptive Study of Wildlife Conservation Officers in South Africa'. International Journal of Comparative and Applied Criminal Justice 36(2):83-101.

Warchol, Greg L. 2004. 'The Transnational Illegal Wildlife Trade'. Criminal Justice Studies 17(1):57-73.

Warf, Barney. 2016. 'Global Geographies of Corruption'. GeoJournal 81(5):657-69.

Wato, Yussuf Adan, Geoffrey M. Wahungu, and Moses Makonjio Okello. 2006. 'Correlates of Wildlife Snaring Patterns in Tsavo West National Park, Kenya'. Biological Conservation 132(4):500-509.

Watson, Fred, Matthew S. Becker, Rachel McRobb, and Benson Kanyembo. 2013. 'Spatial Patterns of Wire-Snare Poaching: Implications for Community Conservation in Buffer Zones around National Parks'. Biological Conservation 168:1-9. 
Wellsmith, Melanie. 2011. 'Wildlife Crime: The Problems of Enforcement'. European Journal on Criminal Policy and Research 17(2):125-48.

De Wet, Neil James. 2014. 'The South African Regulatory Framework Relating to Illegal Trade in Rhino Horn'. North-West University.

Wickham, Hadley. 2016. Ggplot2: Elegant Graphics for Data Analysis. Springer-Verlag New York.

Wilensky, U. 1999. 'NetLogo'. Center for Connected Learning and Computer-Based Modeling, Northwestern University, Evanston, IL. Retrieved (http://ccl.northwestern. edu/netlogo/).

Williams, A., and R. Parry-Jones. 2016. 'Corruption and Wildlife Trafficking: The Elephant in the Room'. Retrieved 20 April 2020 (http://www.ipsnews.net/2016/09/corruption-andwildlife-trafficking-the-elephant-in-the-room/).

Xu, Haifeng, Benjamin Ford, Fei Fang, Bistra Dilkina, Andrew Plumptre, Milind Tambe, Margaret Driciru, Fred Wanyama, Aggrey Rwetsiba, Mustapha Nsubaga, and Joshua Mabonga. 2017. 'Optimal Patrol Planning for Green Security Games with Black-Box Attackers'. Pp. 458-477 in Decision and Game Theory for Security. Vol. 10575, Lecture Notes in Computer Science, edited by S. Rass, B. An, C. Kiekintveld, and S. Schauer. Cham: Springer.

Ye, Hang, Fei Tan, Mei Ding, Yongmin Jia, and Yefeng Chen. 2011. 'Sympathy and Punishment: Evolution of Cooperation in Public Goods Game'. Journal of Artificial Societies and Social Simulation 14(4).

Zausinová, Jana, Martin Zoričak, Marcel Vološin, and Vladimír Gazda. 2019. 'Aspects of Complexity in Citizen-Bureaucrat Corruption: An Agent-Based Simulation Model'. Journal of Economic Interaction and Coordination 15(2):527-52.

Zhang, Yunlong, Zhirui Ye, and Dominique Lord. 2007. 'Estimating Dispersion Parameter of Negative Binomial Distribution for Analysis of Crash Data: Bootstrapped Maximum Likelihood Method'. Transportation Research Record 2019(2019):15-21.

Zhou, Zhao-Min, Youbing Zhou, Chris Newman, and David W. Macdonald. 2014. 'Scaling up Pangolin Protection in China'. Frontiers in Ecology and the Environment 12(2):97-98.

Zorn, Christopher. 2014. 'A Solution to Separation in Binary Response Models'. Political Analysis 13(2):157-70. 



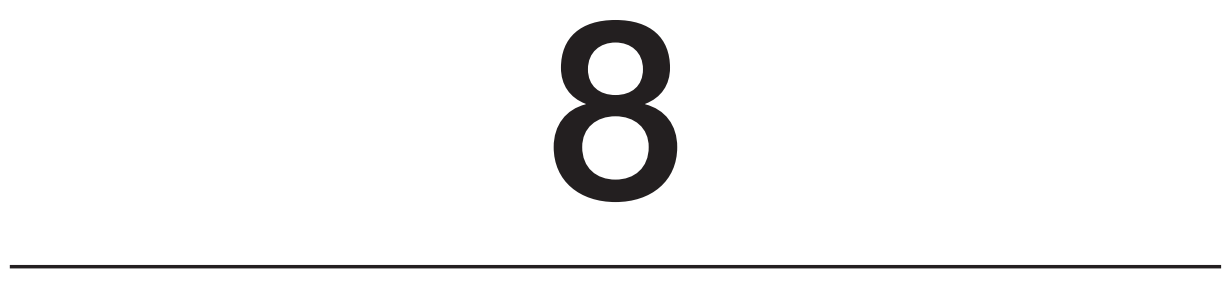

Acknowledgements

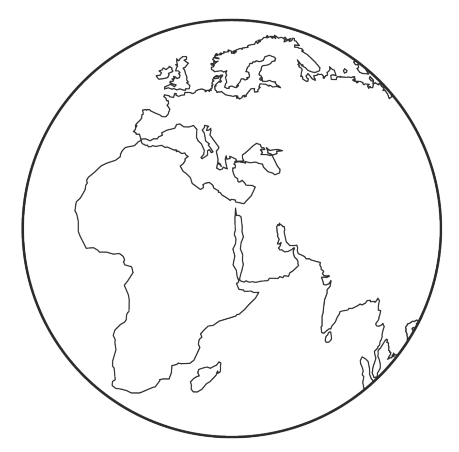


If you would have told me at the end of my master studies that I would end up at a criminological research institute for five years, I most likely would not have believed you. I met a number of people throughout my journey; people who pushed me forward or back on track whenever I tended to stumble or go astray.

First, and foremost, I am forever indebted to my supervisors, Stijn and Andrew. Thank you for providing me with the opportunity to set out on this journey. Without Stijn's incredible eye for detail and vision for the bigger picture, I would probably still be focussed on some small, irrelevant aspect of a project. Without a doubt, you helped me to become a much better scientist, and I really hope you will to visit South Africa at one point. I am sure you will love it. Andrew, your approach to use academic research for assisting wildlife practitioners always inspired me. I still think back of the good ol' days when we set up our first two projects in South Africa. The combination of the expertise and experience you both have made me feel lucky to have you as supervisors. I highly value the way in which we worked together and like to believe we provided a valuable contribution to the current wildlife crime research. If there is unfulfilled potential in this dissertation it is solely due to my own shortcomings and not due to the guidance that I had.

There are two colleagues and roomies without whom I probably would not have made it all the way through: Robin and Peter. Both of you are always cheerful, more than willing to lend a hand, brainstorm about little things, and, of course, go for coffee. While we never got our office dog, we at least got some dancing rhinos and office plants (at least for a while...) Best of luck with finishing your own research! I have great memories of our time in the office, and I hope we can relive them once more some time in the future.

A big thank you to everyone at NSCR. I definitely felt as the odd one out with my weird nature conservation degree in a room full of criminologists and other social scientists when I just started working. But everyone was extremely friendly and supportive. I very much enjoyed working in the open and supportive environment you all helped creating. 
This acknowledgement would not be complete without thanking the amazing people at Transfrontier Africa NPC in South Africa. My first field visit to Olifants West Nature Reserve was unforgettable and I am indebted to Craig Spencer and this team. Without your support this dissertation would have never reached the level it is now. I am honoured that you invited me to stay long-term at TA and it is therefore a shame that our plans got disrupted in 2020. I will keep hope, however, that I can visit South Africa soon again. A special thanks to the people at TA who helped me throughout my studies: Paul Allin, Leonie Hofstra, Lisa Trueman, and Chris Farren. I also made some great friends who made my stay in the field always great fun, and in particular I want to thank Chris Banotai and Mark Wright.

Tot slot: mams, paps, Laura, Jan, en mijn vrienden in Brabant. Misschien zijn jullie niet echt bewust van de steun die jullie mij hebben gegeven in de afgelopen jaren. Soms konden jullie ook niet bijhouden in welk deel van de wereld ik nu weer zat. Maar ik kon altijd bij ieder van jullie terecht voor wat dan ook, en daarvoor ben ik jullie ontzettend dankbaar. 



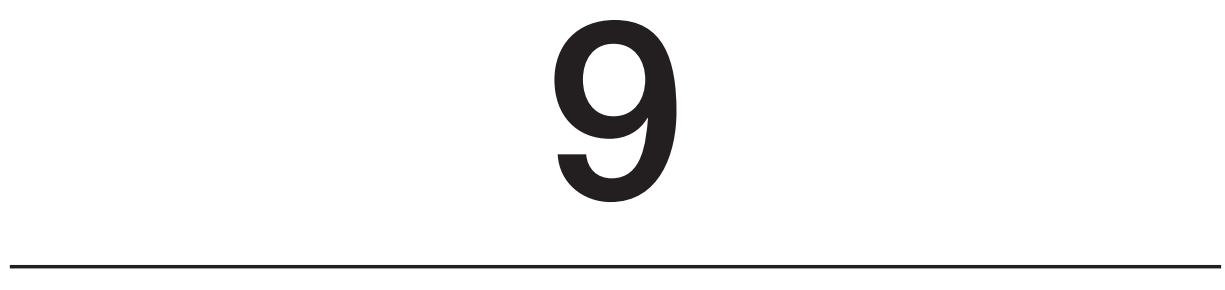

About the author

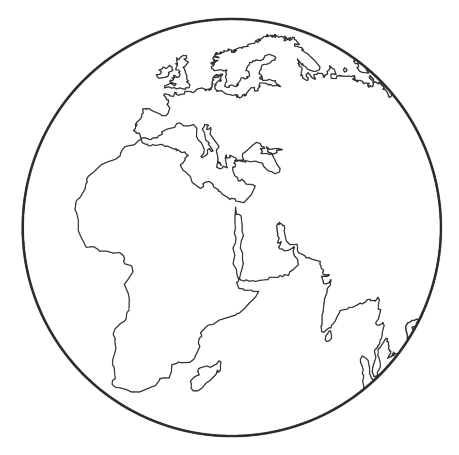


Nick van Doormaal was born in Diessen (NB), the Netherlands, on September 26, 1989. He completed his Bachelor of Applied Sciences in Wildlife Management at the University of Applied Sciences Van HallLarenstein in 2012. Nick continued his studies at Wageningen University and obtained his master degree in Forest and Nature Conservation with a specialisation in Ecology and a minor in Geographic Information Systems in 2015. He started working as a junior researcher at the Netherlands Institute for the Study of Crime and Law Enforcement (NSCR) in Amsterdam in May 2015. This position gradually evolved into a larger PhD project under the supervision of prof. dr. S. Ruiter (NSCR | UU) and dr. A.M. Lemieux (NSCR). Throughout his studies, Nick collaborated on several occasions with 'Transfrontier Africa NPC', a non-profit environmental conservation organisation based in the Balule region of the Greater Kruger National Park in South Africa. His work has appeared in Progress in Artificial Intelligence (EPIA 2017), Crime Science, and Oryx. Nick's research interests include wildlife crime, environmental criminology, and human-wildlife conflicts. 
